\title{
(c)
}

UNIVERSIDAD PERUANA DE CIENCIAS APLICADAS

ESCUELA DE POSTGRADO

PROGRAMA ACADÉMICO DE MAESTRÍA EN GESTIÓN DE OPERACIONES Y LOGÍSTICA

\section{Propuesta de mejora de los procesos de servicio postventa de una empresa comercializadora de bienes de capital}

\section{TESIS}

Para optar el grado académico de Maestro en Gestión de Operaciones y Logística

AUTOR

Zelada Zavaleta, Carlos Segundo (0000-0001-5157-4782)

\author{
ASESOR \\ Gustavo Guerrero Vasquez (0000-0002-0767-5663)
}

Lima, septiembre de 2017 
DEDICATORIA

Dios, por ser mi guía constante, y por darme la fortaleza necesaria para superar cada uno de los obstáculos que se me presentaron. A mi esposa y mis hijas, y a mis padres por su incondicional colaboración y apoyo permanente. 
AGRADECIMIENTO

Mi más sincero agradecimiento a todos los docentes de la escuela de postgrado de la UPC por las enseñanzas recibidas a lo largo del programa de maestría en gestión de operaciones y logística, y un agradecimiento especial al Ing. Gustavo Guerrero Vásquez por su asesoramiento en el desarrollo de ésta tesis. 


\section{RESUMEN EJECUTIVO}

El presente estudio tiene como tema central la mejora del proceso de atención al cliente y planificación de la orden de trabajo en una empresa de comercialización de bienes de capital y servicios. Dicho proceso fue analizado a través de una herramienta secuencial de la calidad, específicamente la metodología de los 15 pasos la cual se basa en los pasos fundamentales del PEVA.

El trabajo se estructuró en 4 capítulos. El primero presenta el marco teórico sobre la cual se basa el estudio, el segundo se realiza el diagnóstico del proceso actual. En el tercero se elabora la propuesta de mejora y se analiza su costo beneficio $\mathrm{y}$, por último, se redactaron las conclusiones y recomendaciones al estudio.

Las conclusiones del diagnóstico del proceso fueron dos; falta de estandarización en el proceso de "atención al cliente" y falta de estandarización en el proceso "planificación de la OT". Estos dos problemas fueron enfocados para darles solución a través de una alternativa o propuesta global de mejora, la cual incluye su respectivo anális is costo beneficio.

Al finalizar el trabajo se determinó que las recomendaciones sugeridas tendrán un beneficio al largo plazo en comparación con el costo por no realizar las mejoras sugeridas

Palabras clave: mejora de procesos, PEVA, flujograma de procesos 


\begin{abstract}
The main theme of this study is the improvement of the customer service process and the planning of the work order in a company that sells capital goods and services. This process was analyzed through a sequential quality tool, specifically the methodology of the 15 steps which is based on the fundamental steps of the PEVA.

The work was structured in 4 chapters. The first presents the theoretical framework on which the study is based, the second is the diagnosis of the current process. In the third one, the improvement proposal is elaborated and its cost benefit is analyzed and finally, the conclusions and recommendations to the study were written.

The conclusions of the diagnosis of the process were two; lack of standardization in the process of "customer service" and lack of standardization in the process "planning of the OT". These two problems were focused to solve them through an alternative or global improvement proposal, which includes its respective cost-benefit analysis.
\end{abstract}

At the end of the work, it was determined that the suggested recommendations will have a longterm benefit compared to the cost of not making the suggested improvements.

Keywords: process improvement, PEVA, process flowchart 


\section{TABLA DE CONTENIDO}

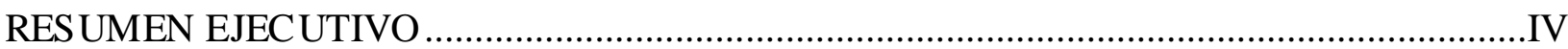

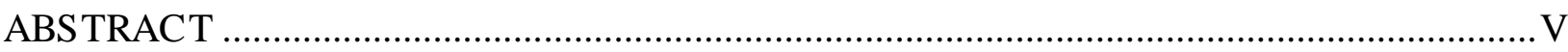

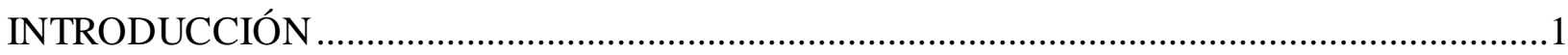

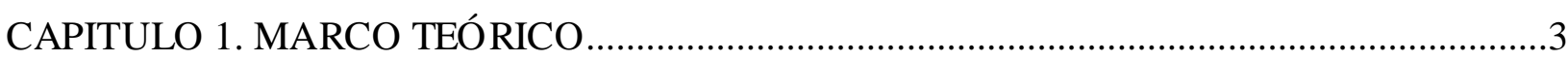

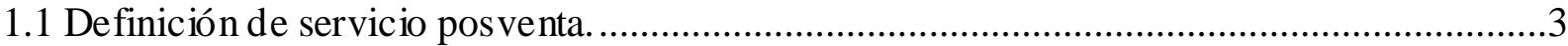

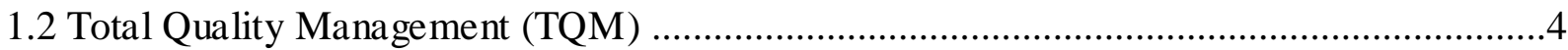

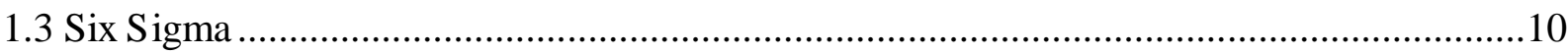

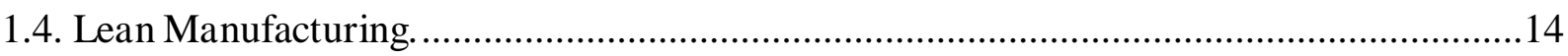

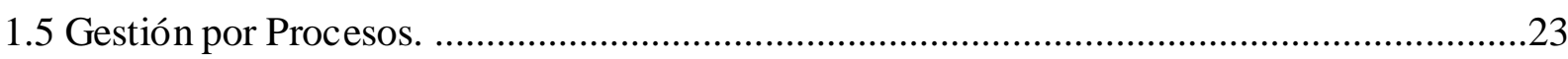

1.5.1 Herramienta de los quince pasos para la mejora de procesos ....................................25

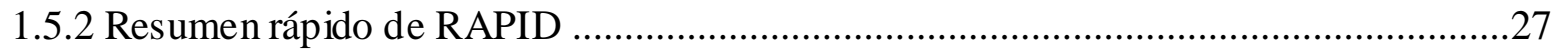

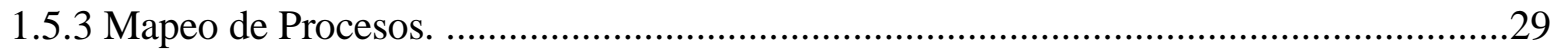

1.6 Ciclo de Deming o ciclo PEVA (PDCA en siglas en inglés) ..........................................29

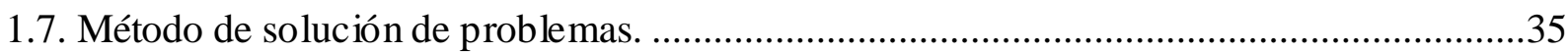

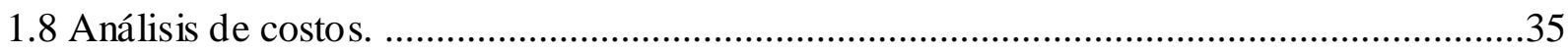

CAPITULO 2. ANALISIS Y DIAGNOSTICO DEL PROCESO ACTUAL ..............................38

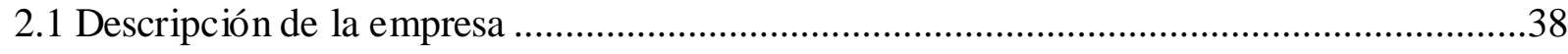

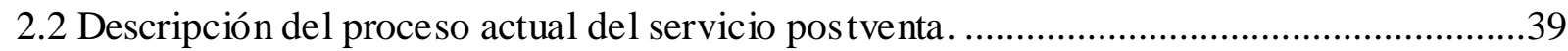

2.3 Proceso de Atención al Cliente / Apertura / Planificación de OT. .......................................44

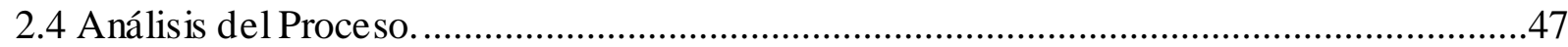

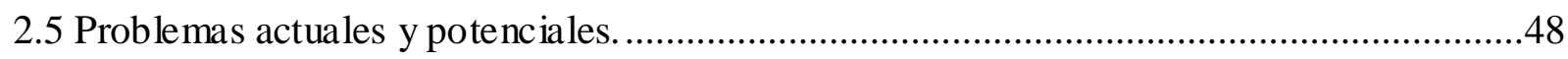

2.6 Impacto económico de las ineficiencias del proceso. .......................................................52

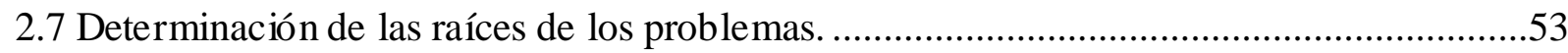

CAPITULO 3. ELABORACION DE PROPUESTA DE MEJORA AL PROCESO ..................56

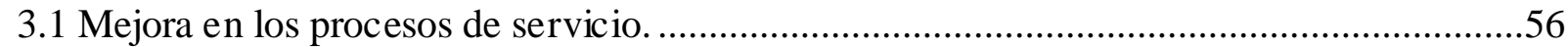

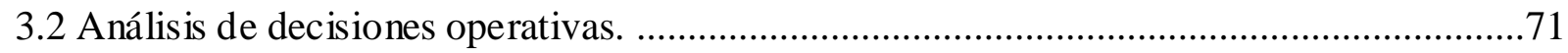

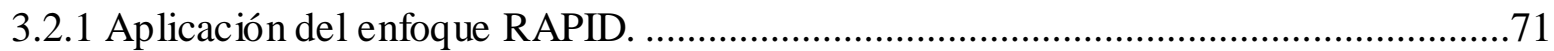

3.2.2 Observaciones de la aplicación del enfoque en el proceso. ......................................72

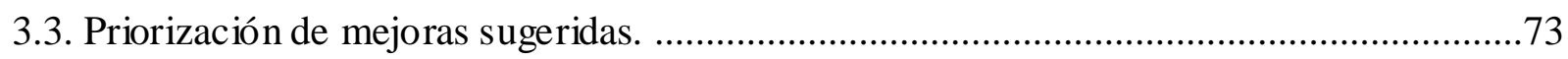

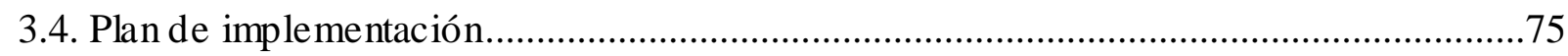


3.6. Costo y beneficio de la implementación de mejoras

3.6.1. Costo

3.6.2. Beneficio .84

CAPITULO 4 CONCLUSIONES, RECOMENDACIONES Y LIMITACIONES DEL ESTUDIO

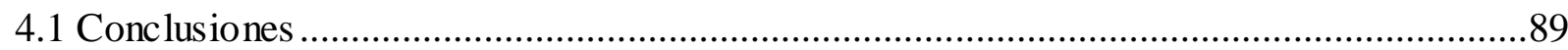

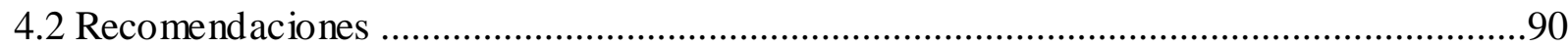

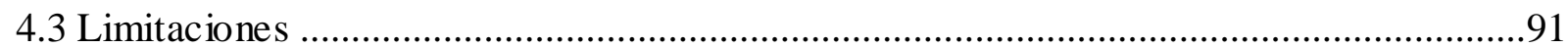

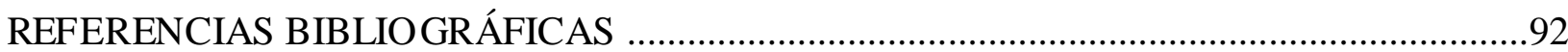

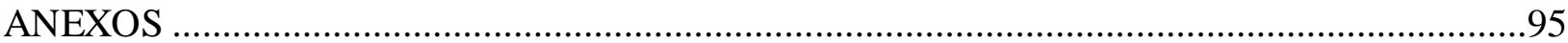

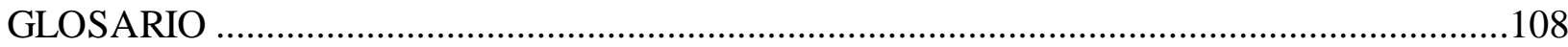




\section{ÍNDICE DE TABLAS}

Tabla 1: Ventajas y desventajas del servicio postventa. ........................................................

Tabla 2 Ventas anuales de Servicios línea CAT del 2006 al 2010............................................39

Tabla 3 Rentabilidad bruta de Servicios línea CAT del 2006 al 2010....................................40

Tabla 4 Comparativo de media de encuestas de lealtad a nivel nacional y media de la sucursal

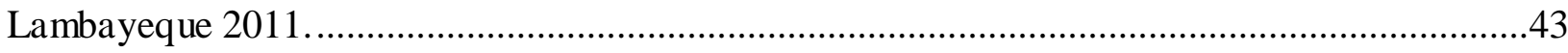

Tabla 5 Lluvia de ideas de problemas en el proceso. ..................................................................48

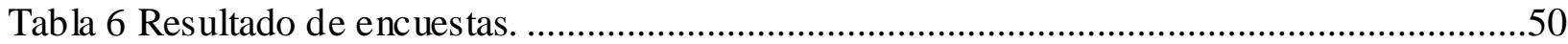

Tabla 7 Tabla de porcentajes acumulados de problemas........................................................51

Tabla 8 Tabla de horas pérdidas acumuladas en el mes julio 2011 ..........................................53

Tabla 9 Clasificación de matriz de oportunidades...................................................................57

Tabla 10 Matriz de oportunidades de mejora del proceso A. ...................................................59

Tabla 11 Matriz de oportunidades de mejora del proceso. .....................................................60

Tabla 12 Matriz de oportunidades de mejora del proceso. .......................................................61

Tabla 13 Matriz de oportunidades de mejora del proceso. ........................................................62

Tabla 14 Matriz de oportunidades de mejora del proceso. ....................................................63

Tabla 15 Matriz de oportunidades de mejora del proceso .....................................................64

Tabla 16 Ficha de Proceso de atención al cliente y planificación de la OT. ….............................70

Tabla 17 Matriz de análisis de decisiones operativas actual. ...................................................72

Tabla 18 Implementación de mejoras de alto impacto y alto esfuerzo......................................77

Tabla 19 Implementación de mejoras de alto impacto y medio esfuerzo....................................78

Tabla 20 Implementación de mejoras de alto impacto y bajo esfuerzo .....................................79

Tabla 21 Implementación de mejoras de medio impacto y bajo esfuerzo...................................80

Tabla 22 Costos de implementación de mejoras. ..................................................................83

Tabla 23: Escenarios de comparación costo-beneficio cualitativo. ..............................................85

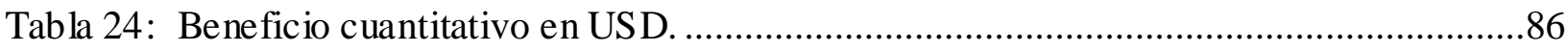

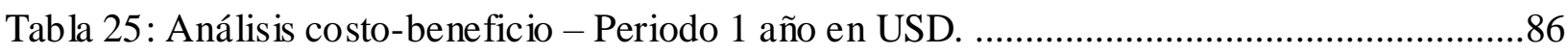

Tabla 26: Análisis costo-beneficio - Periodo 1 año (USD) * ....................................................87 


\section{INDICE DE FIGURAS}

Figura 1 Mapa de Procesos del Area de Servicios. ...................................................................42

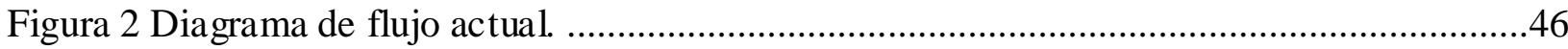

Figura 3 Afinidades de los problemas del proceso. ................................................................49

Figura 4 Diagrama de Pareto de frecuencias de problemas del proceso. .....................................51

Figura 5 Diagrama de Ishikawa problema G: Informan a última hora del trabajo. .....................54

Figura 6 Diagrama de Ishikawa problema I: atención lenta de almacén. ...................................54

Figura 7 Organigrama del equipo formado para recomendar las mejoras al proceso. ..................56

Figura 8 Flujograma propuesto proceso atención al cliente/apertura OT................................66

Figura 9 Flujograma propues to del proceso planificación de la OT. ..........................................69

Figura 10 Gráfico impacto Vs esfuerzo de implementación de mejoras.....................................74

Figura 11 Organigrama de equipo para implementación de mejoras. .........................................81 


\section{INTRODUCCIÓN}

Para las empresas de servicios en general, los últimos años han estado marcados por grandes desafíos, un mercado más complejo, con más competidores y clientes más exigentes que requieren una atención rápida a sus necesidades. En ese sentido, es importante para las empresas mejorar la gestión por procesos ya que la calidad de un producto o servicio está determinada por la calidad del proceso que se usa para desarrollarlo y mantenerlo. Así mismo, la rentabilidad y sostenimie nto del negocio en el tiempo, aseguran la permanencia de la empresa en el mercado

El presente estudio evalúa los procesos de la atención de servicios técnicos para equipos pesados de un taller de una empresa dedicada a la comercialización de bienes de capital y servicios. La necesidad de esta evaluación parte de los resultados de una encuesta realizada por el área de marketing de la empresa donde se ha detectado la baja satisfacción de los clientes respecto a la velocidad de respuesta del taller mecánico en la atención de los servicios requeridos. Por otra parte, se tiene en los resultados financieros de los últimos 05 años una tendencia a la baja rentabilidad bruta del área de servicios lo que compromete los resultados económicos de la sucursal.

Con el objetivo de encontrar las causas a los problemas presentados en el área de servicios se estructuró el marco teórico y se desarrollaron las herramientas de gestión de la calidad como encuestas, hojas de control, histogramas, diagrama de Pareto, diagrama de Ishikawa, etc. así como la teoría del Lean Manufacturing (gestión por procesos, mapeo de procesos, etc.) Six Sigma, Total Quality Management y el Ciclo de Deming PHVA. Esta actividad nos permitió establecer las alternativas de solución a los problemas encontrados

Se constituye el grupo de trabajo que lleva a cabo la investigación de los procesos, los mismos que recopilan los datos necesarios: antecedentes, la información actual del proceso y los datos estadísticos con la finalidad de hacer un diagnóstico y análisis del proceso actual. Para el estudio de los resultados se utilizaron las herramientas desarrolladas en el capítulo 1. Partiendo de la elaboración del mapa de proceso actual donde se ubican los procesos claves que comprometen la satisfacción del cliente y mediante una lluvia de ideas donde participan todos los actores de los procesos claves, se identifican todos los problemas de las actividades desarrolladas. Luego, mediante el diagrama de Pareto se ubican y se seleccionan los problemas que se presentan con 
mayor frecuencia. Así mismo se realiza el estudio del impacto económico de las ineficiencias del proceso y se determinan las causas raíces de los problemas.

Luego se elabora la propuesta de mejora al proceso de servicio a través de la matriz de oportunidades y la mejora del flujo del proceso actual, así mismo se realiza el análisis de las decisiones operativas y se priorizan las mejoras sugeridas. Luego se redacta el plan de implementación de las mejoras con los indicadores de seguimiento necesarios a fin de medir la mejora del proceso estableciendo un periodo de 04 meses para desarrollar la implementación de las mejoras propuestas. A continuación, se realiza la evaluación del costo-beneficio de la implementación de las mejoras obteniendo un beneficio económico en el corto plazo.

Finalmente, se llega a la conclusión de que el poco conocimiento que existe en todas las etapas del proceso por parte del personal del área de servicios no permite una gestión adecuada de los procesos de servicios. Así mismo se recomienda el fortalecimiento del equipo de trabajo durante la etapa de implantación de las mejoras del proceso. Respecto a las limitaciones más resaltantes, se tiene la falta de integración del sistema Domino Work Flow utilizado para abrir OTs con los sistemas de créditos y cobranzas. 


\section{CAPITULO 1. MARCO TEÓRICO}

El objetivo de este capítulo es presentar la definición de servicio postventa y la importancia de la mejora de los procesos. En este capítulo se estructura el marco teórico en que nos apoyaremos para realizar el análisis y la evaluación del diagnóstico de los procesos de servicio postventa describiendo la variedad de las herramientas de calidad disponibles; esto nos permitirá finalmente establecer las alternativas de solución a los problemas encontrados en los procesos de servicio.

\subsection{Definición de servicio posventa.}

La palabra postventa se deriva del latín post que significa después, al unirse con la palabra venta se define como: después de la venta. Sin embrago, este término tan utilizado en el ámbito empresarial no define por sí mismo todo el conjunto de actividades y operaciones que se realizan después de cualquier transacción mercantil.

Otra definición es:

"Plazo posterior a la compra durante el cual el vendedor o fabricante garantiza asistencia, mantenimiento o reparación de lo comprado", de acuerdo al diccionario de la lengua española (C) 2005 Espasa-Calpe S.A., Madrid.

El servicio postventa es el servicio de atención al cliente que proporciona una empresa para relacionarse con sus clientes. Es el conjunto de actividades que ofrece un suministrador o fabricante con el fin de que el cliente obtenga el máximo valor de un producto durante toda la vida útil del mismo. El servicio postventa es una potente herramienta de mercadeo que sirve no solo para difundir nuestros servicios sino para asegurar una larga relación comercial con nuestros clientes. El servicio al cliente es un concepto de trabajo y una forma de hacer las cosas que compete a toda la organización, tanto en la forma de atender a los clientes externos (que nos compran y nos permiten ser viables) como en la forma de atender a los clientes internos, es decir, a las diversas áreas de nuestra propia empresa. Los servicios postventa siempre generarán una inversión de dinero, pero a la larga es compensada por las oportunidades de negocios que se pueden cerrar en el futuro y por la fidelización del cliente. 
Las ventajas y desventajas de este concepto se muestran en la tabla 1, en éste se evidencia la importancia de desarrollar y hacer seguimiento a todas las etapas de ésta actividad.

"En el mundo actual, para mantener el negocio no se puede actuar como si se vendiese un producto. Se debe suministrar un servicio de valor añadido", Raymond Langton, Chief Executive, SKF North America.

Tabla 1: Ventajas y desventajas del servicio postventa.

\begin{tabular}{|l|l|}
\hline VENTAJAS & DESVENTAJAS \\
\hline Mayor satisfacción al cliente, & Gastos \\
Mejor imagen de la empresa y del producto & Necesidad de control. \\
Mejor conocimiento directo del mercado. & Posible aumento del número de reclamaciones. \\
Recepción más rápida de la información. & Mayores exigencias de servicio y calidad \\
Mayor objetividad en las prestaciones. & Modificaciones en la propia empresa. \\
Probable incremento de las ventas & Incidencias \\
Más posibilidad de aplicación de & medidas \\
correctoras sobre el mercado. & Relaciones Beneficio/Coste \\
\hline
\end{tabular}

Fuente: elaboración propia.

\subsection{Total Quality Management (TQM)}

Los conceptos de calidad y gestión de la calidad han evolucionado notablemente en los últimos setenta años, dando lugar a sucesivas teorías y enfoques que se han ido complementando hasta llegar a la denominada gestión de la calidad total. Desde el punto vista de los servicios, un producto o servicio será de calidad cuando satisfaga o exceda las expectativas del cliente.

"La gestión de la calidad total implica una aproximación sistémica que integra a la organización a toda la cadena de suministro (clientes internos, externos y consumidores finales), mediante el aprendizaje continuo y la adecuada gestión del cambio" (Evans \& Lindsay, 2005). 
La metodología TQM se enfoca en elevar la satisfacción del cliente, agregando valor a las actividades desarrolladas orientándose a reducir los costos de una mala calidad: todo aquello que implique pérdidas operativas, materiales, y pérdidas de potenciales clientes.

El camino hacia la Calidad Total además de requerir la implantación de una filosofía de calidad y creación de una nueva cultura, impulsar y mantener un liderazgo, desarrollar los recursos humano y trabajar en equipo, desarrollar a los proveedores, tener un enfoque dirigido al cliente y planificar la calidad demanda vencer una serie de hábitos, costumbres y dificultades en el trabajo que se realiza día a día. Se requiere dar solución a las variaciones que van surgiendo en los diferentes procesos de producción, reducir los defectos y además mejorar los niveles estándares de actuación.

Para resolver estos problemas o variaciones y mejorar la calidad de las organizaciones, es necesario basarse en hechos, datos estadísticos y no dejarse guiar solamente por el sentido común o la intuición, la experiencia o la audacia. Además es necesario aplicar un conjunto de herramientas estadísticas siguiendo un procedimiento sistemático y estandarizado de solución de problemas.

De acuerdo a la experiencia de los conocedores de la aplicación de estos instrumentos o herramientas, indican que si estas se aplican correctamente es posible resolver hasta el $95 \%$ de los problemas.

Para el presente estudio escogeremos entre las herramientas básicas que han sido ampliamente adoptadas en las actividades de mejora de la calidad describiendo aquellas que mejor se ajustan al presente estudio como son: la hoja de control, el histograma, el diagrama de Pareto, el diagrama de causa-efecto, la estratificación y el diagrama de dispersión.

\section{Hoja de control.}

La hoja de recolección de datos (registro), sirve para reunir y clasificar las informaciones según determinadas categorías, mediante la anotación y registro de sus frecuencias bajo la forma de datos. Una vez que se ha establecido el problema que se requiere estudiar y se han identificado las categorías que los caracterizan, se registran estas en una hoja, indicando la frecuencia de observación.

Lo más importante de los datos es que el objetivo este claro y que los datos sean un reflejo de la verdad. Una vez que se ha determinado las razones para recolectar los datos, es importante analizar las siguientes cuestiones: la información es cualitativa o cuantitativa, como, se recogerán los datos 
y en qué tipo de documento se plasmarán, cómo se utilizara la información recopilada, cómo se analizará, quién se encargará de la recogida de datos, con qué frecuencia se va a analizar, dónde se va a efectuar.

Los objetivos de la hoja de control son: investigar procesos de distribución, artículos defectuosos de ser el caso, localizar defectos y causas de efectos.

La secuencia de pasos útiles para aplicar esta hoja en un taller es la siguiente:

a. Identificar el elemento de seguimiento.

b. Definir el alcance de los datos a recoger

c. Fijar la periodicidad de los datos a recolectar

d. Diseñar el formato de la hoja de recogida de datos, de acuerdo con la cantidad de información a recoger, dejando un espacio para totalizar los datos, que permita conocer: las fechas de inicio y término, las probables interrupciones, la persona que recoge la información, fuente, etc.

\section{Histograma}

Un histograma es la presentación de una serie de medidas clasificadas y ordenadas, es necesario colocar las medidas de manera que formen filas y columnas. Para esto se coloca las medidas en cinco filas y cinco columnas. La forma más sencilla es determinar y señalar el número máximo y mínimo por cada columna y posteriormente agregar dos columnas en donde se colocan los números máximos y mínimos por fila de los ya señalados. Se toma el valor máximo de la columna X+ (medidas máximas) y el valor mínimo de las columnas X - (medidas mínimas) y obtendremos el valor máximo y el valor mínimo.

Con los valores máximos y mínimos, se puede determinar el rango de la serie de medidas, el rango no es más que la diferencia entre los valores máximos y mínimos.

El histograma se usa para obtener una comunicación clara y efectiva de la variabilidad del sistema, mostrar el resultado de un cambio en el sistema, identificar anormalidades examinando la forma, comparar la variabilidad con los límites de especificación.

El procedimiento para elaborar un histograma es: 
a. Reunir datos para localizar por lo menos 50 puntos de referencia

b. Calcular la variación de los puntos de referencia, restando el dato del mínimo valor del dato de máximo valor

c. Calcular el número de barras que se usaran en el histograma (un método consiste en extraer la raíz cuadrada del número de puntos de referencia)

d. Determinar el ancho de cada barra, dividiendo la variación entre el número de barras por dibujar

e. Calcular el intervalo o sea la localización sobre el eje $\mathrm{X}$ de las dos líneas verticales que sirven de fronteras para cada barrera

f. Construir una tabla de frecuencias que organice los puntos de referencia desde el más bajo hasta el más alto de acuerdo con las fronteras establecidas por cada barra.

g. Se elabora el histograma respectivo.

\section{Diagrama de Pareto.}

El diagrama de Pareto es una herramienta que se utiliza para priorizar los problemas o las causas que los genera.

El nombre de Pareto fue dado por el Dr. Juran en honor del economista italiano Vilfredo Pareto (1848-1923) quien realizó un estudio sobre la distribución de la riqueza, en el cual descubrió que la minoría de la población poseía la mayor parte de la riqueza y la mayoría de la población poseía la menor parte de la riqueza. El Dr. Juran aplicó este concepto a la calidad, obteniéndose lo que hoy se conoce como la regla $80 / 20$.

Según este concepto, si se tiene un problema con muchas causas, podemos decir que el $20 \%$ de las causas resuelven el $80 \%$ del problema y el $80 \%$ de las causas solo resuelven el $20 \%$ del problema.

Los procedimientos para elaborar el diagrama de Pareto son:

a. Decidir el problema a analizar.

b. Diseñar una tabla para conteo o verificación de datos, en el que se registren los totales. Aquí se puede utilizar las hojas de control. 
c. Recolección de los datos y efectuar el cálculo de totales.

d. Se debe elaborar una tabla de datos para el diagrama de Pareto con la lista de ítems, los totales individuales, los totales acumulados, la composición porcentual y los porcentajes acumulados.

e. Se debe ordenar los ítems por orden de cantidad llenando la tabla respectiva.

f. Se debe dibujar dos ejes verticales y un eje horizontal.

g. se construye un gráfico de barras en base a las cantidades y porcentajes de cada ítem.

h. Se dibuja la curva acumulada. Para lo cual se marcan los valores acumulados en la parte superior, al lado derecho de los intervalos de cada ítem, y finalmente una los puntos con una línea continua.

i. Se escribe cualquier información necesaria sobre el diagrama.

Para determinar las causas de mayor incidencia en un problema se traza una línea horizontal a partir del eje vertical derecho, desde el punto donde se indica el $80 \%$ hasta su intersección con la curva acumulada. De ese punto trazar una línea vertical hacia el eje horizontal. Los ítems comprendidos entre esta línea vertical y el eje izquierdo constituyen las causas cuya eliminación resuelve el $80 \%$ del problema.

Las principales ventajas del diagrama de Pareto son:

1. Separa los problemas principales de algunos de los posibles problemas lo que permite concentrar los esfuerzos de mejora en los principales problemas.

2. Organiza los datos de acuerdo a la prioridad e importancia.

3. Determina cuales son los problemas más importantes con los datos, no percepciones.

\section{Diagrama de Causa-Efecto}

El diagrama causa-efecto ayuda a pensar sobre todas las causas reales y potenciales de un fenómeno o problema, y no solamente en las causas más obvias o simples. Este diagrama a la vez motiva el análisis y la discusión en equipo, de manera que cada grupo de trabajo pueda ampliar su comprensión del problema, visualizar las razones, motivos o factores principales y secundarios, identificar posibles soluciones, tomar decisiones y, organizar planes de acción. 
El Diagrama Causa-Efecto es llamado también Diagrama de "Ishikawa" o "Diagrama Espina de Pescado" fue creado por Kaoru Ishikawa, japonés experto en dirección de empresas interesado en mejorar el control de la calidad. Este diagrama está compuesto por un recuadro (cabeza), una línea principal (columna vertebral), y 4 o más líneas que apuntan a la línea principal formando un ángulo aproximado de $70^{\circ}$ (espinas principales). Estas últimas poseen a su vez dos o tres líneas inclinadas (espinas), y así sucesivamente (espinas menores), según sea necesario.

Este diagrama permite lograr un conocimiento común de un problema, sin ser nunca sustitutivo de los datos. Es importante señalar que los diagramas de causa-efecto presentan y organizan teorías. Sólo cuando estas teorías son contrastadas con datos podemos probar las causas de los fenómenos observables.

Los pasos que se siguen para elaborar un diagrama de causa efecto son:

a. Definir claramente el efecto o problema cuyas causas han de identificarse.

b. Encuadrar el efecto a la derecha y dibujar una línea gruesa central apuntándole

c. Usar Brainstorming para identificar las posibles causas.

d. Distribuir y unir las causas principales a la recta central mediante líneas de $70^{\circ}$.

e. Añadir sub-causas a las causas principales a lo largo de las líneas inclinadas.

f. Descender de nivel hasta llegar a las causas raíz (fuente original del problema).

g. Comprobar la validez lógica de la cadena causal.

h. Comprobar la integridad: ramas principales con, ostensiblemente, más o menos causas que las demás o con menor detalle.

Las principales ventajas de este diagrama son:

Permitir que el equipo de trabajo se enfoque en el problema, no en los antecedentes del problema ni en los responsables de los integrantes del grupo de trabajo.

Ayuda a determinar las causas principales de un problema, o las causas de las características de calidad, utilizando para ello un enfoque estructurado. 
3. Motiva la participación de los miembros del equipo de trabajo, permitiendo así captar mejor el conocimiento que cada uno de ellos tiene del proceso.

4. Incrementa el grado de conocimiento sobre un proceso.

En la práctica estas herramientas requieren ser complementadas con otras técnicas cualitativas y no cuantitativas como son: la lluvia de ideas o brainstorming, la encuesta, la entrevista, el diagrama de flujo, la matriz de selección de problemas, etc.

-La lluvia de ideas (Brainstorming)

- La Encuesta

-La Entrevista

-Diagrama de Flujo

-Matriz de Selección de Problemas, etc.

\subsection{Six Sigma}

La filosofía six sigma en cuanto a su aplicación se refiere se remonta a los años 80 (Hammer, 2002:26) en la empresa Motorola. Esta filosofía no es más que un sistema flexible y de gran alcance para alcanzar, mantener y maximizar el éxito del negocio. 'Es una herramienta que engloba las necesidades del cliente, análisis de hechos, datos estadísticos y la gestión adecuada y atenta para mejorar o reinventar procesos." (Forrest, 2003, p.28).

Esta herramienta al igual que otras aplicables a la mejora de la calidad, tiene especial interés en reducir en gran margen la cantidad de fallas que se desarrollan en los procesos " 3.4 defectos por millón" (Rucoba, 2000, p.69). Sin embargo, dicho objetivo no es nada fácil de alcanzar, requiere de toda una cultura que tiene que ser implantada dentro de la organización. Es por ello que el beneficio de esta herramienta no se basa sólo en su aplicación; sino que deben establecerse y seleccionarse personas idóneas que relacionen las necesidades específicas de la empresa con la herramienta. Es más, el seis sigma puede ser integrado con otros sistemas o modelos como el Kaizen, TQM, etc. Pero esta herramienta, sugiere comprender los procesos claves e identificar y establecer los indicadores de desempeño que permitan relacionarlos con los objetivos estratégicos, la satisfacción del cliente y la eficiencia de los procesos de la empresa. 
'La estructura sobre la cual se basa esta herramienta es integrar el pensamiento estratégico de la organización con 3 recursos fundamentales: la tecnología, herramientas y técnicas y sobre todo el personal humano." (Kate, 2004, p.24).

El primer recurso se refiere a la tecnología utilizada para el normal desarrollo de los procesos, sean productivos o administrativos. Las herramientas y técnicas, segundo recurso, son necesarios para la medición y control de los procesos, para disminuir la variabilidad de los mismos. Y por último el personal humano, recurso fundamental, y quienes se encargan que los procesos se desarrollen. Cabe resaltar que estos recursos varían de empresa a empresa es por ello que debe existir personal adecuado para adaptar la filosofía con las necesidades de la empresa, tal como ya se indicó. Estas personas que deben ser seleccionadas por la alta gerencia deben recibir un adecuado entrenamie nto en temas de calidad, gestión, manejo y control de procesos, entre otros. Actualmente se disponen de talleres, cursos y programas que incluyen los temas indicados como los programas Black Belt, Green Belt y Yellow Belt. Incluso dichos programas se están realizando en instituciones peruanas.

En cuanto a la implementación de esta herramienta "no hay normas ni reglas establecidas, pero el profesor Helfin Rowland de la University of Wallage Collage nos indica los pasos mínimos necesarios para una adecuada implementación de la filosofía seis sigma. Estos pasos se resumen en seis." (Rowlands, 200, p.21):

Esclarecer la misión, visión e identificar los objetivos estratégicas.

Identificar las ventajas competitivas de la organización y las necesidades de los clientes.

Identificar proyectos a implantar y determinar las necesidades para hacer el entrenamiento respectivo.

Implementar el plan de entrenamiento seis sigma: black, green belt aplicado o priorizando las mejoras de procesos; por ejemplo el uso de la herramienta DMAIC (definir, medir, analizar, mejorar y controlar).

Evaluar la ganancia o beneficios de las mejoras

Sostener los beneficios en el tiempo con desarrollo de controles, comunicando los éxitos y seleccionando otros proyectos. 
El primer paso es fundamentalmente estratégico, el cual tiene que ser desarrollado por la alta gerencia conjuntamente con los representantes y jefes de las distintas áreas y de la organización para que las metas sean reconocidas y avaladas por todo el personal. Es fundamental que los objetivos sean cuantificables para así determinar en reuniones periódicas los avances y desempeño de los mismos.

El segundo consiste en hacer una retro-inspección a nivel de empresa para determinar lo que diferencia a la empresa de los competidores a nivel operativo, de servicio, alianzas, entre otros. Por otro lado el hacer un minucioso estudio del cliente es primordial para alinearlos con los objetivos estratégicos de la empresa.

El tercer paso refiere a analizar los puntos potenciales de mejora de los procesos, priorizando los procesos más importantes y a los cuales se les asigna un proyecto de mejora. Así mismo, determinar los requisitos para que los proyectos se realicen de la mejor manera. Estos requisitos incluyen la preparación adecuada del personal para mejorar los procesos o problemas que se presentan.

El siguiente paso es el entrenamiento de las personas seleccionadas para capacitarlas en el manejo y control de los procesos, así como la utilización de las herramientas estadísticas y de ingeniería industrial. Este paso es necesario para disminuir la variabilidad de los procesos con el fin de llegar a la meta del número determinado de defectos por millón que especifica esta filosofía.

La penúltima etapa consiste en analizar o evaluar los resultados obtenidos con las mejoras propuestas que se implementaron, aquí es donde se estudian los beneficios económicos, de productividad, eficiencia, que se han producido para retroalimentar el proyecto, precisamente el último paso de la implementación.

El mantener los beneficios económicos a largo plazo y sostenidamente es la meta de esta etapa, por la cual mediante el establecimiento de indicadores se trata de retroalimentar y controlar los procesos mejorados. Para asegurarse que el ciclo nunca se termina y que se mantenga continuamente es necesario seleccionar otros proyectos que incluyan mejoras en otros procesos claves y que necesitan de un rediseño.

Hasta este punto se ha desarrollado los beneficios de una correcta implantación de la filosofía, ahora se expondrán algunos problemas que se generan por una mala implantación de la filosofía seis sigma. "Estos problemas son cinco" (Goodman, 2005, p.37): 
1. No hay expectativas por parte de la gerencia.

2. No se usan adecuadamente las herramientas de medición.

3. Pensar que los problemas de la empresa no tienen solución.

4. Se mejora o elimina procesos sin tener en cuenta la retroalimentación respectiva.

5. Medidores de desempeño no reflejan el comportamiento real de los procesos.

Por ejemplo, para resolver estos problemas, la solución al primer problema enumerado está en hacer reuniones con todos los grupos influyentes de la empresa y trazar con ellos un plan de trabajo, tomando en cuenta las expectativas de los propios clientes internos. Posteriormente determinar si los recursos están disponibles y comprometer al grupo en formular metas y de ser posible definir el éxito en conjunto.

La solución al segundo problema es mirar los resultados en al menos cuatro categorías: financiero, satisfacción del cliente, procesos internos e innovación, talento y aprendizaje del personal.

El tercer problema tendrá solución al entrenar o capacitar con las herramientas sobre todo en las etapas iniciales del proceso. Esto los servirá para diferenciar situaciones y así escoger la herramienta y enfoque que mejor se aplique al caso.

El problema cuatro se soluciona identificando las necesidades del cliente. Usar entrevistas con el cliente, así como encuestas sobre satisfacción de éstos. Escoger las expectativas de los clientes que afectan a los procesos principales.

El último y quinto problema se elimina consiguiendo que el área financiera acepte como serán medidos los ahorros y beneficios del proceso. En este punto se considera no solo medir reducciones de costo y el impacto que se tiene a nivel empresa, sino también medir el impacto dentro del departamento a analizar o estudiar. 


\subsection{Lean Manufacturing.}

Lean Manufacturing es una filosofía de trabajo enfocada en crear una manufactura limpia, sin generar excedentes, desperdicios o bien operaciones que no le agregan valor al producto, servicio o proceso.

Tiene como objetivo proponer mejoras en los procesos a través del análisis de la cadena de valor y la implementación de herramientas de calidad e indicadores macro.

Lean manufacturing ('producción ajustada', 'manufactura esbelta', 'producción limpia' o 'producción sin desperdicios') es un modelo de gestión enfocado a la creación de flujo para poder entregar el máximo valor para los clientes, utilizando para ello los mínimos recursos necesarios: es decir ajustados.

La creación de flujo se focaliza en la reducción de los siete tipos de "desperdicios" en productos manufacturados:

Sobre-producción

Tiempo de espera

Transporte

Exceso de procesados

Inventario

Movimientos

Defectos

Al igual se habla de un octavo desperdicio en la manufactura como lo es: potencial humano subutilizado

Eliminando el despilfarro, mejora la calidad y se reducen el tiempo de producción y el coste. Las herramientas lean (en inglés, 'ágil', 'esbelto' o 'sin grasa') incluyen procesos continuos de anális is (llamadas kaizen en japonés), producción pull ('disuasión e incentivo', en el sentido del término japonés kanban), y elementos y procesos «a prueba de fallos» (poka yoke, en japonés), todo desde el genba japonés o área de valor. 
Un aspecto crucial es que la mayoría de los costes se calculan en la etapa de diseño de un producto. A menudo un ingeniero especificará materiales y procesos conocidos y seguros a expensas de otros baratos y eficientes. Esto reduce los riesgos del proyecto, o lo que es lo mismo, el coste según el ingeniero, pero a base de aumentar los riesgos financieros y disminuir los beneficios. Las buenas organizaciones desarrollan y repasan listas de verificación para validar el diseño del producto.

Los principios clave del lean manufacturing son:

Calidad perfecta a la primera: búsqueda de cero defectos, detección y solución de los problemas en su origen.

Minimización del despilfarro: eliminación de todas las actividades que no son de valor añadido y redes de seguridad, optimización del uso de los recursos escasos (capital, gente y espacio).

Mejora continua: reducción de costes, mejora de la calidad, aumento de la productividad y compartir la información.

Procesos "pull": los productos son tirados (en el sentido de solicitados) por el cliente final, no empujados por el final de la producción.

Flexibilidad: producir rápidamente diferentes mezclas de gran variedad de productos, sin sacrificar la eficiencia debido a volúmenes menores de producción.

Construcción y mantenimiento de una relación a largo plazo con los proveedores tomando acuerdos para compartir el riesgo, los costes y la información.

Lean es básicamente todo lo concerniente a obtener las cosas correctas en el lugar correcto, en el momento correcto, en la cantidad correcta, minimizando el despilfarro, siendo flexible y estando abierto al cambio.

La manufactura ajustada tiene un estrecho no calculado. Es una metodología de trabajo simple, profunda y efectiva que tiene su origen en Japón, enfocada a incrementar la eficiencia productiva en todos los procesos a partir de que se implanta la filosofía de gestión kaizen de mejora continua en tiempo, espacio, desperdicios, inventario y defectos involucrando al trabajador y generando en él un sentido de pertenencia al poder participar en el proceso de proponer sus ideas de cómo hacer las cosas mejor. 
Esta metodología de mejora de la eficiencia en manufacturas fue concebida en Japón por Taiichi Ohno, director y consultor de la empresa Toyota. Ingresado en 1937, Ohno observó que antes de la guerra, la productividad japonesa era muy inferior a la estadounidense. Después de la guerra, Ohno visitó Estados Unidos, donde estudió los principales pioneros de productividad y reducción de desperdicio del país como Frederick Taylor y Henry Ford. Ohno se mostró impresionado por el énfasis excesivo que los estadounidenses ponían en la producción en masa de grandes volúmenes en perjuicio de la variedad, y el nivel de desperdicio que generaban las industrias en el país más rico de la posguerra. Cuando visitó los supermercados tuvo un efecto inspirador inmediato; Ohno encontró en ellos un ejemplo perfecto de su idea de manejar inventarios reducidos, eliminar pasos innecesarios y controlar las actividades primarias y dar control al que hace el trabajo (en este caso el cliente) como apoyo a la cadena de valor (Lean Manufacturing. Wikipedia) La palabra japonesa muda significa 'desperdicio' y se refiere en específico, a cualquier actividad humana que consume recursos y no crea valor.

\section{Origen}

El origen de la propia palabra lean se atribuye al equipo de JP Womack, y Daniel Jones, actualmente en la Lean Global Network (leanglobal.org). Estos investigadores no fueron los únicos pioneros en la materia, pero sí los que consiguieron hacer llegar la filosofía lean a través de dos libros: "La máquina que cambió el mundo" y "Lean Thinking".

El objetivo es encontrar herramientas que ayuden a eliminar todos los desperdicios y todas las operaciones que no le agregan valor al producto o a los procesos, aumentando el valor de cada actividad realizada y eliminando lo que no se requiere. Este proceso de manufactura está relacionado con la utilización del activity-based costing (generación de costes basado en la actividad) el cual — de acuerdo a su versión original - busca relacionar los costes con todos los valores que el cliente percibe en el producto. Por otro lado, sirve para implantar una filosofía de mejora continua que le permita a las compañías reducir sus costes, mejorar los procesos y eliminar los desperdicios para aumentar la satisfacción de los clientes y mantener el margen de utilidad. El propósito de la manufactura esbelta es serle útil a la comunidad lo cual implica estar en busca de la mejora continua.

\section{Principios}

El cliente en general lo que adquiere no es un producto o servicio sino una solución. 
La mejora continua como principio de que «todo puede mejorar» en cada uno de los pasos del proceso como en la producción en sí, representa un avance consistente y gradual que beneficia a todos, en donde se dinamizan los esfuerzos del equipo para mejorar a un mínimo coste conservando el margen de utilidad y con un precio competitivo cumpliendo con las especificaciones de entrega en el tiempo y en el lugar exacto así como de la entrega en cantidad y calidad sin excederse.

El flujo en los pasos del proceso debe ser lo más uniforme por lo tanto debe ser continuo, optimizando recursos y eliminando lo que no es de valor añadido (espacio, capital y gente): minimización del despilfarro.

Detección y solución de problemas desde su origen eliminando defectos (buscando la perfección) de manera que satisfaga las necesidades del cliente por su alta calidad.

Procesos "pull": Producir solo lo necesario sobre la base de que los productos son solicitados o tirados o por lograr la producción del "jale" del cliente final.

Desarrollar una relación a largo plazo con los proveedores a partir de acuerdos para compartir información y compartir el riesgo de los costes.

Cuando los volúmenes de producción sean menores, desarrollar la capacidad de ser flexibles para poder producir ágilmente diferentes misceláneas de gran diversidad de productos.

\section{Áreas de aplicación}

Gestión

Planificación y ejecución

Reducción de actividades sin valor añadido

Exceso de producción o producción temprana

Retrasos

Transportes desde o hacia el lugar del proceso

Inventarios 
Procesos

Defectos

Desplazamientos

Las principales herramientas del Lean Manufacturing son:

$5 S$.

Sistemas de cambios rápidos (SMED)

Mantenimiento productivo total (TPM)

Sistemas a prueba de errores (Poka Yoke)

Gestión por procesos

Mapeo de los procesos

Teoría de las restricciones (TOC)

Just in time - kanban (JIT)

Estandarización de los procesos

Presentar los conceptos y metodología de auditoria de planta;

Presentar las técnicas y posturas de auditorías;

Comprender los requisitos del MSA (Manufacturing Site Assessment)

Presentar los criterios de evaluación del MSA.

\section{5'S}

Este concepto se refiere a la creación y mantenimiento de áreas de trabajo más limpias, más organizadas y más seguras, es decir, se trata de imprimirle mayor "calidad de vida" al trabajo. Las 5 'S provienen de términos japoneses que diariamente ponemos en práctica en nuestra vida cotidiana y no son parte exclusiva de una "cultura japonesa" ajena a nosotros, es más, todos los 
seres humanos, o casi todos, tenemos tendencia a practicar o hemos practicado las 5'S, aunque no nos demos cuenta.

Las 5'S son:

- Clasificar, organizar o arreglar apropiadamente: Seiri

- Ordenar: Seiton

- Limpieza: Seiso

- Estandarizar: Seiketsu

- Disciplina: Shitsuke

Cuando nuestro entorno de trabajo está desorganizado y sin limpieza perderemos la eficiencia y la moral en el trabajo se reduce.

El objetivo central de las 5'S es lograr el funcionamiento más eficiente y uniforme de las personas en los centros de trabajo. La implantación de una estrategia de 5'S es importante en diferentes áreas, por ejemplo, permite eliminar despilfarros y por otro lado permite mejorar las condiciones de seguridad industrial, beneficiando así a la empresa y sus empleados. Algunos de los beneficios que genera la estrategias de las 5'S son:

- Mayores niveles de seguridad que redundan en una mayor motivación de los empleados

- Mayor calidad.

- Tiempos de respuesta más cortos.

- Aumenta la vida útil de los equipos.

- Genera cultura organizacional.

- Reducción en las pérdidas y mermas por producciones con defectos.

\section{SMED}


SMED (Quick Changeover) por sus siglas en inglés (Single-Minute Exchange of Dies), es una metodología o serie de técnicas, de Lean Manufacturing, que hacen posible la reducción dramática en el tiempo de alistamiento y cambio de referencia de una máquina.

El tiempo de cambio de referencia se define como el tiempo que transcurre desde que se produce la última pieza correcta del producto A hasta que se produce la primera pieza correcta del producto B a la eficiencia total.

Los objetivos de SMED son:

- Crear la posibilidad de producir mediante lotes más pequeños sin afectar el costo.

- Reducir la cantidad e inventario.

- Mejorar la calidad del producto.

- Reducir desperdicios (tiempo, movimientos y material).

- Incrementar la flexibilidad de la planta.

- Mejorar en el tiempo de entrega del producto.

En el enfoque de SMED las operaciones de alistamiento o cambio de referencia se componen de actividades internas y actividades externas. Las actividades internas son aquellas que se deben realizar mientras el equipo está apagado o no se encuentra produciendo; por ejemplo un nuevo dado solo se puede instalar en la prensa cuando esta se encuentra parada. Las actividades externas en cambio son las que se pueden realizar mientras el equipo está operando; por ejemplo los tornillos para instalar el dado, pueden ser ensamblados y ordenados mientras la prensa está operando.

La clave del SMED está en poder identificar las actividades que son internas y externas, separarlas, convertir la mayor cantidad de actividades internas a externas y luego perfeccionarlas para optimizar la operación al máximo.

\section{TPM}

TPM es una filosofía de mantenimiento cuyo objetivo es eliminar las pérdidas en producción debidas al estado de los equipos, o en otras palabras, mantener los equipos en disposición para 
producir a su capacidad máxima productos de la calidad esperada, sin paradas no programadas. Esto supone:

- Cero averías

- Cero tiempos muertos

- Cero defectos achacables a un mal estado de los equipos

- Sin pérdidas de rendimiento o de capacidad productiva debidos al estado de los equipos.

Se entiende entonces perfectamente el nombre: mantenimiento productivo total, o mantenimiento que aporta una productividad máxima o total.

En una empresa en la que TPM se ha implantado toda la organización trabaja en el mantenimiento y en la mejora de los equipos. Esta cultura se basa en cinco principios fundamentales:

- Participación de todo el personal, desde la alta dirección hasta los operarios de planta. Incluir a todos y cada uno de ellos permite garantizar el éxito del objetivo.

- Creación de una cultura corporativa orientada a la obtención de la máxima eficacia en el sistema de producción y gestión de los equipos y maquinarias. Se busca la eficacia global.

- Implantación de un sistema de gestión de las plantas productivas tal que se facilite la eliminación de las pérdidas antes de que se produzcan.

- Implantación del mantenimiento preventivo como medio básico para alcanzar el objetivo de cero pérdidas mediante actividades integradas en pequeños grupos de trabajo y apoyado en el soporte que proporciona el mantenimiento autónomo.

- Aplicación de los sistemas de gestión de todos los aspectos de la producción, incluyendo diseño y desarrollo, ventas y dirección.

Las seis grandes pérdidas.

Desde la filosofía del TPM se considera que una máquina parada para efectuar un cambio, una máquina averiada, una máquina que no trabaja al $100 \%$ de su capacidad o que fabrica productos defectuosos está en una situación intolerable que produce pérdidas a la empresa. La máquina debe considerarse improductiva en todos esos casos, y deben tomarse las acciones correspondientes 
tendentes a evitarlos en el futuro. TPM identifica seis fuentes de pérdidas (denominadas las seis grandes pérdidas) que reducen la efectividad por interferir con la producción:

Fallos del equipo, que producen pérdidas de tiempo inesperadas.

Puesta a punto y ajustes de las máquinas (o tiempos muertos) que producen pérdidas de tiempo al iniciar una nueva operación u otra etapa de ella. Por ejemplo, al inicio en la mañana, al cambiar de lugar de trabajo, al cambiar una matriz o matriz, o al hacer un ajuste.

Marchas en vacío, esperas y detenciones menores (averías menores) durante la operación normal que producen pérdidas de tiempo, ya sea por problemas en la instrumentación, pequeñas obstrucciones, etc.

Velocidad de operación reducida (el equipo no funciona a su capacidad máxima), que produce pérdidas productivas al no obtener e la velocidad de diseño del proceso.

Defectos en el proceso, que producen pérdidas productivas al tener que rehacer partes de él, reprocesar productos defectuosos o completar actividades no terminadas.

Pérdidas de tiempo propias de la puesta en marcha de un proceso nuevo, marcha en vacío, periodo de prueba, etc.

El análisis cuidadoso de cada una de estas causas de baja productividad lleva a encontrar las soluciones para eliminarlas y los medios para implementar estas últimas. Es fundamental que el análisis sea hecho en conjunto por el personal de producción y el de mantenimiento, porque los problemas que causan la baja productividad son de ambos tipos y las soluciones deben ser adoptadas en forma integral para que tengan éxito

\section{Poka Yoke}

Poka-yoke es una técnica de calidad desarrollada por el ingeniero japonés Shigeo Shingo en los años 1960`s, que significa "a prueba de errores". La idea principal es la de crear un proceso donde los errores sean imposibles de realizar. La finalidad del poka-yoke es la eliminar los defectos en un producto ya sea previniendo o corrigiendo los errores que se presenten lo antes posible. Shingo autor del libro "Zero Qua lity Control: Source Inspection and the Poka-Yoke System" (1986) recomienda los siguientes puntos en la aplicación de poka-yoke: 
Control en el origen, cerca de la fuente del problema; por ejemplo, incorporando dispositivos de monitoreo que adviertan los defectos de los materiales o las anomalías del proceso.

Establecimiento de mecanismos de control que ataquen diferentes problemas, de tal manera que el operador conozca con certeza qué problema debe eliminar y cómo hacerlo con un cambio mínimo al sistema de operación.

Aplicar un enfoque de paso a paso con avances cortos, simplificando los sistemas de control sin perder de vista la factibilidad económica.

No debe retardarse la aplicación de mejoras a causa de un exceso de pilotos o estudios.

Muchas de las ideas de aplicación de poka-yoke pueden ponerse en práctica cuando se hayan definido los problemas con poco o ningún costo para la compañía. El poka-yoke enfatiza la cooperación Inter-departamental y es la principal herramienta para la mejora continua, pues motiva las actividades de resolución continua de problemas (Shingo, 1986).

\subsection{Gestión por Procesos.}

"Las organizaciones son tan eficaces y eficientes como lo son los procesos que realizan, aunados al grado de experticia de sus empleados". Esta frase es muy conocida por las organizaciones actuales quienes se han visto alentadas a mejorar sus procesos teniendo como base las normas de gestión de calidad como la ISO 9000:2000 y EFQM (European Foundation for Quality Management). En estas normativas se plantean no solo cómo se debe documentar, plasmar y difundir los procesos operacionales, sino además como adoptar las llamadas "mejores prácticas" para así crear organizaciones que sean líderes dentro de su ámbito industrial u operacional.

El mejorar constantemente los procesos operativos evita algunos males habituales como:

-Bajo rendimiento de los procesos.

-Falta de enfoque de los procesos hacia el cliente.

-Barreras departamentales y falta de flujo de información.

-Subproceso inútil debido a la falta de visión global del proceso. 
-Excesivas inspecciones y controles.

-Reprocesamiento constante.

-Pobre control de calidad.

-Imposibilidad de adoptar e implantar mejores prácticas, etc.

La Gestión por Procesos es la forma de gestionar toda la organización basándose en los Procesos.

"La gestión de procesos es una forma sistemática de identificar, comprender, y aumentar el valor agregado de los procesos de la empresa para cumplir con la estrategia del negocio y elevar el nivel de satisfacción de los clientes". (Bravo, 2005).

Los procesos son como una secuencia de actividades que tienen por objetivo generar un valor añadido sobre una entrada (input) para conseguir un resultado, y una salida (out put) que a su vez satisfaga las necesidades del Cliente. La estandarización (automatización) de los procesos reduce errores, asegurando que los procesos se comporten siempre de la misma manera y dando elementos que permitan visualizar el estado de los mismos. La administración de los procesos permite asegurar que los mismos se ejecuten correctamente (eficiente y eficazmente) y la obtención de información que luego puede ser usada para mejorarlos. El analizar la información que se obtiene del seguimiento diario de los procesos, ayuda a identificar posibles ineficiencias en los mismos, y actuar sobre las mismas para optimizarlos.

Para soportar esta estrategia es necesario contar con un conjunto de herramientas que den el soporte necesario para cumplir con el ciclo de vida de BPM (Business Process Management System).

"La gestión de los procesos considera tres grandes puntos de acción sobre los procesos: describir, mejorar y rediseñar. No como opciones excluyentes, sino como seleccionadas de un abanico de infinitas posibilidades", Bravo 2005, p.39.

Los procesos se dividen en tres tipos:

Procesos estratégicos, son aquellos relacionados con las estrategias de la organización: misión, visión, cumplimiento de objetivos, etc. 
Procesos del negocio: son aquellos que atienden directamente la misión del negocio y satisfacen las necesidades concretas del cliente.

Procesos de apoyo: son aquellos servicios internos necesarios para realizar los procesos del negocio (procesos secundarios).

Como se puede apreciar en todo proceso existen sub-procesos que contribuyen y/o afectan en mayor o menor grado el flujo normal de las actividades.

\subsubsection{Herramienta de los quince pasos para la mejora de procesos}

Esta herramienta fue desarrollada para la mejora de un proceso de entrega de efectivo en una empresa telefónica en los Estados Unidos, específicamente en el área de contabilidad (Bisson y otros, 2000: vol 23, fas 1). La herramienta se basa en quince pasos; estos son:

1. Crear un mapa de relaciones. En dicho mapa se identifican los procesos que necesitan especial atención. Esto es el mapa de procesos.

2. Escoger a las personas. Esta actividad sugiere identificar a las personas que están directamente involucradas en el proceso y son las que más conocen de él así mismo también se podría invitar a terceros o consultores para que analicen el proceso siempre y cuando trabajen en equipos con personal de la empresa.

3. Entrenar a las personas. Se debe capacitar a las personas o al equipo de trabajo en herramientas estadísticas como de levantamiento de información (tablas de frecuencias $\mathrm{u}$ ocurrencias, histogramas, entre otras).

4. Escoger el proceso y el equipo específico. Esto se puede extraer del mapa de procesos lo cual permite involucrar a todas las áreas que participan en el proceso a analizar o mejorar.

5. Planear las actividades para el mejoramiento del proceso. Esto implica proponer un cronograma definiendo los objetivos a desarrollar por cada actividad.

6. Crear un flujograma del proceso. Aquí la idea es analizar los procedimientos actuales de trabajo identificando los grupos que están directamente implicados en el proceso clave.

7. Construir un posible flujograma mejorado. Los encargados del proceso deberán dirigir sesiones de equipo conjuntamente con los encargados del proceso a fin de construir el flujograma mejorado. 
8. Identificar lo que desconecta el proceso. El equipo de trabajo revisa el flujo del proceso para identificar los siguientes puntos: punto en el proceso donde se producen duplicación de trabajos, los pasos que deben ser realizados por otras áreas, así como las discrepancias entre las áreas involucradas y demoras en el tiempo de ciclo.

9. Decidir si reparar o volver a diseñar el proceso. En esta etapa el equipo de trabajo deberá decidir entre fijar o eliminar el agente desconector del proceso o diseñar un nuevo proceso.

10. Definir los atributos del proceso mejorado. Antes de realizar el flujograma nuevo, se listarán las características que se requieren incorporar al proceso nuevo.

11. Diseñar el proceso ideal. El equipo de trabajo deberá resumir en un diseño ideal el nuevo proceso.

12. Especificar los puntos de control o medición. A fin de monitorear la evolución de la mejora se debe asignar indicadores de desempeño durante el proceso.

13. Criticar y revisar los diseños propuestos. Los diseños del proceso y los puntos de control o indicadores son presentados a la administración y/o alta gerencia de la empresa.

14. Formular recomendaciones. La aplicación del nuevo proceso no se puede ejecutar sin hacer otros cambios en la sucursal. Estos cambios deberán ser definidos en una serie de recomendaciones. Entre éstas recomendaciones se presentan como alternativas la automatización de actividades manuales, planes de medición de desempeño, transferencia de personal entre áreas, cambios en la comunicación, reasignación de tareas del personal, etc.

15. Decidir si aplicar o no las recomendaciones. El equipo de trabajo presenta las recomendaciones a la administración quienes deben aprobar o no las recomendaciones.

Entre los beneficios de mayor impacto de la implantación de esta herramienta cuyo objetivo principal era la reducción de costos en el proceso se encuentran: reducción de pasos por encima del 50\% (de 50 a 24), ahorro de 930 mil dólares anuales, reducción de $45 \%$ de personal requerido para el proceso (Bisson y otros, 2000).

Cabe resaltar que la herramienta antes detallada se utilizó para un proceso administrativo, el cual es el tipo de proceso que analizaremos en el presente estudio. 


\subsubsection{Resumen rápido de RAPID}

RÁPIDO fue desarrollado por Paul Rogers y Marcia Blenko - dos Bain \& Company

consultores. Su artículo: "Who Has the D?: How Clear Decision Roles Enhance Organizational Performance" que apareció en enero de 2006 Harvard Business Review y desde entonces se ha convertido en uno de los tpo 10 HBRs de lecturas".

El acrónimo rápido describe los diferentes roles y responsabilidades de la clara toma de decisiones dentro de una empresa. Con respecto a las decisiones críticas, en última instancia, muestra cómo la energía fluye a través de una unidad de la organización o empresa. El objetivo de este enfoque es crear un enfoque hacia el proceso de toma de decisiones dentro de una organización más formal, participativa. También resulta útil como una herramienta "post mortem" para diagnosticar fallidas decisiones - para ver qué elemento o elementos en el proceso de rápida fue/falta o que faltan para que la próxima vez que una decisión crítica debe hacerse por lo que no se repite los mismos errores una y otra vez.

La implementación RAPIDO puede ser desordenada; puede revelar un proceso decisorio enrevesado y defectuoso por lo que debe haber un compromiso total para "comprobar los egos en la puerta" y aceptar la necesidad de aprobar RAPIDO como parte de una iniciativa de mejora organizativa. Si su organización es en cambio, no puede ser el momento adecuado para implementar RAPIDO.

Aquí es lo que R.A.P.I.D. significa:

Recommend:

Hacer una propuesta sobre una decisión clave, recoger la entrada y proporcionar datos y anális is para hacer una elección razonable, de manera oportuna.

Consultoría con proveedores de entrada: audiencia incorporando sus puntos de vista y ganando su compra.

AGreen:

Negociando una propuesta modificada con quien recomienda si tienen cambios o preocupaciones a la propuesta original. 
Escalada sin resolver las diferencias y los problemas para el decidió si a y r no puede resolver sus diferencias.

Si es necesario, ejercer su poder de veto sobre la recomendación.

Perform:

La ejecución de una decisión una vez que se hace.

Viendo que la decisión se aplique correctamente y con eficacia.

Nput:

Proporcionar hechos relevantes a la OMS recomienda arrojan luz sobre la viabilidad de la propuesta y consecuencias prácticas.

Decide:

Sirviendo como el único punto de responsabilidad.

Lo que la decisión de cierre por resolver cualquier situación de estancamiento en el proceso de toma de decisiones.

Confirmando la organización para la aplicación de la decisión.

Las decisiones son la moneda del reino de los negocios. Pero incluso en empresas altamente respetadas, las decisiones pueden quedar atascadas al interior de la organización como cambio suelto. En consecuencia, todo el proceso de toma de decisiones puede estancarse, habitualmente en uno de cuatro cuellos de botella: global versus local, centro versus unidades de negocios, función versus función, socios internos versus socios externos. Los cuellos de botella en la toma de decisiones pueden suceder siempre que hay ambigüedad o tensión sobre quién tiene que decidir sobre qué cosa. Por ejemplo, ¿son los expertos en marketing o los desarrolladores de producto los que deben decidir las características de un producto nuevo? ¿Debería una importante inversión de capital depender de la aprobación de la unidad que la gestionará, o debería ser la sede corporativa la que tenga la última palabra? ¿Cuáles son las decisiones que pueden ser delegadas a un socio de tercerización y cuáles deben ser tomadas internamente? Los consultores de Bain, Paul Rogers y Marcia Blenko, usan un enfoque llamado RAPID (acrónimo en inglés de rápido, acordar, desempeño, información y decidir) para ayudar a las empresas a despejar sus cuellos de botella en 
la toma de decisiones, definiendo explícitamente roles y responsabilidades. Por ejemplo, British American Tobacco alcanzó un nuevo equilibrio entre la toma de decisiones global y local para tomar ventaja de la escala de la compañía y para mantener su agilidad en los mercados locales. En Wyeth Pharmaceuticals, una oportunidad de crecimiento reveló la necesidad de empujar más decisiones hacia las unidades de negocios. Y en la cadena de tiendas por departamento británica John Lewis, los compradores y el personal de ventas aclararon sus roles de decisión, para implementar una nueva estrategia para vender sus molinillos de sal y pimienta. Cuando renueva su proceso de toma de decisiones, una empresa debe tomar algunos pasos prácticos: alinear los roles de decisión con las fuentes de valor más importantes, asegurarse de que las decisiones son tomadas por las personas correctas en los niveles precisos de la organización, y dejar que las personas que vivirán con el nuevo proceso ayuden a diseñarlo.

\subsubsection{Mapeo de Procesos.}

El Mapeo de Proceso es una de las técnicas de mejora propuestas por Lean Manufacturing. Es una representación gráfica de un proceso, mostrando la secuencia de tareas a realizar y su trayectoria.

Para elaborar el mapa de procesos se sigue una metodología sencilla que parte de la misión y la visión del Servicio, de los clientes/usuarios y de las necesidades y expectativas de los mismos. Partiendo de esta base se identifican los procesos y se organizan en el mapa de procesos. El propósito de todo proceso es ofrecer al cliente/usuario un servicio correcto que cubra sus necesidades, que satisfaga sus expectativas, con el mayor grado de rendimiento en coste, servicio y calidad.

El análisis de cada proceso culmina con la elaboración del Diagrama de flujo, la ficha del proceso, la identificación de los indicadores de control y resultados y, finalmente, con la organización de la documentación correspondiente.

\subsection{Ciclo de Deming o ciclo PEVA (PDCA en siglas en inglés)}

Esta herramienta fundamental que es en realidad una espiral de mejora continua de solución a problemas, tan difundida mundialmente, es aplicada a todo nivel en las empresas de producción y servicios y en las organizaciones a nivel mundial. Incluso tiene versiones de cuatro y ocho pasos (Rucoba, 2000: 77), los cuales difieren de acuerdo a si se conocen las causas del problema. Esto es, para un problema del cual se reconocen fácilmente y con anterioridad sus causas, se utiliza el ciclo de cuatro pasos; mientras el de ocho pasos se utiliza en caso las causas son aún desconocidas 
por las personas encargadas del proceso por lo cual se tiene que hacer previamente una investigación exhaustiva para la identificación de las causas del problema, además de identificarlo claramente. Estos 8 pasos no son más que la disgregación de los 4 pasos fundamentales, (planear, ejecutar, verificar o controlar y actuar) especialmente antes de la fase de planeación propiamente dicha.

El empleo de esta herramienta tiene beneficios importantes los cuales se resumen en (Cole, 2002, p.105):

- La participación activa del personal

- El tiempo de respuesta

- La calidad en el desempeño de la organización, aprender continuo.

El primer beneficio se entiende porque el cambio y las mejoras se sustentan en sugerencias del mismo personal, que se mueve cerca del proceso, lo que provoca que la investigación sea más intuitiva y así las alternativas de mejoras sean más prácticas. El cambio es más beneficioso cuando todo el personal de la empresa conoce el por qué o la necesidad del cambio que se quiere implantar.

El segundo beneficio, el tiempo de respuesta rápido, es una consecuencia del primero, ya que el cambio al ser dirigido por los cercanos al proceso, se generan las recomendaciones que se pueden aplicar inmediatamente.

El tercer beneficio, refiere que al establecerse el estudio de diferentes procesos en una organización, ésta se encontrará en un estado de aprendizaje continuo. De esta manera los empleados son capaces de ver los resultados inmediatos de su esfuerzo, y los incorpora a sus procesos de trabajo sin demora. Así cuando el personal sienta seguridad al tomar los riesgos y aprendan de sus éxitos y fracasos, se estará instalando la mejora continua.

Luego de haber explicado los beneficios se mostrarán los requisitos mínimos indispensables para que la herramienta y su aplicación sean lo más eficiente y eficaz posible. "Estas condiciones claves son tres" (Houser, 1996, p.215): El liderazgo y compromiso, soporte y apoyo a los equipos encargados de las mejoras y la flexibilidad al cambio dentro de la organización.

El liderazgo, sobre todo la ejercida por la alta gerencia de la organización es importante por cuanto son fuente de estímulo y motivación para los empleados y de esta manera éstos se sientan 
respaldados en el desarrollo de sus actividades de trabajo diarias. Es por ello que los altos mandos deberán asignar todos los recursos necesarios para que las mejoras se puedan aplicar y den los resultados esperados. Los equipo encargados de la mejoras también deberán tener reuniones periódicas con la alta gerencia para reportar los avances respectivos para reconocer si los objetivos se están cumpliendo de acuerdo a los proyecto de mejora.

Ahora procederemos a explicar el ciclo PEVA pero con un adicional, el de la herramienta FOCUSPDCA el cual es una herramienta aumentada del PEVA convencional pero tiene la ventaja que la etapa de reconocimiento de causas se desarrolla de una forma más detallada y minuciosa, además proporciona una base amplia para conocer el flujo del proceso de tal manera que se elevan las probabilidades de descubrir las maneras de hacer los cambios de mejora fundamentales en el proceso que tendrán como resultados niveles altos de desempeño. Esta parte aumentada (los 5 pasos FOCUS) sirve como una base teórica para seleccionar mejor las alternativas de cambio y para predecir el efecto de éstas en el proceso. "Esta herramienta aumentada consiste en 9 pasos, los cuales son" (Stoltz, 1996, p.223) (el nombre de los pasos se deben a su traducción al inglés):

1. Paso F: Encontrar un proceso a mejorar.

2. Paso O: Organizar un equipo que conoce el proceso

3. Paso C: Clarificar el conocimiento actual del proceso.

4. Paso U: Entender las fuentes de variación en el proceso.

5. Paso S: Seleccionar las mejoras en el proceso

6. Paso P: Planear el piloto.

7. Paso D: Hacer la mejora. Colección de datos y análisis

8. Paso C: Controlar y verificar los resultados.

9. Paso A: Actuar para extender el beneficio y aplicar la mejora continua.

Paso 1: el objetivo del "Paso F" es identificar plenamente el proceso a ser mejorado, para lo cual se deberán explicar las razones por la cual el proceso es más importante frente a otros. Las actividades que implica esta etapa son: revisar la misión general de la organización, la visión y las declaraciones de valores, en caso existan; analizar la información detallada, pertinente e 
importante como los requisitos del cliente, información sobre desempeño, metas estratégicas y los requisitos a nivel operacional importantes (cómo se lleva el proceso actualmente el proceso); identificar, priorizar y escoger las oportunidades de mejora; y por último describir el por qué se desea mejorar el proceso.

Paso 2: El objetivo del "Paso O" es identificar y reunir a las personas con el conocimiento detallado del proceso, es decir al personal involucrado con las actividades y proveer a los equipa con los recursos adecuados para realizar la mejora. Las acciones que son necesarias para este paso incluyen:

1. Asegurar que estén representados todas las personas involucradas en el proceso, incluso si hay personas que funcionalmente pertenezcan a otras áreas.

2. Identificar al dueño del proceso o al empleado con la autoridad y responsabilidad para dirigir la mejora.

3. Las fuentes de identificación de apoyo técnico o educativo, deben recaer en una persona encargada de ser un facilitador/consejero.

4. Identificar el enlace entre la mejora a realizar y las prioridades de la organización, y así asegurar los recursos necesarios

5. Formular un plan o cronograma para conseguir la mejora.

6. Iniciar los métodos para mantener comunicados a todo el personal sobre el progreso de la mejora.

Paso 3: en el "paso C" se construyen diagramas para la comprensión clara y completa de cómo el proceso opera actualmente. Basado en su comprensión y lógica común, el equipo de mejora tratará de bosquejar la mejora. Las acciones a realizar en el paso 3 son:

- Diagramar cómo el proceso trabaja verdaderamente (no cómo debe trabajar).

- Los pasos superfluos o innecesarios se eliminan.

Paso 4: el objetivo del "paso U" es que el equipo de mejora entienda los tipos y las fuentes de la variación y/o cambios en el proceso estudiando el desempeño del proceso con el tiempo e 
identificando qué factores dentro del proceso tienen una fuerte influencia, sobretodo en el cliente. Las acciones incluyen:

- Reconocer los requisitos o expectativas del cliente.

- Traducir el conocimiento sobre el cliente en medidas operacionalmente definidas del desempeño del proceso.

- Reunir al equipo de mejora y analizar los datos recolectados en las variaciones del desempeño del proceso.

- Quitar o incorporar las causas especiales que hacen que el proceso sea previsible.

- Identificar, reunir, y analizar los datos o factores dentro del sistema de las causas comunes que tienen una influencia significativa en el resultado del proceso.

- Realizar los planes de la recolección de datos, así como gráficos de datos. Este plan deberá contener información sobre qué datos se levantarán, quién los reunirá, cuándo y dónde se reunirán, cuánto tiempo se reunirán y por cuáles métodos se recogerán o levantarán.

- Utilizar herramientas como histogramas, gráficos de Pareto, etc.

Paso 5: en el "paso S" el equipo de trabajo identifica y prioriza los cambios del proceso que se pueden predecir para hacer la mejora, basado en el conocimiento adquirido en los pasos anteriores. La velocidad con la que se puede introducir el cambio, el costo, y el impacto en clientes son algunos criterios utilizados para priorizar los cambios. Las acciones que se incluyen en este paso son:

- Redactar una lista de cambios posibles.

- Indicar los criterios para la selección y priorización de los cambios

- Escoger un cambio para trabajarlo con los pasos siguientes (PDCA)

- Incluir una matriz de la decisión o priorización.

- Reunir información adicional acerca de otras mejoras posibles. 
Paso 6: el objetivo del "paso P" es establecer el plan cómo se debe efectuar el cambio y medir su efecto. Las acciones que se deben realizar en este paso son: desarrollar un plan de acción para introducir el cambio que contenga: lo que se ha cambiado, quien es el responsable de la implementación, qué se debe informar y/o a quién se debe capacitar, dónde se realizará la prueba piloto, cuándo empezará y cuánto durará ésta y por último determinar los requisitos de la implementación así como las vías de comunicación, el equipo y las instrucciones necesarias.

Paso 7: el objetivo del "paso E" es que el equipo de trabajo aplique los planes de acción, dirigie ndo el cambio, observando y registrando el efecto para así analizar los resultados. Las acciones que se realizan son:

- Preparar a los empleados y el ambiente de trabajo para el cambio del proceso.

- Aplicar el cambio y conducir el trabajo.

- Observar y documentar los efectos del cambio.

- Observar el cambio para documentar y para dirigir como se producen las sorpresas o las circunstancias imprevistas tales como los fracasos o las deficiencias en la planificación y la implementación, así como los cambios en la organización que podrían afectar el proceso en estudio.

Paso 8: el objetivo del "paso V" es estudiar los resultados para observar si el cambio ha producido la mejora deseada y se han producido resultados importantes en el cliente. Se necesitan de acciones como:

- Comparar las medidas antes del cambio de proceso con los resultados del plan piloto.

- Entender los fracasos para demostrar que hay resultados que excede la predicción.

Paso 9: el objetivo del "paso A" es tomar la acción apropiada en base al conocimiento adquirido en todos los pasos anteriores. Para la realizar este paso se requiere:

- Mantener el beneficio y extender el período de ganancia. Esto a menudo requiere cambios en la política y procedimientos de la empresa, como en comunicación e instrucciones, y así establecer un mecanismo para controlar el proceso nuevo. 
- Continuar la mejora. Esto requiere volver a la lista de cambios y empezar por otras pruebas potenciales y así encontrar pilotos de otros procesos a mejorar.

- Adaptar el cambio (y conducir otra prueba piloto): Esto ocurre cuando los resultados y las observaciones sugieren la probabilidad de lograr los resultados predichos modificando el cambio.

- Abandonar el cambio: Esto debe suceder cuando los resultados sugieren que la teoría fundamental en que el cambio predicho se basó estaba defectuoso o que las prioridades de la organización han cambiado y algún otro enfoque al proceso o el sistema es más pertinente.

\subsection{Método de solución de problemas.}

Una vez los problemas se hayan identificado y se haya elaborado información de su importancia, envergadura, costes que ocasiona etc., se procede a utilizar las herramientas apropiadas detalladas anteriormente (las herramientas de medición y control).

El AMFE (Failure Mode and Effects Analysis - Análisis del Modo de Falla y sus Efectos es un método estructurado para prevenir e identificar problemas potenciales (modos de falla), sus causas y efectos con la participación de equipos multifuncionales.

Se utilizan AMFEs de Sistema, Diseño y de Proceso, en las fases de concepción de diseño, (antes de la producción), y de análisis de los procesos de servicio a ser utilizados. Los AMFEs mejoran la calidad, la confiabilidad, la seguridad y satisfacción del cliente.

En las nuevas versiones, como aspectos más significativos, se destacan los nuevos criterios en las tablas de ponderación de severidad, detección y ocurrencia y el tratamiento de procesos en cantidad, además de la inclusión de las características de alto impacto y las características de seguridad del personal técnico.

\subsection{Análisis de costos.}

En un entorno de fuerte competencia, las organizaciones enfrentan el desafío de vencer limitaciones y desarrollarse como empresas focalizadas en resultados sostenibles y creadores de valor para el cliente. 
Para lograr este objetivo, tanto desde el plano directivo como en el operativo, se tienen que reformular los conceptos de gestión.

El planteo excede la reducción de costos y se centra en el aprovechamiento máximo de los recursos disponibles. "Cuando hablamos de "costes" normalmente pensamos de forma negativa, sin embargo, los costes no sólo se deben intentar reducirlos, sino que, los costes de calidad, son una excelente herramienta de información, que nos facilitan la toma de medidas de tipo estratégico" (Feinfembaum, 1991, p. 109).

"Conocer el ahorro en costes tiene un efecto impactante para la alta dirección, pues, permite la obtención de los recursos necesarios para el mantenimiento y la mejora de la calidad y sugiere la cantidad que debería ser invertida en dichas actividades", Padrón. 2001 p. 137).

En los tiempos actuales no se puede hablar de gestión de la calidad total sin hablar de una continua disminución de costes. Los costes de calidad en empresas no consientes de la calidad pueden llegar a ser muy elevados, y no son visibles en la cuenta de resultados. El primer paso a seguir es identificar y medirlo los costes para poder tomar conciencia de algún problema de calidad y así justificar las inversiones que se deben desarrollar para reducirlos.

El ABC es una herramienta fundamental para el desarrollo de la gestión de la calidad total, con el diseño del modelo se sientan las bases para el desarrollo de acciones de gestión de la calidad. Es muy importante dirigir el papel que el $\mathrm{ABC}$ va a jugar en el proceso de cambio de la organización. El objetivo es crear expectativas positivas de mejora, unir el $\mathrm{ABC}$ con los objetivos de mejora de la empresa, definir cuáles han de ser las áreas en las que se van a producir las mejoras, facilitar a los usuarios apoyo técnico y comunicar las conclusiones que se han obtenido en otras partes de la organización.

Dos de las clasificaciones que se utilizan como modelos generalmente aceptados donde se descomponen los costes de calidad son las de AECA y la ASQC.

AECA (1995: p 73-79) y la ASQC (1974) establecen una clasificación de los costes de calidad en dos grandes grupos: costes de calidad y costes de no calidad. A su vez los costes de calidad los subdivide en costes de prevención y costes de evaluación y los costes de no calidad en costes de fallos internos y costes de fallos externos. 


\section{CAPITULO 2. ANALISIS Y DIAGNOSTICO DEL PROCESO ACTUAL}

En este capítulo analizaremos la estructura orgánica del área de servicios de la empresa Ferreyros S.A.A. identificando los procesos claves y la forma como su ejecución contribuyen a determinar el grado de calidad en el servicio prestado logrando identificar las causas de los problemas de calidad y determinar sus posibles soluciones.

\subsection{Descripción de la empresa}

Ferreyros es una empresa privada que se dedica a la comercialización de bienes de capital y servicios en los mercados de minería, construcción, agricultura, forestal, transporte, energía, industria y pesca. Fundada en 1922 bajo el nombre de Enrique Ferreyros y Cia. Se dedicó inicialmente a la comercialización de abarrotes. Veinte años después asume la representación de Caterpillar Tractor Co. en el Perú. En 1998 se transforma en una sociedad anónima abierta bajo la denominación de Ferreyros S.A.A. Actualmente y bajo la denominación de Ferreyros S.A. forma parte del holding Ferreycorp, corporación que agrupa a 16 subsidiarias a nivel nacional e internacional.

Ferreyros es en el Perú representante exclusivo de las marcas Caterpillar, Massey Ferguson, Kenworth, Atlas Copco entre otras.

Su oficina principal se encuentra en Monterrico, Jr. Cristóbal de Peralta 820, Surco y su taller más importante se ubica en la Av. Industrial 675, cercado Lima. El taller principal cuenta con un laboratorio de análisis de aceites, un Centro de Reparación de Componentes "CRC", taller de máquinas, taller de pre-entregas de equipos, laboratorio de análisis de fallas, dinamómetros, bancos de pruebas de motores y transmisiones hidrostáticas, talleres de reconstrucción de componentes y de trenes de rodamiento, taller hidráulico, taller de mecanizado, taller de armado de mangueras, taller de soldadura, y modernos almacenes de herramientas y repuestos interconectados a través del sistema DBS (Dealer Bussiness System). 
La empresa cuenta con un capital humano de más de 4,000 personas entre empleados y obreros. Posee 17 sucursales (pequeñas réplicas de su taller principal) y 5 oficinas distribuidas estratégicamente en el Perú. Así mismo atiende más de 20 proyectos mineros en los puntos donde opera el cliente con todo el personal y la logística necesaria.

La visión de la empresa es: "Fortalecer nuestro liderazgo siendo reconocidos por nuestros clientes como la mejor opción, de manera que podamos alcanzar las metas de crecimiento". FERREYROS 2015 (https://www.ferreyros.com.pe).

La misión de la empresa es: "Proveer las soluciones que cada cliente requiere facilitándole los bienes de capital y servicios que necesita para crear valor en los mercados que actúa". FERREYROS 2015 (https://www.ferreyros.com.pe).

Por esta razón uno de los principales objetivos de la empresa es fortalecer y mejorar el servicio postventa como herramienta fundamental y diferenciadora de la competencia.

\subsection{Descripción del proceso actual del servicio postventa.}

El área de servicios de la Sucursal Lambayeque es una unidad de negocios de la empresa Ferreyros dedicada principalmente a atender tres tipos de servicio: servicio interno (cliente es Ferreyros), servicio de garantía (facturable a fábrica) y servicio cliente (facturable al cliente externo).

Las ventas de servicios internas y de garantía siempre tienen márgenes de ventas positivos debido a que el sistema DBS asigna automáticamente $25 \%$ de rentabilidad respecto a los costos y gastos cargados en el sistema. Respecto a las ventas de servicio de tipo cliente de la línea CAT, en los últimos 5 años las ventas han incrementado año a año, sin embargo, la rentabilidad en los dos últimos años fue negativa. En la tabla 2 se puede visualizar el incremento del volumen de ventas del área en los últimos 5 años, así mismo en la tabla 3 se observa la rentabilidad bruta de las ventas de los últimos 5 años habiéndose resaltado la baja rentabilidad de los dos últimos años. Es importante señalar que de acuerdo a los objetivos del área, la rentabilidad bruta debe ser mayor a $35 \%$.

Tabla 2 Ventas anuales de Servicios línea CAT del 2006 al 2010. 


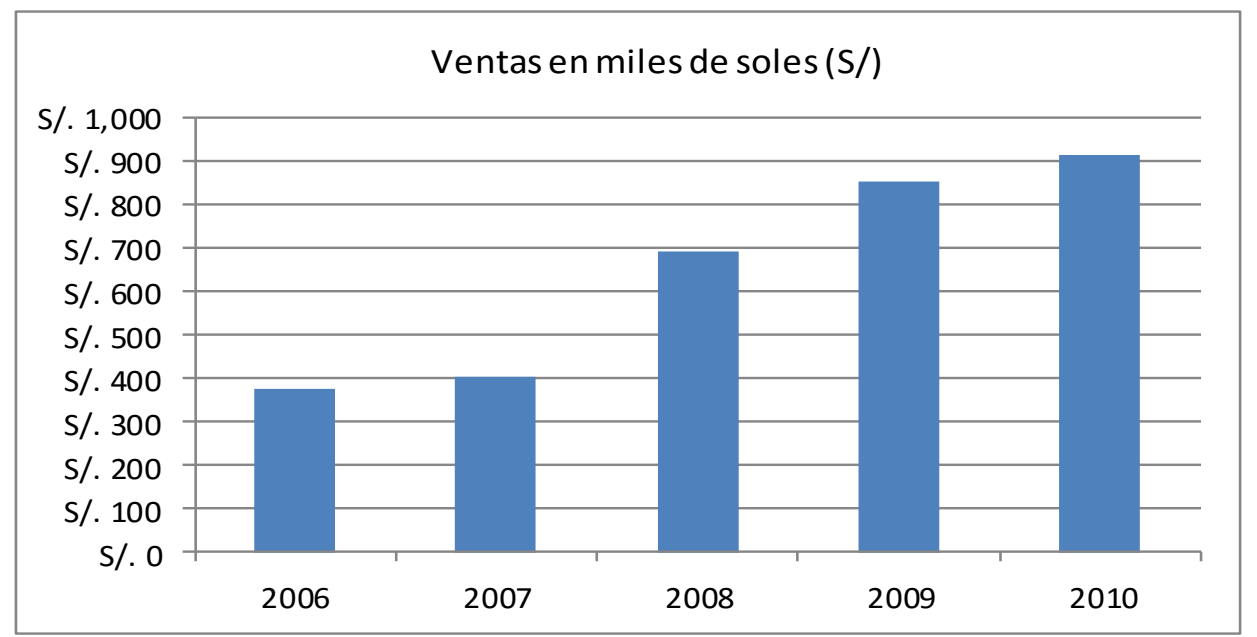

Fuente: Elaboración propia.

Tabla 3 Rentabilidad bruta de Servicios línea CAT del 2006 al 2010.

\begin{tabular}{|l|l|l|l|l|l|}
\hline AÑO & $\mathbf{2 0 0 6}$ & $\mathbf{2 0 0 7}$ & $\mathbf{2 0 0 8}$ & $\mathbf{2 0 0 9}$ & $\mathbf{2 0 1 0}$ \\
\hline Ventas en soles (S/.) & 376,222 & 403,275 & 693,896 & 851,969 & 913,703 \\
\hline Costo en soles (S/.) & 252,498 & 300,951 & 506,493 & 645,431 & 725,161 \\
\hline Rentabilidad Bruta & $\mathbf{4 9 \%}$ & $\mathbf{3 4 \%}$ & $\mathbf{3 7 \%}$ & $32 \%$ & $26 \%$ \\
\hline
\end{tabular}

Fuente: Elaboración propia.

Por lo expuesto, centraremos nuestro análisis de estudio en los procesos del servicio de tipo cliente.

Existe dos tipos de servicio cliente, el servicio de "evaluación" que normalmente se atiende entre 24 y 48 horas y el servicio de "reparación" el cual se atiende normalmente dentro de las 72 horas siguientes a la solicitud y es el servicio posterior al servicio de evaluación.

Para atender cualquier servicio a un cliente, es necesario abrir una orden de trabajo (OT) en el sistema DWF (Domino Work Flow). En la OT se carga el costo incurrido para atender el trabajo: mano de obra, repuestos y misceláneos.

El costo de la mano de obra se calcula multiplicando la tarifa horaria del personal técnico por las horas trabajadas en la labor asignada, estas horas normalmente ya están calculadas dentro de los estándar Jobs del sistema SIS de Caterpillar. La tarifa horaria de la mano de obra se estima 
mensualmente y es el resultado de dividir todos los costos y gastos (directos e indirectos) sobre la producción horaria mensual.

El costo de los repuestos se estima en base a la política de precios de repuestos el cual se cotiza a través del sistema DBS, el sistema otorga un descuento automático para cada cliente de acuerdo a su volumen de compra.

El costo de los misceláneos está compuesto por: los suministros de taller, trabajos de terceros, gastos de viaje y otros. Los suministros de taller están estimados para fines prácticos en un $5 \%$ del costo de repuestos siendo los principales suministros: film strech, pegamento, silicona, disolventes, guantes, limpia contactos, lijas, EPP, etc. Los trabajos de terceros están constituidos por servicios externos como: soldadura, rectificadora de piezas, laboratorios de bombas de inyección de combustible, servicio de aire acondicionado, pintura, carpintería, etc. Los gastos de viaje del personal técnico están constituidos por el alquiler de la movilidad, combustible, peajes, teléfono, lavandería, alimentación, alojamiento, etc. El concepto "otros" abarca fletes, etc.

Los servicios de reparación tienen una garantía de 06 meses de acuerdo a nuestra "carta de garantías de servicios". En caso de presentarse algún reclamo del cliente por un mal diagnóstico y/o por una mala reparación, se apertura una OT en el sistema DWF la cual se carga a una cuenta interna que es asumida por el área de servicios como parte de sus gastos operativos. A esta cuenta se la conoce con el nombre de REDOS o rehacer trabajo.

Para cumplir con las funciones de atención de servicio cliente, ésta área se soporta en el siguie nte mapa de procesos donde se identifican las tres categorías existentes:

1. Procesos Estratégicos: Proceso de Dirección, Proceso de Comunicación y Proceso de Medición y Control.

2. Procesos Claves: Proceso de Atención al Cliente (Apertura de OT), Proceso de Planificación (Programación de OT), Proceso de Ejecución (Desarrollo de OT) y Proceso de facturación (Cierre de OT).

3. Procesos de Apoyo: Proceso Logístico, Proceso Contable, Proceso de Ventas, Proceso Informático, Proceso de Trámite Documentario, Proceso de Mantenimiento y Proceso de Marketing. 
Para elaborar el análisis requerido se debe describir los procesos claves por ser estos los de mayor impacto en el resultado de la percepción de la calidad del servicio por parte del cliente. En la figura 1 se muestra el mapa de procesos del área de servicios donde se visualizan los tres tipos de proceso del área de servicios.

Figura 1 Mapa de Procesos del Área de Servicios.

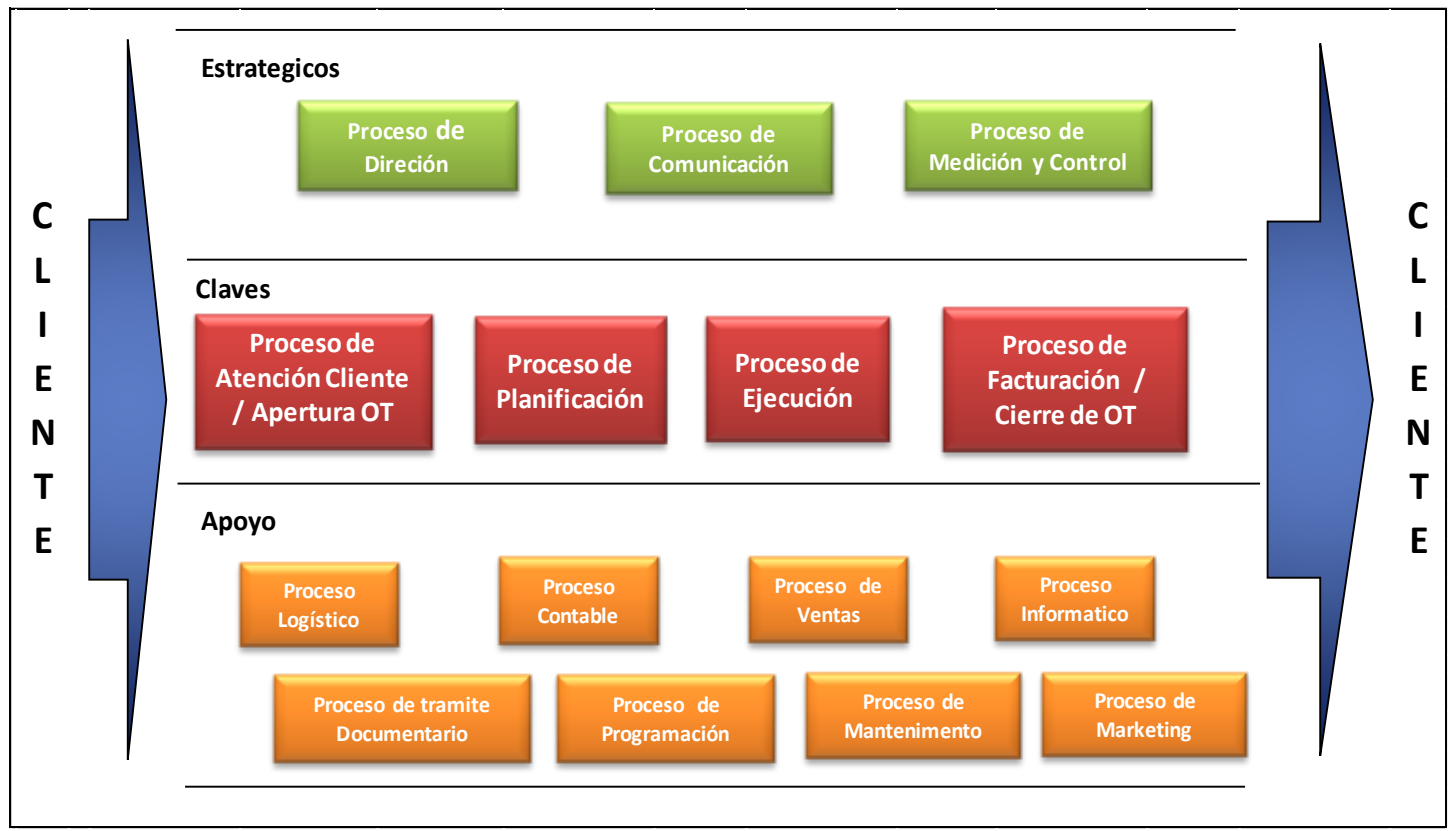

Fuente: Elaboración propia.

Para escoger el o los procesos claves que tienen mayor impacto en la percepción de la calidad del servicio de atención del cliente utilizaremos el estudio de la valoración del cliente realizada por Caterpillar entre los meses de abril y julio del 2011. La OAC (oficina de atención al cliente) a través de la intranet de Ferreyros proporcionó los resultados del programa de encuestas transaccionales de lealtad de Caterpillar realizados a veintidós de nuestros principales clientes. Esta calificación se base en el siguiente puntaje.

Leal $=$ Clientes que dieron puntajes de 9 o 10 a las tres preguntas de lealtad: satisfacción general, recompra de producto, recomendación de producto a otro cliente.

Vulnerable $=$ Clientes que dieron puntajes de 6 o mayor a las tres preguntas de lealtad, pero menos de 9 en al menos una pregunta. 
En Riesgo $=$ Clientes que dieron puntajes menores a 6 en al menos alguna de las preguntas de Lealtad.

Se realizó un comparativo entre la media de los resultados de las encuestas a nivel nacional y la media de la sucursal Lambayeque. Dichos resultados se encuentran plasmados en la tabla 4.

Tabla 4 Comparativo de media de encuestas de lealtad a nivel nacional y media de la sucursal Lambayeque 2011.

\begin{tabular}{|lcc|}
\hline \multirow{2}{*}{ Número de encuestas completadas } & $\mathbf{9 8 0}$ & $\mathbf{2 2}$ \\
\cline { 2 - 3 } & Distribuidor & 040: Lambayeque \\
\hline Categoria de la Pregunta & Media & Media \\
\hline Satisfacción General & 7.5 & 7.6 \\
\hline Recompra & 8.2 & 8.2 \\
\hline Recomendación & 8.1 & 8.7 \\
\hline Facilidad para hacer negocios & 8.2 & 8.5 \\
\hline Disponibilidad y Fiabilidad & 7.3 & 7.4 \\
\hline Respuesta & 6.9 & 6.4 \\
\hline Comuncación & 7.2 & 7.9 \\
\hline Preparación & 8.4 & 8.2 \\
\hline Duración & 7.2 & 8.1 \\
\hline Tangibles/Factura & 8.1 & 7.9 \\
\hline Calidad & 8.1 & 8.2 \\
\hline Puntualidad de la factura & 7.5 & 7.7 \\
\hline Precisión de la factura & 7.9 & 8.1 \\
\hline
\end{tabular}

Fuente: Elaboración personal.

De los veintidós encuestados, 14 de ellos (64\%) manifestaron que el personal técnico llegó de 30 minutos a 1 hora después de la hora programada.

En la encuesta de lealtad procesada se nota que ante la pregunta $\mathrm{n}^{\circ} 6$ sobre "Respuesta": ¿Qué tan satisfecho se encontró $U d$. de que el técnico de servicio llegara a la hora prometida?, se observa claramente que tenemos un problema crítico por resolver ya que es el que tiene menor puntaje en la calificación promedio del cliente de la sucursal Lambayeque. Lo antes indicado pone a los clientes en la calidad de RIESGO respecto a su lealtad con la empresa. En el anexo 1 se muestra el cuestionario de preguntas realizada por Caterpillar. En el anexo 1 se encuentran la estructura de las encuestas y algunos ejemplos de las 22 encuestas realizadas donde se aprecia la respuesta a la pregunta $\mathrm{N}^{\circ} 6$. 
Identificando en el mapa de procesos en que parte de los procesos claves se ubica esta deficiencia de incumplimiento en la hora de llegada al servicio programado tenemos dos procesos claves que son los de "atención al cliente" y "planificación".

Por las razones expuestas, escogeremos los procesos claves de "atención al cliente" y "planificación" de la OT como los procesos a mejorar. A continuación se procederá a detallar como se ha estado desarrollando actualmente el proceso de atención al cliente/apertura/planificación de la OT.

\subsection{Proceso de Atención al Cliente / Apertura / Planificación de OT.}

Propósito: Satisfacer las necesidades del cliente en la recepción oportuna del presupuesto del servicio de evaluación y la fecha y hora estimada de atención del servicio.

Alcance: Este proceso involucra la atención de todas las solicitudes del cliente verbales o por email y/o todas las OTs aperturadas por evaluación de los clientes que tienen sus equipos operando en el departamento de Lambayeque.

Responsables: Jefe de servicios y/o ingeniero de Servicio: verifica los datos del cliente: razón social, código RUC, ubicación e identificación del equipo (número de serie, horómetro). Es responsable de enviar el presupuesto del servicio y la fecha y hora de atención del servicio al cliente. Autoriza el máximo descuento posible de solicitarlo el cliente.

d) Asistente de Servicio: verifica línea de crédito e informa el $N^{\circ}$ de la OT CYOXXXX abierta al cliente.

e) Personal Técnico: recepciona y alista las herramientas de diagnóstico, documentos y suministros de taller.

Descripción del proceso. El proceso se inicia cuando el cliente tiene necesidad de un servicio por fallas en su equipo y se comunica con la empresa. Generalmente lo hace por teléfono o por e-mail apoyado normalmente en las siguientes personas: representante de ventas, comunicador técnico, jefe de servicios, ingeniero de servicios, asistente de servicios y administrador. Se le informa al jefe de servicios o al ingeniero de servicios de la solicitud del cliente y estos luego de comunicarse con el cliente obtienen información de la falla presentada, ubicación y disponibilidad de la 
máquina. Se han presentado casos en que datos como el código del cliente, RUC ó N/S de la máquina no coinciden con los del sistema lo que obliga a realizar una segunda comunicación con el cliente para aclarar esta información.

Luego el jefe de servicio o ingeniero de servicios estiman el presupuesto de servicio agregando al "costo estándar de servicio de evaluación" para maquinaria Caterpillar, los costos horarios del personal técnico por viaje de ida y vuelta a la zona de operación además de otros gastos que se requieran por la ubicación de la máquina (alojamiento y peajes). Por desconocimiento de las zonas de operación, el ingeniero de servicios estima los tiempos de viaje en base a la información del personal técnico, así mismo los tiempos de evaluación varían de un técnico a otro por la experiencia que tienen lo cual hace en algunos casos que varíe el presupuesto de evaluación.

Luego de estimar el presupuesto, informa al cliente verbalmente y/o envía el presupuesto vía email.

En caso de rechazo del presupuesto enviado, el ingeniero de servicios coordina con el jefe de servicios el máximo descuento permitido el mismo que no debe afectar la rentabilidad objetivo del trabajo (35\% de rentabilidad bruta).

De aprobarse el presupuesto por parte del cliente, el jefe de servicio o ingeniero de servicios informa la fecha y hora estimada de atención del servicio al cliente. En paralelo solicita al asistente de servicios la apertura de la OT y asignación de gastos de viaje para el personal técnico e informa al personal técnico la fecha de atención del servicio el cual a la vez solicita las herramientas de diagnóstico al auxiliar de almacén. El asistente de servicios gestiona ante el administrador de la sucursal la orden de pago por gastos de viaje para el personal técnico. Estos gastos deben cubrir: alimentación, movilidad, combustible, alojamiento, teléfono, lavandería, peajes, otros.

También en la asignación de técnicos tenemos que de acuerdo a la experiencia del personal técnico, éste se califica desde los de mayor experiencia nivel SP1 y SP2, hasta los de menor experiencia niveles SP3, SP4 y SP5. El personal del nivel Service Pro SP1 y SP2 especializado en "diagnóstico de fallas", no siempre se encuentran disponibles razón por la cual se asigna el trabajo al personal de nivel Service Pro SP3 y en ausencia de éste se recurre al personal de nivel Service Pro SP4 o SP5. Esto eleva el riesgo de entregar un mal diagnóstico de falla. De tener a todo el personal técnico de la sucursal ocupado dentro de las próximas 72 horas, el ingeniero de servicios informa al jefe de servicios de la sucursal quien a su vez coordina con los jefes de servicio de las sucursales 
más cercanas (Trujillo, Piura, Cajamarca, Chimbote o Tarapoto) y con los jefes de servicio de Lima de los mercados de construcción, pesca, energía y minería, la necesidad de apoyo del personal técnico especializado de acuerdo al mercado que se esté atendiendo. El gasto en que se incurre por pago de pasajes aéreos, alojamiento y transporte debido a la movilización de personal técnico externo de la sucursal no están considerados en el presupuesto inicial.

Luego de esto, el ingeniero de servicios alcanza la OT CY0XXXX al personal técnico e informa la "fecha y hora final" del servicio de evaluación (o reclamo de servicio si fuera el caso) acordada con el cliente y la falla presentada en la máquina. Después el personal técnico consolida la información técnica, alista las herramientas necesarias, computadora personal (lap top) y recibe gastos de viaje del personal de caja (cajero). En algunas ocasiones ha sucedido que el cajero no dispone de efectivo $\mathrm{y} / \mathrm{o}$ del $\mathrm{V}^{\circ} \mathrm{B}^{\circ}$ del administrador para entregar el efectivo de gastos de viaje al personal, así mismo, frecuentemente debido a la presión del cliente por atención inmediata, no se le otorga al técnico el tiempo suficiente para solicitar/buscar/consolidar información técnica valiosa que le ayudará al diagnóstico de la falla.

Finalmente, el técnico entrega al auxiliar de almacén el $\mathrm{N}^{\circ}$ de la OT CYOXXXX y solicita los repuestos, materiales (suministros de taller y EPP) y las herramientas de diagnóstico). El auxiliar de almacén le entrega lo solicitado con los documentos respectivos para la salida de la sucursal: guía de remisión de repuestos y vale de salida de materiales (suministros y EPP, otros). Luego el personal técnico, realiza el check list de la camioneta, alista todo lo recibido y se traslada al campo. En algunas oportunidades se han dado situaciones en que no se ha encontrado la camioneta de servicio disponible y/o con problemas mecánicos que han impedido su uso inmediato.

A continuación se adjunta en la figura 2 el flujograma donde se muestra el diagrama del flujo actual del proceso.

Figura 2 Diagrama de flujo actual. 


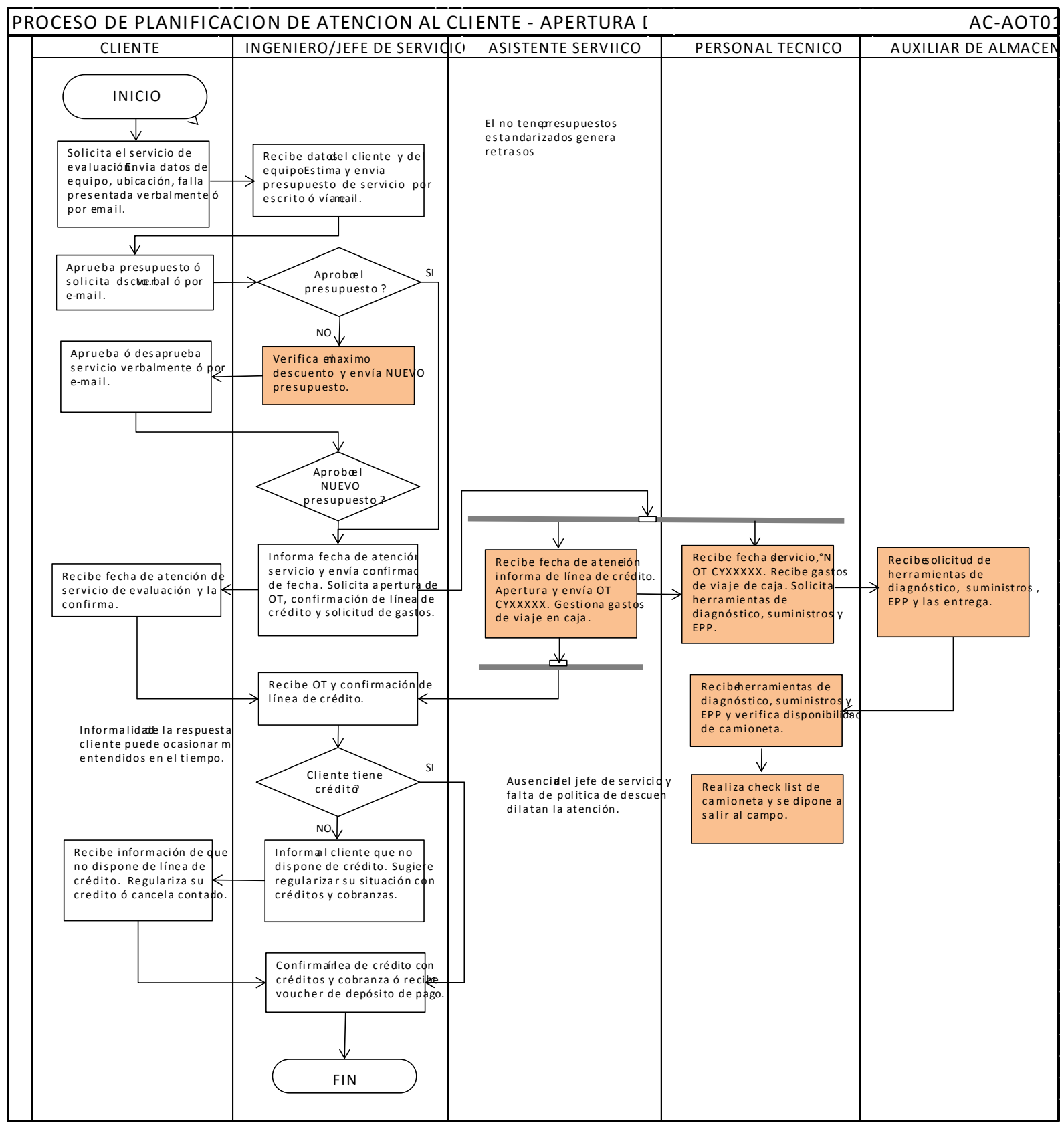

Fuente: Elaboración propia.

\subsection{Análisis del Proceso.}

Procederemos a analizar el proceso actual descrito anteriormente y utilizaremos algunas de las herramientas descritas en el marco teórico que nos permitirá detectar y eliminar las posibles ineficiencias del proceso de atención al cliente y planificación de la OT. Para realizar lo antes indicado se constituyó un equipo de mejora compuesto por los principales actores involucrados en los procesos claves. Las personas convocadas vía e-mail y seleccionadas fueron: Jefe de servicios, 
Ingeniero de servicios, Asistente de servicios, Auxiliar de almacén y el Personal técnico representado por el técnico líder de mayor experiencia.

Se procedió a establecer la documentación preliminar del proceso describiendo lo que se hace, el alcance, la relación que guardan unos con otros e identificando clientes y proveedores tanto internos como externos.

Puesto que no hay una persona a cargo de este proceso y de sus resultados, se asignó al Jefe de Servicios como la persona indicada puesto que tiene la autoridad y responsabilidad necesaria para dirigir la mejora de este proceso y de establecer el alcance del mismo.

\subsection{Problemas actuales y potenciales.}

Para determinar las deficiencias en los procesos a mejorar encontrados en el programa de encuestas transaccionales de satisfacción del cliente (tabla 4), se convocó a una reunión general de todos los miembros del área de servicios y mediante la herramienta lluvia de ideas se les invitó a manifestar los problemas que tenían en el proceso de atención al cliente/planificación de la OT. Previamente se les explicó que solo se deseaba saber los problemas y/o inconvenientes presentados dentro de sus actividades en el proceso mas no las causas con el único objetivo de mejorar el proceso; no obstante lo indicado, le reacción natural de las personas aludidas a los problemas mencionados era justificar los inconvenientes presentados razón por la cual el moderador (jefe de servicios) reiteró en más de una oportunidad que lo que se necesitaba redactar en la pizarra eran solamente los "problemas" presentados para mejorar el proceso y no las "causas".

El resultado de la lluvia de ideas que tuvo lugar en dicha sesión se presenta en la tabla 5. El paso posterior a la lluvia de ideas es asociar dichas ideas por afinidades y/o características similares, de esto se desprende el cuadro siguiente agrupando los problemas de acuerdo a la relación que tienen unos con otros.

Tabla 5 Lluvia de ideas de problemas en el proceso. 


\begin{tabular}{|c|l|}
\hline 1 & Falta apoyo del comunica dor técnico \\
\hline 2 & Información técnica llega tarde \\
\hline 3 & No hay disponibilidad de camionetas \\
\hline 4 & No cumplen los procedimientos \\
\hline 5 & Falta de programación de técnicos \\
\hline 6 & Falta comunicación \\
\hline 7 & Falta lap top \\
\hline 8 & No asumen sus responsabilidades \\
\hline 9 & No hay persona encargada de recoger repuestos \\
\hline 10 & No hay persona encargada de devolver repuestos \\
\hline 11 & Hay demasiadas devoluciones \\
\hline 12 & Falta orden y limpieza \\
\hline 13 & Faltan herramientas \\
\hline 14 & No se planifica el trabajo \\
\hline 15 & No se abren las OT's a tiempo \\
\hline 16 & Si no tengo OT no me entregan materiales \\
\hline 17 & Muchos jefes \\
\hline 18 & No limpian su zona a tiempo \\
\hline 19 & Falta capcitación a técnicos/ingenieros \\
\hline 20 & No cuidan las herramientas \\
\hline 21 & Devuelven repuestos sin movimiento \\
\hline 22 & Falta coordinación entre ventas y servicio \\
\hline 23 & No hacen check list de camionetas \\
\hline 24 & Los clientes se quejan \\
\hline 25 & El área comercial se queja \\
\hline
\end{tabular}

\begin{tabular}{|l|l|}
\hline 26 & Sistemas: CITRIX, DBS, DWF muy lentos \\
\hline 27 & Muchos documentos por firmar \\
\hline 28 & Se pierde tiempo buscando ` $^{\circ}$ \\
\hline 29 & Tiempos muertos por firmar \\
\hline 30 & No hay a probación de presupuestos \\
\hline 31 & Ofrecen al cliente y no cumplen \\
\hline 32 & Falta capacitación en operación \\
\hline 33 & Falta dinero para gastos de viaje \\
\hline 34 & Cliente entrega datos errados \\
\hline 35 & Se necesita otra persona que apruebe créditos \\
\hline 36 & No saben donde están las herramientas \\
\hline 37 & Se han perdido herramientas \\
\hline 38 & No devuelven las herramientas \\
\hline 39 & No responden correos créditos \\
\hline 40 & No responde correos caja \\
\hline 41 & Se olvidan de las cosas \\
\hline 42 & Falta tiempo \\
\hline 43 & Falta comunicación en programación entre jefes \\
\hline 44 & Costos elevados de presupuestos \\
\hline 45 & Mucha presión \\
\hline 46 & No aprueban las ordenes de pago a tiempo \\
\hline 47 & Se programa a técnico estando pendiente el informe \\
\hline 48 & Cliente no tiene crédito. \\
\hline 49 & No hay vale de combustible \\
\hline 50 & Falta progarmación de fines de semana \\
\hline & \\
\hline
\end{tabular}

Fuente: Elaboración propia.

En la figura 3 se puede visualizar los problemas agrupados en cuatro categorías principales: metodología o procesos, recursos, personal y cliente. Esta forma de clasificar la lluvia de ideas tiene por objetivo ordenar los problemas en base a criterios generales. Se puede visualizar que la mayor cantidad de problemas se encuentran en la metodología o procesos.

Siendo necesario evaluar y cuantificar la ocurrencia de los problemas que se han presentado y teniendo en cuenta que no hay registros de los mismos, se procedió a entrevistar a todos los miembros del equipo que forman parte de los procesos claves y se les consultó la frecuencia (cantidad) de veces que se había presentado los problemas en el lapso de un mes. En el presente estudio se adjunta la encuesta realizada en el Anexo 2. Las encuestas realizadas fueron expuestas en una reunión general con el equipo siendo los resultados los que a continuación se indican en la tabla 6.

Figura 3 Afinidades de los problemas del proceso. 


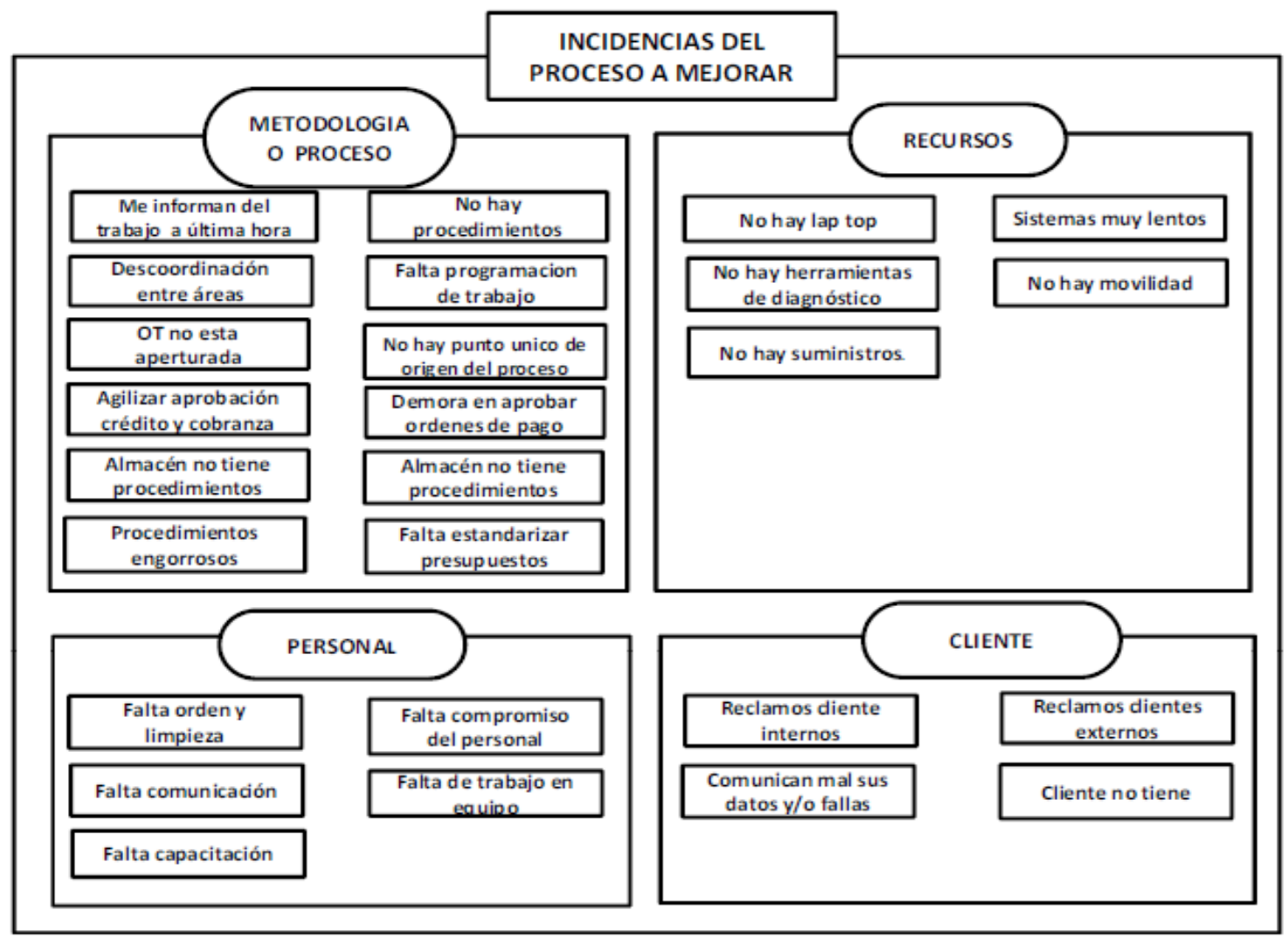

Fuente: Elaboración propia.

Tabla 6 Resultado de encuestas.

\begin{tabular}{|c|l|c|c|c|c|c|c|}
\hline PROB & \multicolumn{1}{|c|}{ CRITERIOS } & $\begin{array}{c}\text { JEFE/ING. } \\
\text { SERVICIOS }\end{array}$ & $\begin{array}{c}\text { ASISTENTE } \\
\text { SERVICIOS }\end{array}$ & $\begin{array}{c}\text { AUXILIAR } \\
\text { ALMACEN }\end{array}$ & $\begin{array}{c}\text { PERSONAL } \\
\text { TECNICO }\end{array}$ & TOTAL & MEDIA \\
\hline A & NO HAY HERRAMIENTAS DE DIAGNOSTICO & 1 & 0 & 6 & 10 & 17 & 4.3 \\
\hline B & NO HAY SUMINISTROS & 0 & 0 & 5 & 9 & 14 & 3.5 \\
\hline C & NO HAY LAP TOP & 6 & 0 & 0 & 28 & 34 & 8.5 \\
\hline D & NO HAY MOVILIDAD & 9 & 0 & 0 & 45 & 54 & 13.5 \\
\hline E & NO RESPONDEN CONSULTA DE ESTADO DE CUENTAS & 5 & 17 & 0 & 0 & 22 & 5.5 \\
\hline F & FALTA COMPROMISO DEL PERSONAL & 2 & 1 & 2 & 3 & 8 & 2.0 \\
\hline G & INFORMAN A ULTIMA HORA DEL TRABAJO & 25 & 31 & 60 & 79 & 195 & 48.8 \\
\hline H & LOS SISTEMAS SON LENTOS & 5 & 7 & 6 & 3 & 21 & 5.3 \\
\hline I & ATENCION LENTA EN ALMACÉN DE SERVICIOS & 58 & 0 & 20 & 105 & 183 & 45.8 \\
\hline J & FALTA ORDEN YLIMPIEZA & 2 & 0 & 2 & 3 & 7 & 1.8 \\
\hline K & NO HAY GASTOS DE VIAJE & 2 & 0 & 5 & 5 & 12 & 3.0 \\
\hline L & OTROS & 0 & 0 & 0 & 3 & 3 & 0.8 \\
\hline
\end{tabular}

Fuente: Elaboración propia.

El siguiente paso consiste en dar prioridad a los problemas más significativos por lo que utilizaremos un diagrama de Pareto para identificar los de mayor impacto previo ordenamiento de mayor a menor frecuencia. En la tabla 7 se puede visualizar el ordenamiento de mayor a menor de los porcentajes de los problemas presentados en el proceso. Esta tabla muestra el sentir del personal 
que indica que $\mathrm{G}$ e I son los problemas más recurrentes. En la figura 4 se muestra el diagrama de Pareto de las frecuencias de problemas del proceso.

Tabla 7 Tabla de porcentajes acumulados de problemas.

\begin{tabular}{|c|c|c|c|}
\hline PROB & PROM & \% & \% ACUM \\
\hline G & 48.8 & $34.2 \%$ & $34.2 \%$ \\
\hline I & 45.8 & $32.1 \%$ & $66.3 \%$ \\
\hline D & 13.5 & $9.5 \%$ & $75.8 \%$ \\
\hline C & 8.5 & $6.0 \%$ & $81.8 \%$ \\
\hline E & 5.5 & $3.9 \%$ & $85.6 \%$ \\
\hline H & 5.3 & $3.7 \%$ & $89.3 \%$ \\
\hline A & 4.3 & $3.0 \%$ & $92.3 \%$ \\
\hline B & 3.5 & $2.5 \%$ & $94.7 \%$ \\
\hline K & 3.0 & $2.1 \%$ & $96.8 \%$ \\
\hline F & 2.0 & $1.4 \%$ & $98.2 \%$ \\
\hline J & 1.8 & $1.2 \%$ & $99.5 \%$ \\
\hline L & 0.8 & $0.5 \%$ & $100.0 \%$ \\
\hline
\end{tabular}

Fuente: Elaboración propia.

Figura 4 Diagrama de Pareto de frecuencias de problemas del proceso.

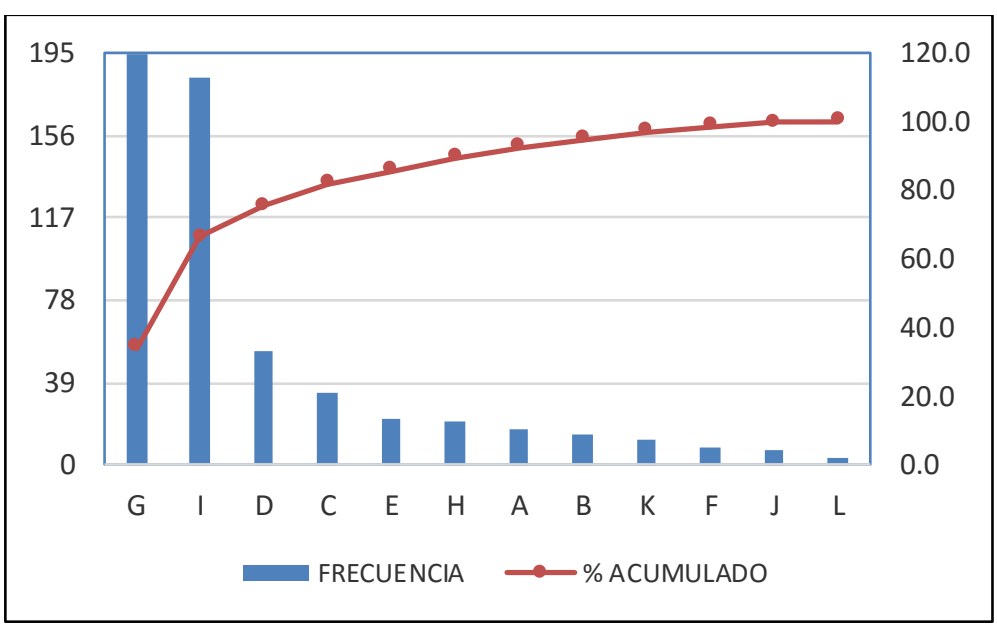

Fuente: Elaboración propia.

De la tabla 7 y la figura 4, se llega a la conclusión de que los problemas que presentan mayor frecuencia o regularidad son los G, I, D y C que acumulan más del $80 \%$ respecto al resto de problemas. Dichos problemas son:

G: Informan a última hora del trabajo.

I: La atención es lenta en almacén de servicios. 


\section{D: No hay movilidad.}

C: No hay lap top.

De los problemas mencionados se puede concluir que la improvisación y falta de planificación de los trabajos obliga a tener que comunicar en último momento al personal de la cadena de procesos sobre un eventual servicio. El área no cuenta con ningún tipo de documentación del flujo del trabajo; el proceso no está estandarizado. Lo antes mencionado tiene implicancia directa en los problemas G e I que son los más importantes. Respecto a los problemas de falta de una lap top C y de la movilidad D, son sencillos de solucionar. El alquiler de una unidad adicional se justifica siempre y cuando en un solo día se presenten en más de una oportunidad dos o tres servicios de atención en paralelo. La falta de movilidad pasa por contactarse con proveedores locales de alquiler de camionetas lo cual está disponible en el mercado. Del mismo modo, la compra de una lap top adicional se puede justificar ante la gerencia de servicios con la pérdida de oportunidades de ventas de servicios, pérdida de horas hombre productivas e insatisfacción del cliente. Este activo no supone mayor inversión y se considerará en el costo de la implementación de las mejoras propuestas.

Entonces, debemos enfocarnos en solucionar los problemas de "comunicación a última hora" G y "atención lenta en almacén de servicios" I.

\subsection{Impacto económico de las ineficiencias del proceso.}

Para estimar las pérdidas de tiempo en que se incurren debido a los contratiempos que se generan en el proceso de atención al cliente y planificación de las OTs, y teniendo en cuenta que los problemas identificados "G" e " $\mathrm{I}$ " repercuten directamente sobre el personal técnico, a fines de junio del 2011, se alcanzó a cada uno de los catorce técnicos un formato donde, previa explicación, debían redactar los tiempos perdidos por las ineficiencias del proceso de atención al cliente y planificación de la OT, es decir, por falta de OT, congestión del almacén, falta de herramientas, falta de movilidad, falta de planificación, etc. El periodo a tomar en cuenta inicia el 01 de marzo y termina el 31 de marzo del 2011. 
Los resultados obtenidos se muestran en la tabla 8. En esta tabla 8 se puede apreciar que en el mes de julio, los 14 técnicos que laboraron en el taller han acumulado 125 horas perdidas debido a las ineficiencias del proceso de atención al cliente y planificación de la OT.

Tabla 8 Tabla de horas pérdidas acumuladas en el mes julio 2011

\begin{tabular}{|c|c|c|c|c|c|}
\hline \multirow{2}{*}{ TECNICO $N^{\circ}$} & \multicolumn{4}{|c|}{ JULIO 2011} & \multirow{2}{*}{ TOTAL } \\
\hline & Sem. 1 & Sem. 2 & Sem. 3 & Sem. 4 & \\
\hline Técnico 1 & 3 & 3 & 2 & 3 & 11 \\
\hline Técnico 2 & 3 & 3 & 2 & 2 & 10 \\
\hline Técnico 3 & 3 & 2 & 2 & 3 & 10 \\
\hline Técnico 4 & 2 & 3 & 3 & 1 & 9 \\
\hline Técnico 5 & 2 & 2 & 3 & 4 & 11 \\
\hline Técnico 6 & 3 & 3 & 2 & 2 & 10 \\
\hline Técnico 7 & Vacaciones & Vacaciones & Vacaciones & Vacaciones & 0 \\
\hline Técnico 8 & 3 & 3 & 2 & 2 & 10 \\
\hline Técnico 9 & 2 & 3 & 2 & 1 & 8 \\
\hline Técnico 10 & 2 & 2 & 3 & 3 & 10 \\
\hline Técnico 11 & 3 & 2 & 1 & 2 & 8 \\
\hline Técnico 12 & 2 & 3 & 2 & 3 & 10 \\
\hline Técnico 13 & 3 & 3 & 1 & 3 & 10 \\
\hline Técnico 14 & 2 & 2 & 2 & 2 & 8 \\
\hline \multicolumn{5}{|c|}{ TOTAL HORAS PERDIDAS EN EL MES } & 125 \\
\hline
\end{tabular}

Fuente: Elaboración propia.

\subsection{Determinación de las raíces de los problemas.}

Los problemas en los cuales centraremos nuestra atención son dos:

-G: Informan a última hora del trabajo.

-I: La atención lenta del almacén de repuestos.

Para determinar las causas raíces de estos problemas que vienen de los datos de la Tabla 2.4, usaremos la herramienta de causa-efecto o diagrama de Ishikawa. 
Figura 5 Diagrama de Ishikawa problema G: Informan a última hora del trabajo.

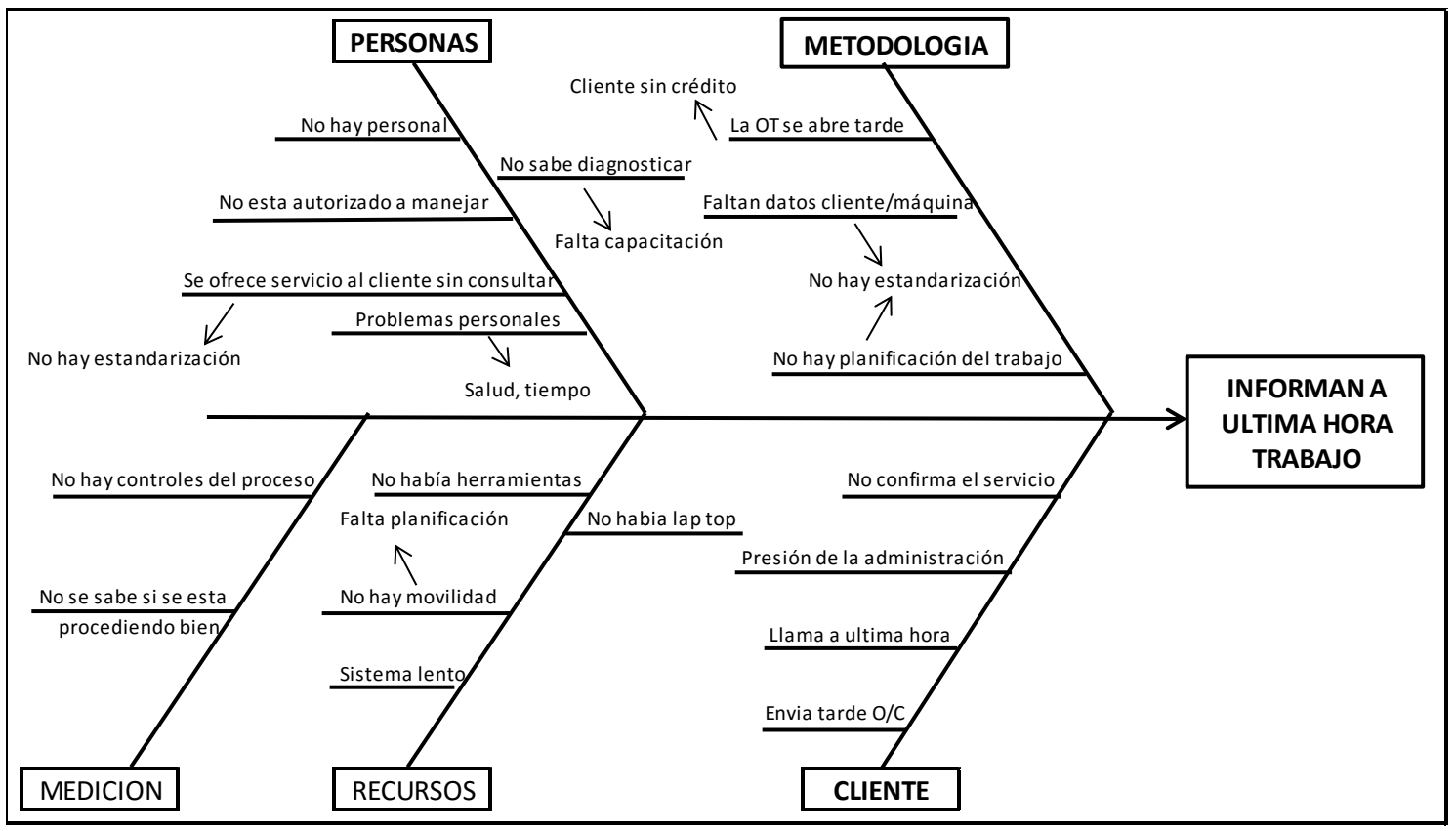

Fuente: Elaboración propia.

Figura 6 Diagrama de Ishikawa problema I: atención lenta de almacén.

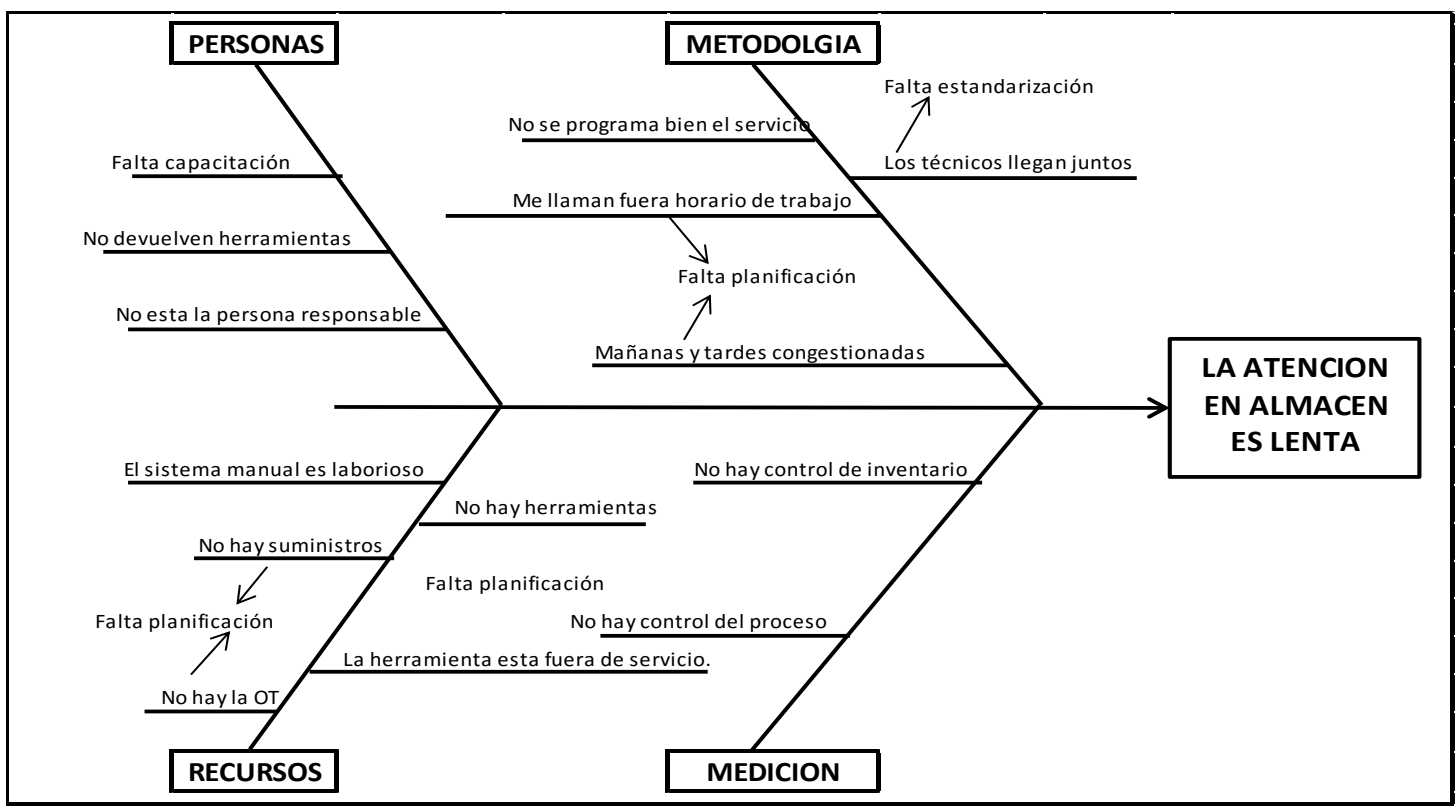

Fuente: Elaboración propia.

Utilizando la información de la Tabla 6, se construyen los Diagramas de Ishikawa (figura 5 y 6 ) donde se evalúan las causas raíces de los problemas más importantes. 
En el caso del problema G, se concluye que la falta de una estandarización del proceso es la causa principal de que se informe a última hora del trabajo. Esto trae consigo ofrecimientos al cliente sin haberse verificado la disponibilidad de los recursos personales y materiales. Por esta razón la mayoría de los actores del proceso perciben que se les solicita el trabajo a última hora, el asistente de servicio no tiene la OT abierta, el auxiliar de almacén verifica la disponibilidad de las herramientas cuando la fecha del servicio ya está ofrecida, el técnico no concluye el servicio en proceso y se le obliga a empezar otro.

En el caso del problema I, se concluye que la falta de estandarización de los procesos en el almacén es la causa de que el personal técnico perciba que la atención es muy lenta. Esto genera pérdidas de tiempo debido a la falta de OT, falta de disponibilidad de herramientas por devolución, pérdida o ausencia (control de inventarios), ausencia del almacenero, atención de más de un técnico a la vez (cola de espera), llamadas a última hora (falta de planificación), falta de capacitación del encargado del almacén, etc.

En conclusión, a partir de los antecedentes de pérdidas de rentabilidad del área de servicios en los dos últimos años y la encuesta de satisfacción del cliente realizada por el área de marketing de la empresa, en el presente capítulo se identificaron los problemas presentes en los procesos claves del área de servicios, se priorizaron los que generan la mayor cantidad de contra tiempos y se identificaron las causas que los producían con la utilización de las herramientas de calidad desarrolladas en el marco teórico. Las causas que se dedujeron fueron la falta de estandarización del proceso tanto en la atención al cliente así como en la planificación de la OT.

En el siguiente capítulo se desarrollará el planteamiento de las mejoras al proceso. 


\section{CAPITULO 3. ELABORACION DE PROPUESTA DE MEJORAAL PROCESO}

El objetivo del presente capítulo es presentar una propuesta de mejora global con el respectivo análisis de costo beneficio como alternativa a los problemas o deficiencias del proceso de atención al cliente y planificación de la OT identificados en el capítulo anterior. Los dos principales problemas identificados fueron: "G" programación de los trabajos a última hora e "I" atención lenta del almacén de servicios, ambos debidos a la falta de estandarización de los procesos.

\subsection{Mejora en los procesos de servicio.}

Para desarrollar las mejoras al proceso se convocó a las personas responsables de las actividades del proceso para que realicen sus recomendaciones teniendo en cuenta su experiencia y conocimiento en el área respectiva. En la figura 7 se muestra el equipo de trabajo representado por los líderes de cada una de las actividades del proceso. Las recomendaciones de estos líderes se plasmaron en una matriz de oportunidades de mejora al proceso.

Figura 7 Organigrama del equipo formado para recomendar las mejoras al proceso.

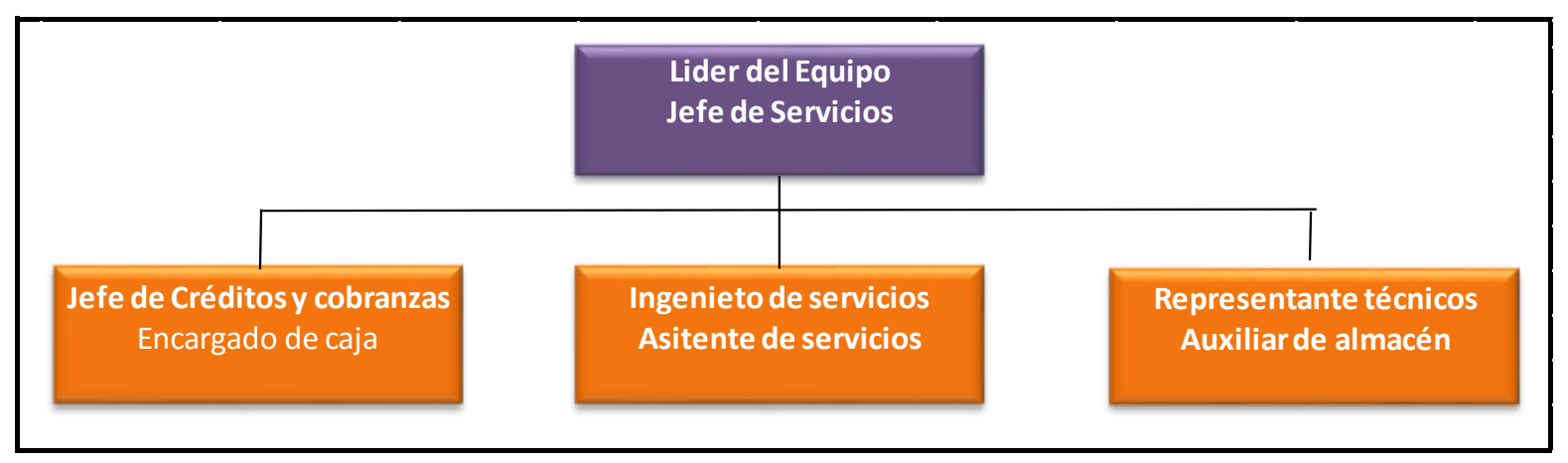

Fuente: Elaboración propia.

La matriz de oportunidades contiene información sobre: 
- $\quad$ Oportunidades de mejora, que son los puntos débiles del proceso.

- Situación actual, es decir la forma como se desarrolla el problema a la cual la oportunidad hace referencia.

- Recomendación para minimizar o eliminar el impacto del problema en el proceso actual.

- Beneficio esperado, que es lo que se lograría de implementarse la recomendación detallada.

En la tabla 9 se plasma la clasificación de la matriz de oportunidades la cual permite clasificar las oportunidades de mejora al proceso respecto a su relación, impacto y esfuerzo.

Tabla 9 Clasificación de matriz de oportunidades.

\begin{tabular}{|c|c|}
\hline CLASIFICACION & TIPOS \\
\hline REL (Relación de la mejora) & $\begin{array}{c}\text { O (Organización), P (Procesos), } \\
\text { S (Sistemas y Tecnología) }\end{array}$ \\
\hline IMP (Impacto en el proceso) & A (Alta), Media (M), Baja (B) \\
\hline EI (Esfuerzo de implementación) & A (Alta), Media (M), Baja (B) \\
\hline
\end{tabular}

Fuente: Elaboración propia.

Teniendo en cuenta la identificación de los procesos a estandarizar, el equipo de trabajo en coordinación con los representantes de todas las áreas involucradas, dieron las recomendaciones del caso las cuales permitieron construir seis matrices de oportunidades de mejoras al proceso.

La tabla 10 nos muestra las deficiencias actuales que se producen al inicio del proceso, las cuales van desde el primer contacto con el cliente el cual se da en diferentes puntos, la emisión del presupuesto, hasta las coordinaciones con el área de créditos y cobranzas y caja. Así mismo se presentan las recomendaciones y las oportunidades de mejora al proceso con el correspondiente beneficio que sería aplicar dichas mejoras como son: iniciar el proceso en un solo punto, estandarizar los presupuestos de servicio y mejorar las comunicaciones entre áreas. Esta matriz tiene por objetivo realizar un eficiente asesoramiento al cliente y estandarizar la emisión de presupuestos. 
La tabla 11 nos muestra las deficiencias actuales que se producen al aperturar la OT por datos incorrectos así como por falta de información oportuna en la línea de créditos y cobranzas los cuales ocasionan retrasos. Aquí también se muestran las recomendaciones, beneficios y las oportunidades de mejora al proceso como son: el ingreso correcto de la información (datos) del cliente y equipo así como tener solicitar oportunamente la forma de pago del cliente. Esta matriz tiene por objetivo identificar correctamente al cliente y equipo en los sistemas de la empresa DBS y asegurar la forma de pago del cliente: crédito o contado.

La tabla 12 nos muestra las debilidades actuales que se presentan debido a que el sistema de apertura de OTs, el DWF, es muy lento (tiempo de respuesta del sistema más de 4 minutos y/o se cuelga el sistema), aunado a esto tenemos las demoras debido a falta de información oportuna de herramientas y por desconocimiento de líneas de crédito para algunos clientes. Esta matriz tiene por objetivo agilizar los tiempos de respuesta del sistema (DWF), facilitar accesos de consulta al módulo de créditos y cobranzas e implementar software de control para activos fijos del almacén de servicios.

La tabla 13 nos muestra las oportunidades de ventas que se pueden perder así como la fidelidad de los clientes que podrían perderse debido a la falta de una política especial del área de créditos y cobranzas para clientes especiales. Esta matriz tiene por objetivo agilizar la apertura de la OT.

La tabla 14 nos muestra que debido a la presión que ejerce el cliente para ser atendido rápidamente ocasiona ofrecimientos que no se cumplirán debido a que no se han previsto todas las condiciones para realizar un trabajo. Aquí se muestran las recomendaciones para no comprometerse inmediatamente a fin de poder asegurar en una comunicación posterior la fecha y hora estimada del trabajo. Dado el tiempo de cuatro horas que se otorga para planificar el servicio, el objetivo de esta matriz es atender solicitud de servicio, gestionar la línea de crédito y/o pago oportunamente y emitir la OT.

La tabla 15 nos muestra que debido a la falta de una política de alquiler de camionetas se presentan retrasos en la atención de los servicios. El objetivo de esta matriz es asegurar la disponibilidad de unidades móviles a fin de asegurar una rápida respuesta a los servicios que se presenten. 
Tabla 10 Matriz de oportunidades de mejora del proceso A.

\begin{tabular}{|c|l|l|l|}
\hline PROCESO: & \multicolumn{3}{|c|}{ ATENCIÓN DE SOLICITUD DEL CLIENTE } \\
\hline OBJETIVO: & $\begin{array}{l}\text { * Asesorar eficientemente al cliente en el servicio solicitado. } \\
\text { * Agilizar la emisión de los presupuestos de servicios. }\end{array}$ & AREA/EQUIPO: & SERVICIOS \\
\cline { 2 - 5 } & & RESPONSABLE: & JEFE DE SERVICIOS \\
\hline
\end{tabular}

\begin{tabular}{|c|c|c|c|c|c|c|}
\hline REL & IMP & E.I & $\begin{array}{c}\text { OPORTUNIDAD DE } \\
\text { MEJORA }\end{array}$ & SITUACIÓN ACTUAL & RECOMENDACIÓN & BENEFICIO ESPERADO \\
\hline$P$ & $\mathrm{M}$ & B & $\begin{array}{l}\text { Iniciar el proceso } \\
\text { en un solo punto. }\end{array}$ & $\begin{array}{l}\text { Actualmente el proceso comienza en dos } \\
\text { puntos. El cliente contacta con el jefe de } \\
\text { servicio o con el ingeniero de servicio } \\
\text { entre los cuales por razones operativas y } \\
\text { de responsabilidades no hay la suficiente } \\
\text { comunicación. }\end{array}$ & $\begin{array}{l}\text { En el corto plazo, el jefe de servicio } \\
\text { deberá informar a la administración y } \\
\text { a la fuerza de ventas que la } \\
\text { programación del servicio se iniciará } \\
\text { formalmente con la comunicación de } \\
\text { La solicitud del cliente al ingeniero de } \\
\text { servicio. }\end{array}$ & $\begin{array}{l}\text { a) Estandarizar el procedimiento actual de } \\
\text { recepción de solicitudes de atención de servicios. } \\
\text { b) Educar al cliente } \\
\text { c) Eliminar actividades que no competen al jefe de } \\
\text { servicios. } \\
\text { d) Realizar una planificación del servicio de forma } \\
\text { mas precisa. }\end{array}$ \\
\hline$P$ & M & B & $\begin{array}{l}\text { Estandarizar los } \\
\text { presupuestos de } \\
\text { servicio de } \\
\text { evaluación. }\end{array}$ & $\begin{array}{l}\text { Se pierde tiempo enviando el } \\
\text { presupuesto al cliente y luego haciendo } \\
\text { un descuento para no perder el servicio. } \\
\text { Este proceso se repite hasta tres veces y } \\
\text { el cliente solicita descuento adicional al } \\
\text { administrador para conseguir su objetivo. }\end{array}$ & $\begin{array}{l}\text { El jefe de servicio debe coordinar con } \\
\text { el administrador la redacción de una } \\
\text { tarifa estandar atractiva de precios de } \\
\text { servicios de evaluación de acuerdo a } \\
\text { la ubicación de la máquina que } \\
\text { asegure la mínima rentabilidad } \\
\text { esperada y comunicada al ingeniero } \\
\text { de servicios. Descuento mayor } \\
\text { debería ser asumido por una unidad } \\
\text { de negocios. }\end{array}$ & $\begin{array}{l}\text { a) Estimulación del consumo de los servicios de } \\
\text { evaluación para descubrir nuevas oportunidades } \\
\text { de ventas de servicio de reparación. } \\
\text { b) Disminución de los tiempos de atención de } \\
\text { servicios invertidos en solicitar autorización de } \\
\text { descuentos. } \\
\text { c) Mejorar la satisfacción del cliente. } \\
\text { d)Incrementar las ventas. }\end{array}$ \\
\hline$P$ & A & B & $\begin{array}{l}\text { Mejorar las } \\
\text { coordinaciones } \\
\text { entre las áreas } \\
\text { de servicios, } \\
\text { créditos y } \\
\text { cobranza y caja }\end{array}$ & $\begin{array}{l}\text { Las descordinaciones entre las áreas de } \\
\text { créditos y cobranzas, caja y servicios se } \\
\text { debe principalmente a la falta de } \\
\text { comunicación adecuada y oportuna. }\end{array}$ & $\begin{array}{l}\text { Se sugiere utilizar el correo (lotus } \\
\text { notes) a fin de integrar en correos } \\
\text { consolidados los requerimientos del } \\
\text { proceso de atención de servicios a las } \\
\text { áreas de créditos y cobranzas, caja, } \\
\text { almacén de servicios y jefatura de } \\
\text { servicios. }\end{array}$ & $\begin{array}{l}\text { a)Dejar registrado los requerimientos del proceso } \\
\text { para el seguimiento respectivo. } \\
\text { b)Agilizar la respuesta de atención de los servicios } \\
\text { de evaluación. } \\
\text { c)Agilizar la entrega de herramientas de } \\
\text { diagnóstico, suministros, EPP y gastos de viaje del } \\
\text { personal técnico. }\end{array}$ \\
\hline
\end{tabular}


Tabla 11 Matriz de oportunidades de mejora del proceso.

\begin{tabular}{|c|c|c|c|c|c|c|}
\hline \multicolumn{2}{|c|}{ PROCESO: } & \multicolumn{5}{|c|}{ ATENCIÓN DE SOLICITUD DEL CLIENTE } \\
\hline \multirow{2}{*}{\multicolumn{2}{|c|}{ OBJETIVO: }} & \multirow{2}{*}{\multicolumn{3}{|c|}{\begin{tabular}{|l|l|} 
* Verificar identificación del equipo y del cliente en el DBS. \\
* Consultar oportunamente la foma de pago: contado o crédito.
\end{tabular}}} & $\begin{array}{c}\text { AREA/EQUIPO: } \\
\end{array}$ & SERVICIOS \\
\hline & & & & & RESPONSABLE: & INGENIERO DE SERVICIOS \\
\hline REL & IMP & E.I & $\begin{array}{c}\text { OPORTUNIDAD DE } \\
\text { MEJORA }\end{array}$ & SITUACION ACTUAL & RECOMENDACIÓN & BENEFICIO ESPERADO \\
\hline & M & B & \begin{tabular}{l|} 
Asegurar la \\
correcta \\
información del \\
cliente y de la \\
máquina.
\end{tabular} & $\begin{array}{l}\text { Se generán atrasos en la apertura de la OT } \\
\text { debido a errores en el RUC del cliente y/o } \\
\text { N/S de la máquina. Así mismo se dan } \\
\text { casos de máquinas que no figuran en el } \\
\text { sistema. }\end{array}$ & $\begin{array}{l}\text { El asistente de servicios deberá enviar } \\
\text { todos los requisitos mínimos para } \\
\text { aperturar la OT y estos deberán ser } \\
\text { verificados en el sistema } \\
\text { inmediatamente por el Ing. de } \\
\text { servicios cuando entre en contacto }\end{array}$ & $\begin{array}{l}\text { a) Estandarizar el procedimiento de repción de } \\
\text { datos del cliente y de la máquina. } \\
\text { b) Evitar pérdidas de tiempo en apertura de OT. } \\
\text { c) Educar al cliente. }\end{array}$ \\
\hline & A & B & $\begin{array}{l}\text { Consultar } \\
\text { oportunamente } \\
\text { la forma de pago } \\
\text { al cliente. }\end{array}$ & $\begin{array}{l}\text { Esta consulta se hace luego de programar } \\
\text { la fecha del servicio y ocasiona retrasos } \\
\text { en la apertura de la OT e insatisfacción } \\
\text { del cliente por información a destiempo } \\
\text { que no cuenta con línea de crédito y } \\
\text { retrasos en las entregas de herramientas, } \\
\text { suministros y EPP. }\end{array}$ & $\begin{array}{l}\text { El ingeniero de servicio debe } \\
\text { consultar la forma de pago en paralelo } \\
\text { con el envío del presupuesto de } \\
\text { servicio e inmediatamente comunicar } \\
\text { al asistente de servicios para que haga } \\
\text { la consulta/gestión con créditos y } \\
\text { cobranzas de la línea de crédito ( } \mathrm{N}^{\circ} \text { de } \\
\text { crédito) en caso el cliente lo solicite ó } \\
\text { solicitar el pago al contado (envío de } \\
\text { voucher). }\end{array}$ & $\begin{array}{l}\text { a) Estandarizar el proceso de autorización de } \\
\text { crédito. } \\
\text { b)Informar al cliente oportunamente problemas } \\
\text { en línea de crédito. } \\
\text { c) Evitar movilizar recursos y pérdidas de tiempo } \\
\text { innecesariamente por clientes que no tienen } \\
\text { crédito. } \\
\text { d)Solicitar el pago al contado para agilizar el } \\
\text { proceso de atención. } \\
\text { e)Educar al cliente. }\end{array}$ \\
\hline
\end{tabular}


Tabla 12 Matriz de oportunidades de mejora del proceso.

\begin{tabular}{|c|c|c|c|c|c|c|}
\hline \multirow{3}{*}{\multicolumn{2}{|c|}{$\begin{array}{l}\text { PROCESO } \\
\text { OBJETIVO: }\end{array}$}} & \multirow{3}{*}{\multicolumn{3}{|c|}{$\begin{array}{l}\text { ATENCIOI } \\
\text { * Agilizar los tiempos de respuesta del sistema (DWF), facilitar } \\
\text { accesos de consulta al modulo de créditos y cobranzas e } \\
\text { implementar software de control para activos fijos del almacén }\end{array}$}} & \multicolumn{2}{|l|}{ DE SOLICITUD DEL CLIENTE } \\
\hline & & & & & AREA/EQUIPO: & INFORMATICA \\
\hline & & & & & RESPONSABLE: & JEFE DE INFORMATICA \\
\hline REL & IMP & E.I & $\begin{array}{c}\text { OPORTUNIDAD } \\
\text { DE MEJORA }\end{array}$ & SITUACIÓN ACTUAL & RECOMENDACIÓN & BENEFICIO ESPERADO \\
\hline $\mathrm{s}$ & A & A & $\begin{array}{l}\text { Mejorar la } \\
\text { velocidad del } \\
\text { sistema DWF. }\end{array}$ & $\begin{array}{l}\text { El sistema usado actualmente es el } \\
\text { DWF (antes era el DBS) el cual es muy } \\
\text { lento (algunos minutos) e incluso en } \\
\text { algunas oportunidades el sistema se } \\
\text { cuelga lo cual obliga a reiniciar el } \\
\text { proceso. }\end{array}$ & $\begin{array}{l}\text { Solictar al departamento de } \\
\text { informática la revisión del software } \\
\text { de este programa ya que es } \\
\text { frustante la lentitud como se emiten } \\
\text { los números de las OT's de } \\
\text { servicios. }\end{array}$ & $\begin{array}{l}\text { a)Mayor celeridad en la emisión de las OTs. } \\
\text { b)Mejorar los tiempos de atención de envío de } \\
\text { los presupuestps de evaluación. } \\
\text { c) Evitar pérdidas de tiempo al personal de } \\
\text { servicio técnico y/o al auxiliar de almacén. }\end{array}$ \\
\hline $\mathrm{s}$ & A & A & $\begin{array}{l}\text { Sistematizar la } \\
\text { información } \\
\text { referida a la } \\
\text { disponibilidad } \\
\text { de recursos del } \\
\text { almacén de } \\
\text { servicios. }\end{array}$ & $\begin{array}{l}\text { Actulamente las consultas sobre } \\
\text { disponibilidad de herramientas de } \\
\text { diagnóstico, suministros y EPP entre el } \\
\text { ingeniero de servicios/jefe de servicios } \\
\text { y el auxiliar de almacén se hacen vía } \\
\text { telefónica. No existe información } \\
\text { integrada en los sistemas de la } \\
\text { empresa para visualizar estos recursos }\end{array}$ & $\begin{array}{l}\text { Crear un módulo que considere la } \\
\text { disponibilidad de los recursos: } \\
\text { herramientas de diagnóstico, } \\
\text { suministros, EPP, otros e integrarlo } \\
\text { a los sistemas existentes DBS, DWF } \\
\text { además de información pertinente } \\
\text { para el área de servicios. }\end{array}$ & $\begin{array}{l}\text { a)Aseguramiento de la disponibilidad de los } \\
\text { recursos. } \\
\text { b)Mayor velocidad de respuesta en la } \\
\text { programación de servicios de evaluación. } \\
\text { c) Evitar pérdidas de tiempo al personal técnico. }\end{array}$ \\
\hline $\mathrm{s}$ & A & $\mathrm{M}$ & $\begin{array}{l}\text { Visualizar el } \\
\text { módulo de } \\
\text { Créditos y } \\
\text { Cobranzas. }\end{array}$ & $\begin{array}{l}\text { Demora en la apertura de la OT por } \\
\text { falta de información de línea de crédito } \\
\text { del cliente por ausencia y/o respuesta } \\
\text { lenta del encargado del área de } \\
\text { Créditos y Cobranza. }\end{array}$ & $\begin{array}{l}\text { Aqui se manejan tres alternativas. } \\
N^{\circ} 1 \text { : Sugerir a la administración } \\
\text { facilitar los accesos en el sistema } \\
\text { para que en casos de ausencia del } \\
\text { responsable, se pueda consultar la } \\
\text { línea de crédito respectiva y } N^{\circ} 2: \\
\text { Asignar a un segundo responsable } \\
\text { de Créditos y Cobranza para } \\
\text { responder. }\end{array}$ & $\begin{array}{l}\text { a)Agilizar los tiempos de respuesta al cliente } \\
\text { respecto a su línea de crédito. } \\
\text { b) Evitar pérdidas de tiempo al personal técnico. } \\
\text { c) No perder oportunidades de venta por falta de } \\
\text { información de línea de crédito. } \\
\text { d)Eliminar la consulta al encargado de créditos } \\
\text { y cobranzas respecto a la línea de crédito del } \\
\text { cliente. }\end{array}$ \\
\hline $\mathrm{s}$ & A & A & \begin{tabular}{l|} 
Control del \\
inventario de \\
herramientas de \\
diagnóstico, \\
suministros y \\
EPP.
\end{tabular} & $\begin{array}{l}\text { El control de ingresos y salidas de } \\
\text { herramientas y materiales se hace } \\
\text { manulamente y no permite visualizar } \\
\text { rápidamente el stock que se tiene en el } \\
\text { almacén de servicios. Así mismo no hay } \\
\text { un registro de las herramientas de } \\
\text { mayor movimiento y de la urgencia de } \\
\text { pedido de alguna de ellas. }\end{array}$ & $\begin{array}{l}\text { Crear un módulo que considere el } \\
\text { ingreso y salida de las herramientas } \\
\text { asi como la cantidad, la frecuencia y } \\
\text { el momento en que se realizan } \\
\text { estos movimientos de tal manera de } \\
\text { evaluar en el tiempo las } \\
\text { estadísticas de los mismos lo que } \\
\text { permitirá tomar decisiones } \\
\text { inmediatas. }\end{array}$ & $\begin{array}{l}\text { a)Agilizar los tiempos de respuesta a los } \\
\text { clientes. } \\
\text { b)Tomar decisones de compra de las } \\
\text { herramientas de mayor demanda } \\
\text { (restricciones). } \\
\text { c)Cuidar el activo de la empresa. } \\
\text { d) Satisfacer las necesidades del cliente. } \\
\text { e)Evitar tiempos muertos de personal técnico } \\
\text { por falta de herramientas. }\end{array}$ \\
\hline
\end{tabular}


Tabla 13 Matriz de oportunidades de mejora del proceso.

\begin{tabular}{|c|c|c|c|c|c|c|}
\hline \multicolumn{2}{|c|}{ PROCESO: } & \multicolumn{5}{|c|}{ ATENCIÓN DE SOLICITUD DEL CLIENTE } \\
\hline \multirow{2}{*}{\multicolumn{2}{|c|}{ OBJETIVO: }} & \multirow{2}{*}{\multicolumn{3}{|c|}{ * Agilizar la apertura de la OT }} & AREA/EQUIPO: & CREDITOS Y COBRANZAS \\
\hline & & & & & RESPONSABLE: & ASISTENTE DE CREDITOS \\
\hline REL & IMP & E.I & $\begin{array}{c}\text { OPORTUNIDAD DE } \\
\text { MEJORA }\end{array}$ & SITUACIÓN ACTUAL & RECOMENDACIÓN & BENEFICIO ESPERADO \\
\hline $\mathrm{P}$ & M & B & $\begin{array}{l}\text { Definir politica } \\
\text { de créditos en } \\
\text { base al tipo de } \\
\text { cliente que se } \\
\text { atiende. }\end{array}$ & $\begin{array}{l}\text { No se otorga créditos a clientes pequeños } \\
\text { por ser los montos de los presupuestos } \\
\text { menores a US } \$ 1,000.00 \text {. Así mismo no se } \\
\text { asumn riesgos pequeños con } \\
\text { Municipalidades que son leales a la marca } \\
\text { y que en algún momento atraviesan } \\
\text { problemas económicos. }\end{array}$ & $\begin{array}{l}\text { Aprobar/asumir el riesgo de otorgar } \\
\text { crédito excepcionalmente a clientes } \\
\text { leales y potenciales por montos } \\
\text { pequeños. }\end{array}$ & $\begin{array}{l}\text { a)Consolidar la relación de socio estratégico del } \\
\text { negocio que se tiene con el cliente. } \\
\text { b)Fidelizar al cliente. } \\
\text { c)Asegurar los ingresos al cliente que le permitan } \\
\text { asumir sus compromsos de pago con nuestra } \\
\text { representada. } \\
\text { d)Evitar pérdida de ventas y nuevas } \\
\text { oportunidades de negocio. }\end{array}$ \\
\hline
\end{tabular}


Tabla 14 Matriz de oportunidades de mejora del proceso.

\begin{tabular}{|c|c|c|c|c|c|c|}
\hline \multicolumn{2}{|c|}{ PROCESO: } & \multicolumn{5}{|c|}{ PLANIFICACIÓN DE LA OT } \\
\hline \multirow{2}{*}{\multicolumn{2}{|c|}{ OBJETIVO: }} & \multirow{2}{*}{\multicolumn{3}{|c|}{$\begin{array}{l}\text { * Atender solicitud de servicio y emisión de presupuesto. } \\
\text { * Gestionar línea de crédito ó pago al contado y emisión de OT. }\end{array}$}} & \multirow{2}{*}{$\begin{array}{r}\text { AREA/EQUIPO: } \\
\text { RESPONSABLE: } \\
\end{array}$} & \multirow{2}{*}{\begin{tabular}{|l|} 
SERVICIOS \\
INGENIERO DE SERVICIOS \\
\end{tabular}} \\
\hline & & & & & & \\
\hline REL & IMP & E.I & $\begin{array}{c}\text { OPORTUNIDAD DE } \\
\text { MEJORA }\end{array}$ & SITUACIÓN ACTUAL & RECOMENDACIÓN & BENEFICIO ESPERADO \\
\hline$P$ & A & $M$ & $\begin{array}{l}\text { Planificar fechay } \\
\text { hora de atención } \\
\text { de servicios. }\end{array}$ & $\begin{array}{l}\text { Se le ofrece al cliente atenderlo en } 24 \\
\text { horas como máximo sin confirmar } \\
\text { disponibilidad de técnicos, herramientas } \\
\text { ni movilidad. Esto osasiona presión sobre } \\
\text { el personal técnico, asistente de servicios } \\
\text { y auxiliar de almacén para que culminen } \\
\text { el trabajo anterior y en algunas } \\
\text { oportunidades se les retira del trabajo en } \\
\text { proceso para atender un nuevo } \\
\text { compromiso asumido. }\end{array}$ & $\begin{array}{l}\text { El ingeniero de servcios debe ofrecer } \\
\text { al cliente en un plazo máximo de } 4 \\
\text { horas informar fecha de atención del } \\
\text { servicio. Para esto solictará al } \\
\text { personal técnico disponible los N/P } \\
\text { de las herramientas de diagnóstico } \\
\text { que necesitará para el servicio } \\
\text { confirmando con el auxiliar de } \\
\text { almacén la disponibilidad de éstas asi } \\
\text { como verificará la disponibilidad de la } \\
\text { movilidad. }\end{array}$ & $\begin{array}{l}\text { a) Estandarizar el proceso de programación de } \\
\text { fecha de atención del servicio. } \\
\text { b) No crear falsas expectativas de atención al } \\
\text { cliente. } \\
\text { c)Cumplir con lo comprometido: mejorar la } \\
\text { satisfacción del cliente. } \\
\text { d)Educar al cliente. } \\
\text { e)Asegurar la culminación de todos los trabajos en } \\
\text { proceso. } \\
\text { f)Evitar accidentes por presión de trabajo. }\end{array}$ \\
\hline
\end{tabular}


Tabla 15 Matriz de oportunidades de mejora del proceso

\begin{tabular}{|c|c|c|c|c|c|c|}
\hline \multirow{3}{*}{\multicolumn{2}{|c|}{$\begin{array}{l}\text { PROCESO: } \\
\text { OBJETIVO: }\end{array}$}} & \multicolumn{5}{|c|}{ PLANIFICACIÓN DE LA OT } \\
\hline & & \multirow{2}{*}{\multicolumn{3}{|c|}{$\begin{array}{l}\text { *Asegurar la disponibilidad de unidades móviles y la p top para } \\
\text { atender las solicitudes de servicios. }\end{array}$}} & \multirow{3}{*}{$\begin{array}{c}\text { AREA/EQUIPO: } \\
\text { RESPONSABLE: } \\
\text { RECOMENDACIÓN }\end{array}$} & \multirow{3}{*}{\begin{tabular}{|r|} 
ADMINISTRACION \\
ADMINISTRADOR \\
BENEFICIO ESPERADO
\end{tabular}} \\
\hline & & & & & & \\
\hline REL & IMP & E.I & $\begin{array}{c}\text { OPORTUNIDAD DE } \\
\text { MEJORA }\end{array}$ & SITUACION ACTUAL & & \\
\hline$P$ & $\mathrm{M}$ & B & $\begin{array}{l}\text { Establecer } \\
\text { política de } \\
\text { contrato de } \\
\text { alquiler de } \\
\text { camionetas para } \\
\text { atender los }\end{array}$ & $\begin{array}{l}\text { Falta de movilidad (camioneta) por picos } \\
\text { de demanada de mano de obra en campo } \\
\text { lo cual ocasiona retrasos en la atención } \\
\text { de servicios.. }\end{array}$ & $\begin{array}{l}\text { Establecer una politica de alquiler de } \\
\text { camionetas que nos permita contratar } \\
\text { las unidades que sean necesarias para } \\
\text { atender eficiente y oportunamente a } \\
\text { nuestros clientes. }\end{array}$ & $\begin{array}{l}\text { a)Satisfacción de las necesidades de atención } \\
\text { oportuna del servicio. } \\
\text { b)Minimizar pérdidas económicas por mano de } \\
\text { obra parada. }\end{array}$ \\
\hline$P$ & $A$ & B & $\begin{array}{l}\text { Adquisión de una } \\
\text { lap top para el } \\
\text { personal técnico. }\end{array}$ & $\begin{array}{l}\text { Debido a la falta de una lap top con los } \\
\text { software de diágnóstico de fallas (ET), se } \\
\text { están presentando retrasos en la } \\
\text { oportuna atención a los clientes. }\end{array}$ & $\begin{array}{l}\text { Solicitar la compra inmediata de una } \\
\text { lap top. }\end{array}$ & $\begin{array}{l}\text { a)Satisfacción de las necesidades de atención } \\
\text { oportuna del servicio. } \\
\text { b)Minimizar pérdidas económicas por mano de } \\
\text { obra parada. }\end{array}$ \\
\hline
\end{tabular}

Fuente: Elaboración propia. 
Luego de la generación de la matriz de oportunidades se procedió a desarrollar el flujograma correspondiente con su respectiva ficha de proceso. Ambos documentos se emiten como parte de la estandarización del proceso. Así mismo esta documentación servirá de consulta tanto al personal actual como al personal que se incorpore más adelante. Es importante señalar que en el caso de la ficha de proceso se han reunido los dos procesos: atención al cliente y planificación de la OT en uno solo toda vez que están estrechamente relacionados. En el caso del flujograma de procesos, estos se han desarrollado independientemente para que puedan ser mejor comprendidos.

En los flujograma de proceso atención al "cliente/apertura OT (figura 8) y flujograma de planificación de la OT (figura 9), se puede apreciar que existen algunas actividades del proceso que se encuentran resaltadas de color gris donde se hace referencia a las actividades consideradas críticas y que en algunos casos pueden ocasionar contratiemp os si no se sigue con el flujo del proceso desarrollado. Por otra parte en todos los flujogra mas se observa que el Ing. de servicios es el protagonista del proceso al recaer sobre su persona la mayor carga de trabajo y la mayor cantidad de la toma de decisiones. También se evidencia que es el único contacto con el cliente lo cual facilita y ordena la comunicación.

Respecto al flujograma "proceso de atención al cliente/apertura de OT" (figura 8) se tienen las siguientes actividades críticas:

- Recepción de solicitud de atención de servicio y envío de presupuesto. En esta actividad el cliente debido a su necesidad de atención, presionará al ingeniero de servicios para ser atendido "inmediatamente".

- Aprobación/desaprobación del presupuesto. En esta actividad y debido a la informalidad de muchos clientes como son en su mayoría los agricultores, se requiere de "educar" al cliente en formalizar sus requerimientos y aprobaciones a los presupuestos emitidos.

- Información de atención dentro de las próximas 72 horas. En esta actividad se tiene normalmente la predisposición a ofrecer al cliente a atenderlo sin tener la seguridad de que se cuenta con todos los recursos. 
Así mismo, se observa que tanto el asistente de servicios como el responsable del área de créditos y cobranzas tienen una participación mínima.

Respecto al flujograma "proceso de planificación/programación de OT" (figura 9) se tienen las siguientes actividades críticas:

- Planificación de la fecha de atención del servicio de evaluación. Para esta actividad el Ing. de servicios se debe mantener una buena comunicación con el auxiliar de almacén y el personal técnico.

- Gestión/confirmación de fecha de disponibilidad de herramientas. Esta actividad sugiere mucha proactividad del auxiliar de almacén ya que deberá coordinar con otras sucursales a nivel nacional en caso no haya disponibilidad en su almacén de las herramientas necesarias, informándose de fechas de despacho y llegada de las mismas.

- Programar personal idóneo y disponibilidad de camioneta. Esto supone realizar una buena gestión de los recursos humanos (personal técnico) asignando eficientemente y de acuerdo a su experiencia a cada técnico para el trabajo correcto.

En este flujograma se observa la participación mínima tanto del auxiliar del almacén como del personal técnico. Así mismo, el cliente participa solamente para recibir la fecha de programación del servicio.

Recepción de solicitud de atención de servicio y envío de presupuesto. En esta actividad el cliente debido a su necesidad de atención, presionará al ingeniero de servicios para ser atendido "inmediatamente".

Figura 8 Flujograma propuesto proceso atención al cliente/apertura OT. 


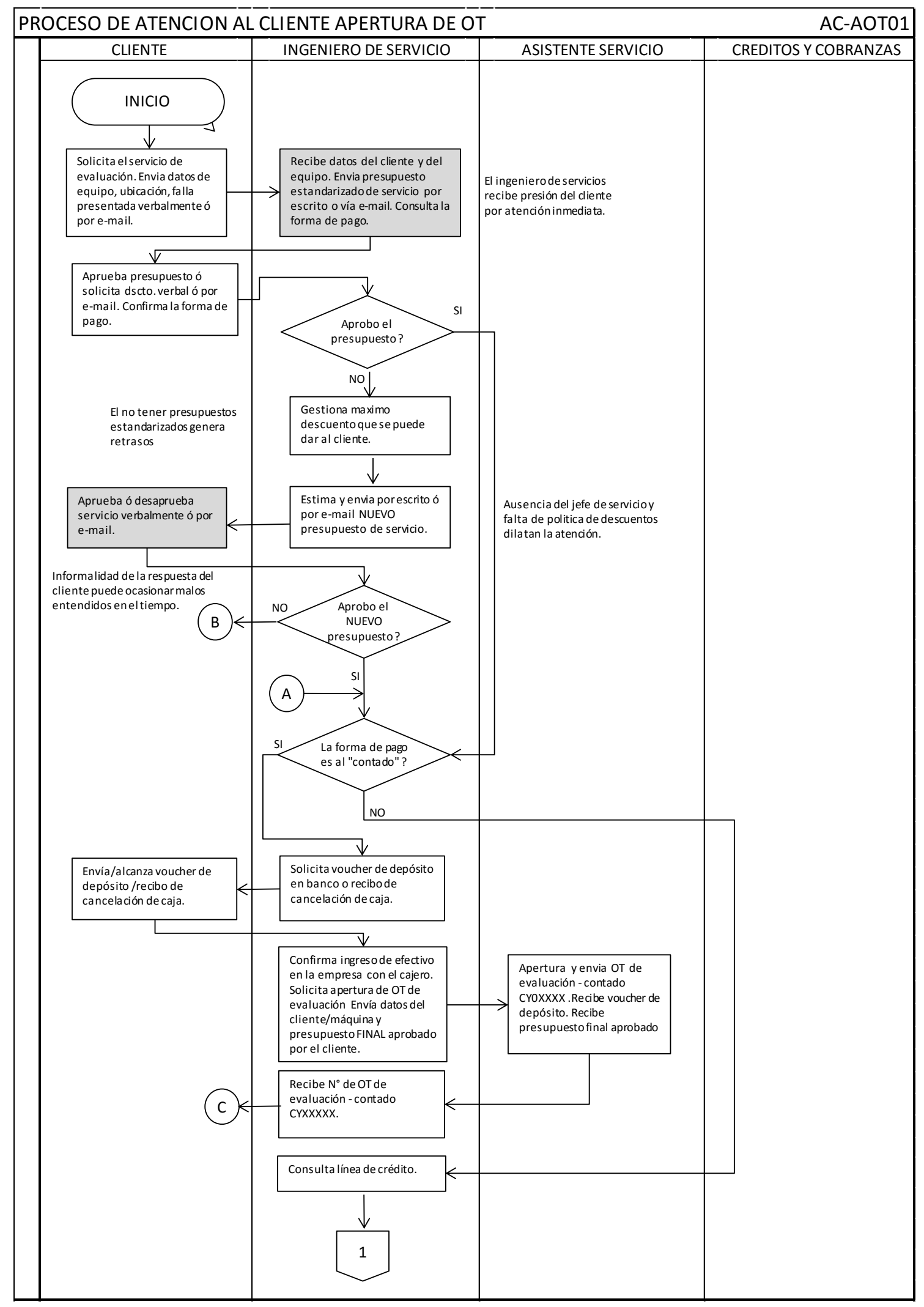




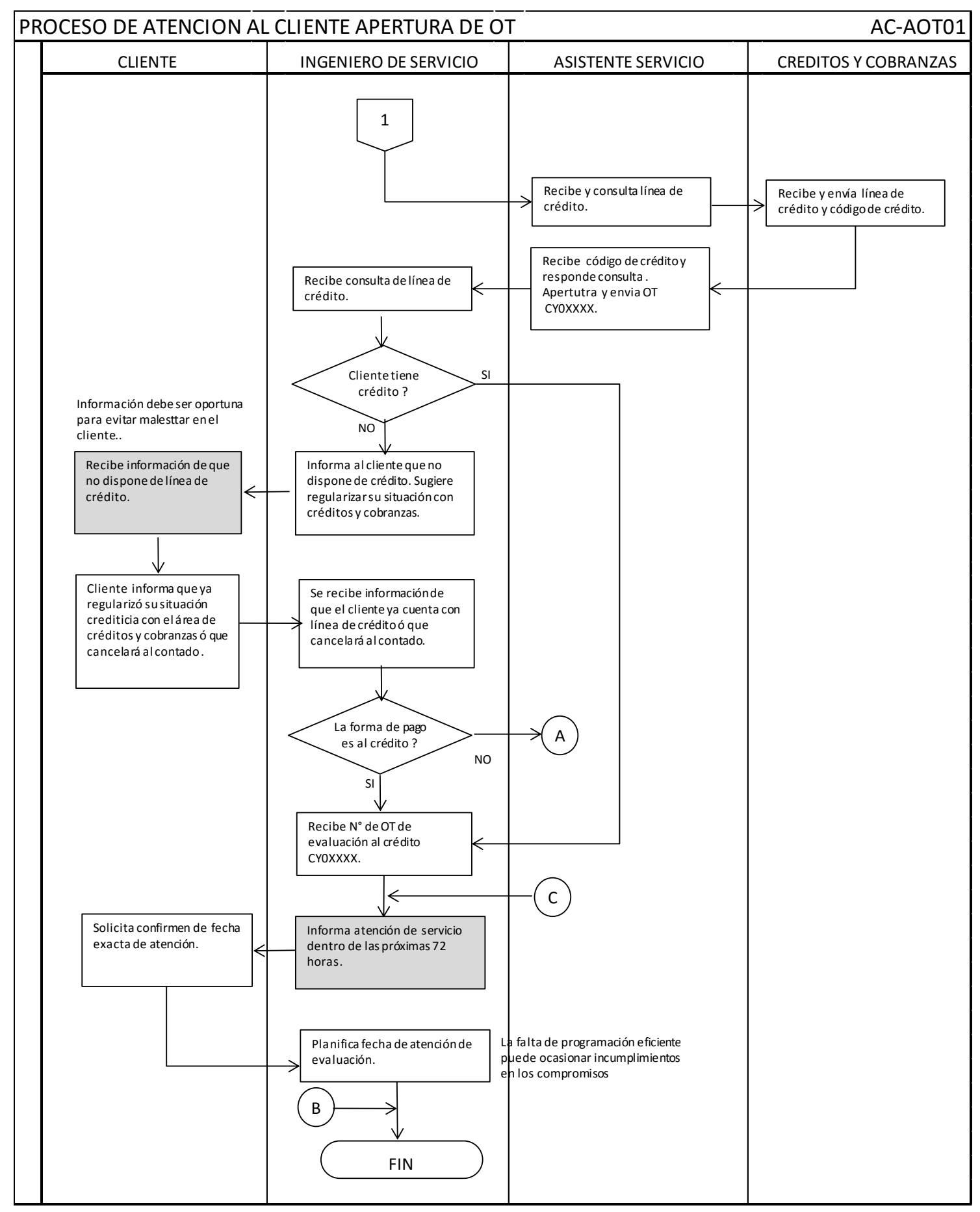

Fuente: Elaboración propia. 
Figura 9 Flujograma propuesto del proceso planificación de la OT.

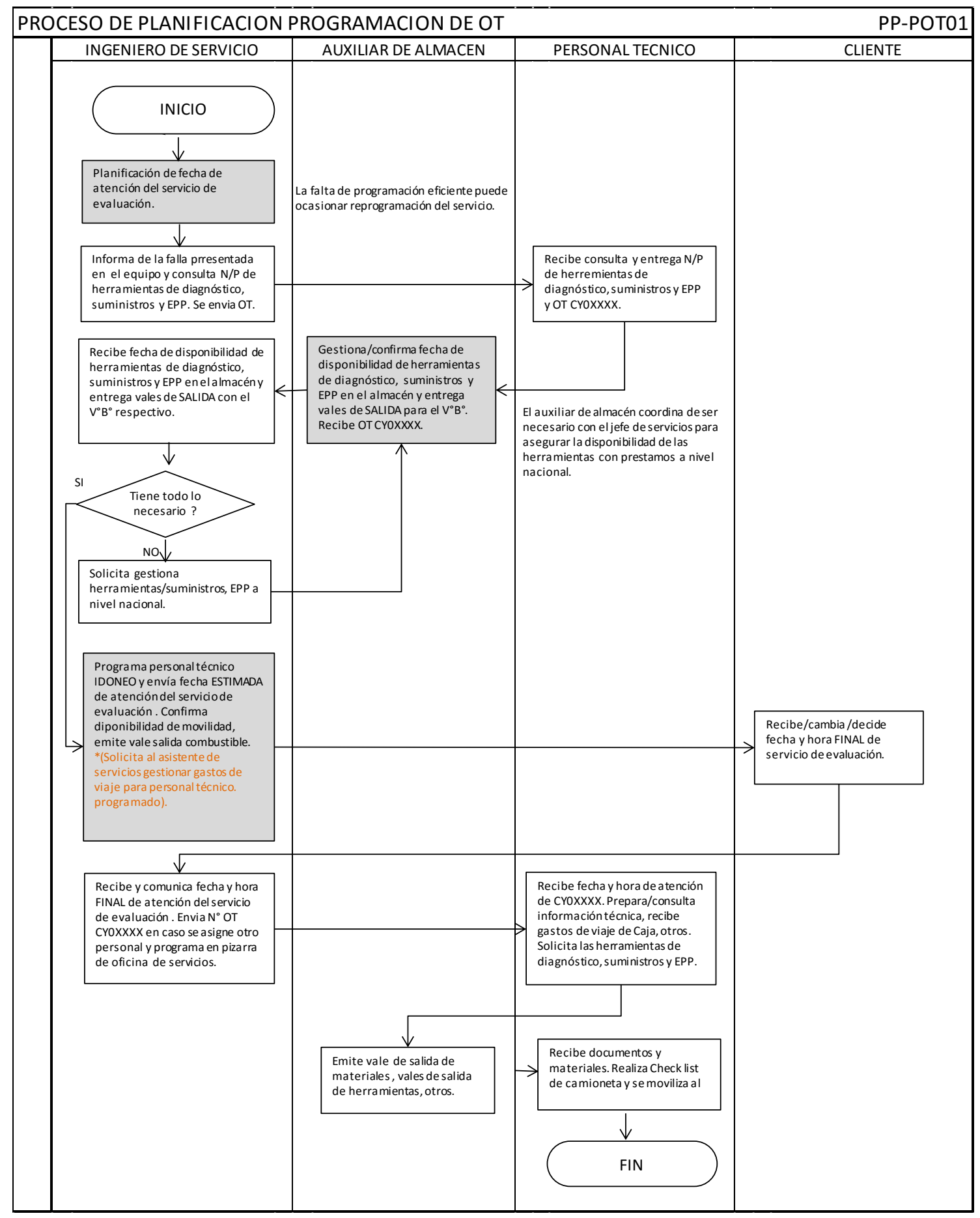

Fuente: Elaboración propia. 
En la ficha de proceso (tabla 16), se muestran los proveedores, sus ingresos o contribuciones al proceso, las principales actividades que desarrollan cada uno de ellos, el producto que deben entregar al proceso y finalmente el receptor de dichos entregables. Respecto a los indicadores propuestos al final de esta ficha, los indicadores deberán ser consolidados por el Asistente de Servicios y presentados mensualmente. El cálculo de los indicadores así como los formatos para recepción de ésta información figuran en el anexo 3 y 4 respectivamente. Los indicadores 4 y 5 se pueden extraer del sistema DBS.

Tabla 16 Ficha de Proceso de atención al cliente y planificación de la OT.

\begin{tabular}{|c|c|c|c|c|c|}
\hline & erreyros $\mathrm{B}$ & \multicolumn{3}{|c|}{$\begin{array}{l}\text { FCHA DE PROCESO: } \\
\text { ATENCION/PLANIFICACION DE OT DE SERVICIO DE EVALUACION }\end{array}$} & PROCESO: ATPL-02 \\
\hline 1.- & PROCESO: & \multicolumn{4}{|c|}{ Apertura y planificación de OT por servicio de evaluación de maquinaria. } \\
\hline 2.- & OBJETIVO: & \multicolumn{4}{|c|}{ Atender la solicitudes de servicio de un cliente. } \\
\hline 3.- & \begin{tabular}{|l} 
PERSONAL \\
INVOLUCRADO
\end{tabular} & \multicolumn{4}{|c|}{ Jefe de servicios, Ingeniero de Servicios, Asistente de Servicios, Auxiliar de Almacén y Personal Técnico. } \\
\hline $\mathbf{N}^{\circ}$ & PROVEEDOR & INPUT & PRINCIPALES ACTIVIDADES & PRODUCTO & CLIENTE \\
\hline A & $\begin{array}{l}\text { Jefe } y / 0 \text { Ingeniero } \\
\text { de Servicios }\end{array}$ & $\begin{array}{l}\text { Solicitud cliente (verbal, escrita, } \\
\text { e-mail). } \\
\text { Datos cliente: RUC, razón socia } \\
\text { código, teléfono, etc. } \\
\text { Datos máquina: modelo, N/S, } \\
\text { ubicación, falla presentada. } \\
\text { Información DBS. }\end{array}$ & $\begin{array}{l}\text { Estimar presupuesto de } \\
\text { servicio. } \\
\text { Gestionar descuento en el } \\
\text { presupuesto. } \\
\text { Consultar N/P herramientas } \\
\text { de diagnóstico. } \\
\text { Programar personal técnico }\end{array}$ & $\begin{array}{l}\text { * Presupuesto de servicio } \\
\text { * Programación de la fecha y } \\
\text { hora del servicio. }\end{array}$ & Cliente \\
\hline B & $\begin{array}{l}\text { Asistente de } \\
\text { Servicios }\end{array}$ & $\begin{array}{l}\text { Consulta de línea de crédito } \\
\text { Solicitud de apertura de OT al } \\
\text { contado ó al crédito }\end{array}$ & $\begin{array}{l}\text { Consultar con créditos y } \\
\text { Cobranzas línea de crédito } \\
\text { del cliente. }\end{array}$ & $\begin{array}{l}\text { * Monto de Línea de crédito } \\
\text { * OT CYXXXXX de contado ó } \\
\text { crédito. }\end{array}$ & Ingeniero de Servicios \\
\hline C & Auxiliar de Almacén & $\begin{array}{l}\text { Consulta de disponibilidad de } \\
\text { herramientas de diagnóstico, } \\
\text { suministros y EPP }\end{array}$ & $\begin{array}{l}\text { Gestionar e informar de la } \\
\text { disponibilidad herramientas, } \\
\text { suministros y EPP. } \\
\text { Gestionar } V^{\circ} \mathrm{B}^{\circ} \text { para salida } \\
\text { materiales y combustible. }\end{array}$ & $\begin{array}{l}\text { * Fecha, hora de disponibilidad } \\
\text { de herramientas, suministros } \\
\text { y EPP } \\
\text { * Vales de salida de materiales } \\
\text { y herramientas. }\end{array}$ & Personal Técnico \\
\hline D & Personal Técnico & $\begin{array}{l}\text { Consulta de N/P de herramienta } \\
\text { Fecha y hora del servicio } \\
\text { Herramientas de diagnóstico, } \\
\text { suministros y EPP }\end{array}$ & $\begin{array}{l}\text { Trasladar las herramientas } \\
\text { suministros y EPP a la } \\
\text { movilidad } \\
\text { Inspección de la movilidad. } \\
\text { camioneta. }\end{array}$ & $\begin{array}{l}\text { * Alistar herramientas para } \\
\text { salir al campo } \\
\text { ^ Check list de camioneta. }\end{array}$ & Cliente \\
\hline \multicolumn{4}{|c|}{ INDICADORES METRICOS ACTUALES } & \multirow{2}{*}{\multicolumn{2}{|c|}{$\begin{array}{l}\text { SISTEMAS UTILIZADOS: } \\
\text { ^ DBS, DWF, Módulo de créditos. }\end{array}$}} \\
\hline No ex & kisten. & & & & \\
\hline \multicolumn{6}{|c|}{ INDICADORES METRICAS PROPUESTAS: } \\
\hline & \multicolumn{5}{|c|}{$\begin{array}{l}\text { El sistema debería crear reportes mensuales con información sobre: } \\
\text { 1. Porcentaje de quejas del cliente. } \\
\text { 2. Porcentaje de quejas por falta de herramientas. } \\
\text { 3. Porcentaje de quejas por falta de OT. } \\
\text { 4. Porcentaje de solicitudes de Ots atendidas. } \\
\text { 5. Tiempos de espera para aperturar Ots. }\end{array}$} \\
\hline
\end{tabular}

Fuente: Elaboración propia. 


\subsection{Análisis de decisiones operativas.}

Para evitar las "subjetividades" en el proceso de toma de decisiones, se ha confeccionado una matriz de decisiones a manera de guía para la resolución de esos casos donde exista alguna duda respecto a la identificación de la persona que tiene la autoridad de decidir de manera rápida y oportuna con el objetivo de asegurar la continuidad del proceso. Esto permitirá asegurar el cumplimiento de las responsabilidades y funciones que cada participante tiene en el proceso a la vez que asegura el cumplimiento de sus responsabilidades.

\subsubsection{Aplicación del enfoque RAPID.}

Como parte de la estandarización del proceso, se aplicará la herramienta RAPID (Rogers \& Blenko, 2005: 35-44) donde se confrontan las actividades principales del proceso con los puestos o personas que toman decisiones acerca de dichas actividades. La elaboración de esta matriz (tabla 17) contó con el apoyo del equipo de trabajo del área de servicios y de las personas directamente involucradas en el proceso. La oportunidad es propicia para indicar que no se desarrolló ningún manual de funciones debido a que éste ya existe y que todo el personal involucrado en este proceso tiene claro cuáles son estas funciones, no obstante, se reconoció que cada miembro cumplía con sus funciones pero de forma independiente y no con un mismo objetivo en mente.

Como una medida preventiva en caso de ausencia del personal "clave" que toma las decisiones y/o aprobaciones, se nombró al administrador como su reemplazo. 
Tabla 17 Matriz de análisis de decisiones operativas actual.

\begin{tabular}{|c|c|c|c|c|c|c|c|}
\hline ACTIVIDAD & 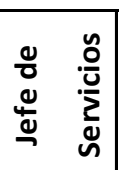 & 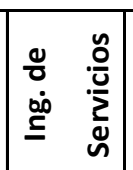 & 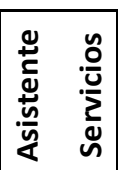 & 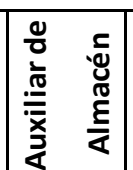 & 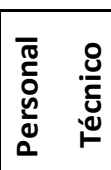 & $\frac{\circ}{\frac{0}{0}}$ & 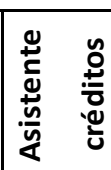 \\
\hline \multicolumn{8}{|l|}{ PROCESO: ATENCION DE CLIENTES } \\
\hline * Contactar al cliente & $\mathrm{R}, \mathrm{I}$ & $E, D$ & $R, I$ & & & & $\mathrm{R}, \mathrm{I}$ \\
\hline${ }^{*}$ Emitir presupuesto & $R, A$ & $E, D$ & & & & & \\
\hline * Otorgar descuento al presupuesto & $A$ & $E$ & & & & & \\
\hline * Otorgar línea de crédito & & & $\mathrm{E}$ & & & & A \\
\hline *Confirmar depósito & & & $E$ & & & 1 & \\
\hline *Aperturar OT & $R, I$ & $R, I$ & $E$ & & & & \\
\hline \multicolumn{8}{|l|}{ PROCESO: PLANIFICACION DE OT } \\
\hline * Programar fecha/hora del servicio & $\mathrm{R}$ & $E, I . D$ & & 1 & 1 & & \\
\hline${ }^{*}$ Requerir herramientas, suministros, etc. & & & & $R, E, I, D$ & $\mathrm{I}, \mathrm{R}$ & & \\
\hline *Atender herramientas, suministros, $\mathrm{G} / \mathrm{R}$ & & & & $R, E, I$ & $\mathrm{I}, \mathrm{R}$ & & \\
\hline *Alquilar movilidad & A & $R, E, I, D$ & & & & & \\
\hline
\end{tabular}

R: Recomendar

A: Aprobar

E: Ejecutar

I: Informar

D: Decidir

Fuente: Elaboración propia.

\subsubsection{Observaciones de la aplicación del enfoque en el proceso.}

Las siguientes observaciones refuerzan las funciones y facultades que tiene cada integrante y/o área en los procesos de atención de cliente y planificación de la OT los mismos que se mencionan a continuación:

- Solo el ingeniero de servicios en representación del área de servicios puede señalar la fecha y hora de la atención de una solicitud de servicio. Esto en virtud de que normalmente el área comercial "ofrece" atención inmediata al cliente sin haber coordinado con el área de servicios creando en muchos casos falsas expectativas. Esto permitirá que el jefe de servicio dedique más tiempo a otras labores propias de sus funciones. 
- Solo el jefe de servicios bajo su responsabilidad y por el cargo de confianza que ocupa y en representación de la empresa puede otorgar los máximos descuentos en un servicio de evaluación. Esta facultad se delega en su persona por su conocimiento y experiencia en el puesto.

- Solo el jefe de servicios bajo su responsabilidad y por el cargo de confianza que ocupa y en representación de la empresa puede otorgar los máximos descuentos en un servicio de evaluación. Esta facultad se delega en su persona por su conocimiento y experiencia en el puesto.

- Solo el área de créditos y cobranzas autoriza los créditos para los clientes. Debido a la falta de un procedimiento, no de una norma de créditos, y con el objetivo de alcanzar el presupuesto de ventas, el área de servicios arriesga el capital de la empresa confiando en que los clientes del sector gobierno durante el proceso de atención de un servicio regularizaran su situación crediticia o que cancelarán al final del servicio. Con la estandarización del proceso, se asegura que todas las atenciones estén debidamente acreditadas.

- De aplicarse las mejoras propuestas, el asistente de servicios podrá aperturar OT’s al crédito para montos menores a US \$1,000.00 debido a que tendrá acceso al módulo de créditos pudiendo evaluar su situación económica rápidamente.

- De aplicarse la mejora propuesta al proceso, solo se cursarán entre áreas las "comunicaciones oficiales" que se desarrollarán para asegurar el flujo continuo del proceso y de acuerdo a los estándares establecidos.

\subsection{Priorización de mejoras sugeridas.}

De la matriz de oportunidades de mejora sugeridas, se desarrolló el gráfico de impacto Vs esfuerzo de implementación (figura 10) como guía para priorizar las oportunidades siendo el orden de priorización el siguiente: 
- Alto impacto, alto esfuerzo de implementación. Dentro de estas propuestas de mejora están las propuestas $\mathrm{N}^{\circ} 4,8$ y 9 que corresponden a ser desarrolladas por el área de informática. Para esto es necesario que la administración de la sucursal determine en coordinación con el área de informática la decisión de realizar estas mejoras con recursos propios o encargarlos a terceros.

- Alto impacto, medio esfuerzo de implementación. Dentro de estas propuestas de mejora están las propuestas $\mathrm{N}^{\circ} 3 \mathrm{y} \mathrm{N}^{\circ} 10$. La propuesta $\mathrm{N}^{\circ} 3$ corresponde a una gestión especial que debe realizar el administrador de la sucursal para solicitar a informática brindar los accesos, al asistente de servicios, al módulo de créditos. Adicionalmente requiere de la autorización del Gerente de Sucursales ya que esta solicitud no es usual. La propuesta $\mathrm{N}^{\circ} 10$ forma parte del proceso de estandarización que ya ha sido desarrollado.

- Alto impacto, bajo esfuerzo de implementación. Dentro de estas propuestas de mejora tenemos dos propuestas. $\mathrm{La} \mathrm{N}^{\circ} 12$ respecto a la mejora de las comunicaciones que debe ser desarrollada en coordinación con las áreas involucradas en el proceso. La $\mathrm{N}^{\circ} 7$ que es consultar oportunamente la forma de pago del cliente por el servicio de evaluación el mismo que ya está desarrollada en la estandarización del proceso de atención al cliente. $\mathrm{La} \mathrm{N}^{\circ} 13$ requiere proponer a la gerencia la compra de una lap top.

- Medio impacto, bajo esfuerzo de implementación. Estas propuestas de mejora pueden agruparse en dos: las de elaboración/aprobación/difusión de políticas de crédito para clientes menores $\left(\mathrm{N}^{\circ} 5\right)$ y alquiler de unidades $\left(\mathrm{N}^{\circ} 11\right)$ y las de propuestas de mejora que forman parte de la estandarización de los procesos como son las propuestas $\mathrm{N}^{\circ} 1,2$ у 6.

Figura 10 Gráfico impacto Vs esfuerzo de implementación de mejoras. 


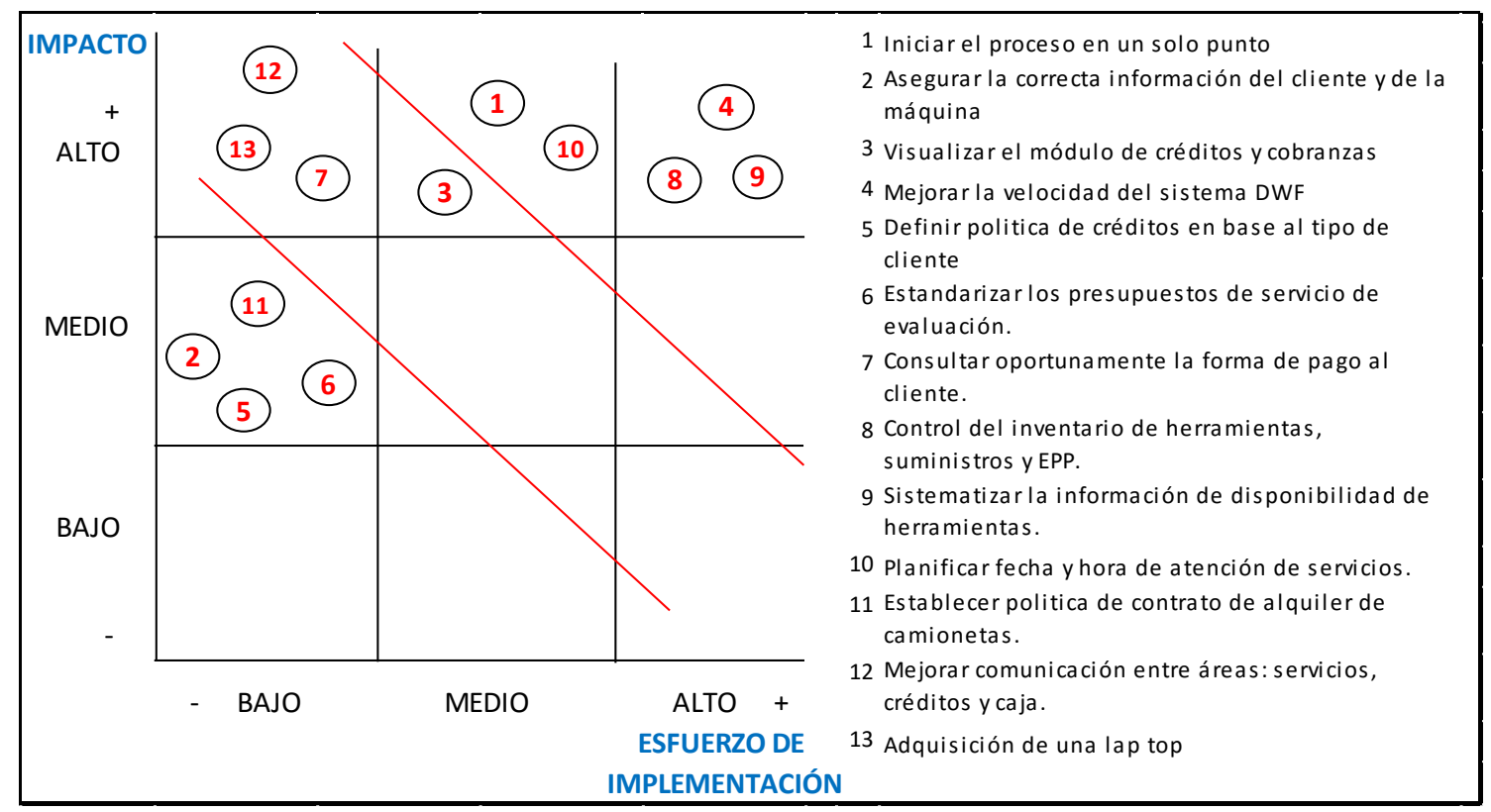

Fuente: Elaboración propia.

\subsection{Plan de implementación}

Para desarrollar el plan de implementación de las mejoras propuestas, se identificaron las actividades necesarias para llegar al resultado esperado: mejorar los procesos de atención al cliente y planificación de la OT de servicio.

De acuerdo a la figura 10 se puede observar que, para el presente caso, todas las propuestas de mejoras se pueden realizar sin inconvenientes excepto las propuestas de mejoras de alto impacto y alto esfuerzo de implementación las cuales corresponden a ser desarrolladas por el área de informática. Para esto es necesario que la administración de la sucursal determine en coordinación con el área de informática de Lima la decisión de realizar estas mejoras con recursos propios o tercerizar el servicio. Por otra parte, no se pudo obtener el costo de estas mejoras por tratarse de información confidencial.

Se procedió a desarrollar el calendario de actividades procurando balancear la máxima rapidez de la implementación sin descuidar las funciones y actividades de las personas 
responsables de la ejecución. El plan de implementación de las mejoras se ha plasmado en cuadros de tiempo el mismo que se puede dividir en cuatro etapas que serían las etapas de:

- Alto impacto y alto esfuerzo de implementación (tabla 18). Esta primera etapa es la más extensa de todas las etapas y se desarrollaría en siete semanas y contempla principalmente la comunicación por parte del jefe de servicios de las mejoras propuestas del área de servicio a las jefaturas de la sucursal involucradas en el proceso, hasta las gestiones necesarias con el área de informática para implementar las mejoras propuestas. Se evidencia el rol protagónico que tendrá el administrador en esta primera etapa quién deberá gestionar con la principal de Lima las mejoras de los sistemas de soporte del área de servicios.

- Alto impacto y medio esfuerzo de implementación (tabla 19). En esta etapa que duraría dos semanas se gestionará el acceso y capacitación del asistente de servicios por parte del asistente de créditos y cobranzas. Así mismo se iniciará la difusión del proceso "atención al cliente" a todo el personal involucrado. Esta gran demanda de personal técnico implicará una gestión especial del jefe de servicios con otras sucursales para no quedarse sin personal técnico disponible en caso sea necesario.

- Alto impacto y bajo esfuerzo de implementación (tabla 20). Esta tercera etapa tendrá una duración aproximada de cuatro semanas y contempla la aprobación, difusión y estandarización del proceso de "planificación de atención al cliente"

- Medio impacto y bajo esfuerzo de implementación (tabla 21). Esta etapa que duraría cinco semanas contempla elaborar, aprobar y difundir la política de alquiler de camionetas, elaborar, estandarizar y emitir los presupuestos de evaluación de servicios y elaborar y difundir la política de créditos para clientes menores. 
Tabla 18 Implementación de mejoras de alto impacto y alto esfuerzo.

\begin{tabular}{|c|c|c|c|c|c|c|c|c|c|c|c|c|c|c|c|c|}
\hline \multicolumn{5}{|c|}{ MEJORAS DE ALTO IMPACTO Y ALTO ESFUERZO DE IMPLEMENTACION } & \multicolumn{12}{|c|}{ Semanas } \\
\hline Actividad & Responsable & $\mathrm{HH}$ & \multicolumn{2}{|l|}{ Detalle de HH } & 1 & 2 & 3 & 4 & 5 & 6 & 7 & 8 & 9 & 10 & 11 & 12 \\
\hline \multirow{3}{*}{$\begin{array}{l}\text { Informar/exponer/coordinar sobre plan de mejora de } \\
\text { los procesos de servicios }\end{array}$} & \multirow{3}{*}{ Jefe de Servicios } & \multirow{3}{*}{12} & Jefe de Servicios & 4 & & & & & & & & & & & & \\
\hline & & & Administrador & 4 & & & & & & & & & & & & \\
\hline & & & $\begin{array}{l}\text { Asistente de Créditos y } \\
\text { Cobranzas }\end{array}$ & 4 & & & & & & & & & & & & \\
\hline $\begin{array}{l}\text { Gestionar/solicitar la mejora de la velocidad del } \\
\text { sistema DWF }\end{array}$ & Administrador & 8 & Administrador & 8 & & & & & & & & & & & & \\
\hline Repotenciar/agilizar el sistema DWF de servicios & Informatica & $* *$ & Informatica (Lima) & $* *$ & & & & & & & & & & & & \\
\hline $\begin{array}{l}\text { Gestión de instalación del sistema para visualización } \\
\text { de herramientas del almacén (software). }\end{array}$ & Administrador & 8 & Administrador & 8 & & & & & & & & & & & & \\
\hline $\begin{array}{l}\text { Instalación del sistema para visualización de } \\
\text { herramientas del almacén (software). }\end{array}$ & Informatica & 8 & Informatica & 8 & & & & & & & & & & & & \\
\hline \multirow{3}{*}{$\begin{array}{l}\text { Capacitación del uso de sistema para visualización de } \\
\text { herramientas del almacén. }\end{array}$} & \multirow{3}{*}{$\begin{array}{l}\text { Auxiliar de } \\
\text { almacén (Lima) }\end{array}$} & \multirow{3}{*}{48} & $\begin{array}{l}\text { Auxiliar de almacén } \\
\text { (Lima) }\end{array}$ & 16 & & & & & & & & & & & & \\
\hline & & & \begin{tabular}{|l|}
$\begin{array}{l}\text { Auxiliar de almacén } \\
\text { (Suc. Lambayeque) }\end{array}$ \\
\end{tabular} & 16 & & & & & & & & & & & & \\
\hline & & & Ingeniero de Servicios & 16 & & & & & & & & & & & & \\
\hline $\begin{array}{l}\text { Gestión de programación de capacitación en gestión } \\
\text { de control de inventarios del almacén de } \\
\text { herramientas. }\end{array}$ & Administrador & 4 & Administrador & 4 & & & & & & & & & & & & \\
\hline \multirow{2}{*}{$\begin{array}{l}\text { Capacitación en gestión de control del inventario de } \\
\text { herramientas del almacén }\end{array}$} & \multirow{2}{*}{$\begin{array}{l}\text { Auxiliar de } \\
\text { almacén (Lima) }\end{array}$} & \multirow{2}{*}{64} & $\begin{array}{l}\text { Auxiliar de almacén } \\
\text { (Lima) }\end{array}$ & 32 & & & & & & & & & & & & \\
\hline & & & $\begin{array}{l}\text { Auxiliar de almacén } \\
\text { (Suc. Lambayeque) }\end{array}$ & 32 & & & & & & & & & & & & \\
\hline
\end{tabular}


Tabla 19 Implementación de mejoras de alto impacto y medio esfuerzo.

\begin{tabular}{|c|c|c|c|c|c|c|c|c|c|c|c|c|c|c|c|c|}
\hline \multicolumn{5}{|c|}{ MEJORAS DE ALTO IMPACTO Y MEDIO ESFUERZO DE IMPLEMENTACION } & \multicolumn{12}{|c|}{ Semanas } \\
\hline Actividad & Responsable & $\mathrm{HH}$ & \multicolumn{2}{|l|}{ Detalle de $\mathrm{HH}$} & 1 & 2 & 3 & 4 & 5 & 6 & 7 & 8 & 9 & 10 & 1. & 12 \\
\hline $\begin{array}{l}\text { Gestionar acceso al módulo de evaluación de créditos } \\
\text { y cobranzas para el ásistente de servicios }\end{array}$ & Administrador & 4 & Administrador & 4 & & & & & & & & & & & & \\
\hline Instalar módulo de evaluación de créditos y cobranzas & Informatica & 8 & Informatica (Lima) & 8 & & & & & & & & & & & & \\
\hline \multirow{2}{*}{$\begin{array}{l}\text { Capacitación en módulo de evaluación de créditos y } \\
\text { cobranzas }\end{array}$} & \multirow{2}{*}{$\begin{array}{l}\text { Asistente de } \\
\text { Crédito y } \\
\text { Cobranzas }\end{array}$} & \multirow[b]{2}{*}{16} & Asistente de Servicios & 8 & & & & & & & & & & & & \\
\hline & & & $\begin{array}{l}\text { Asistente de Créditos y } \\
\text { Cobranza }\end{array}$ & 8 & & & & & & & & & & & & \\
\hline Aprobar nuevo procedimiento: "Atención al cliente" & Administrador & 1 & Administrador & 1 & & & & & & & & & & & & \\
\hline \multirow{6}{*}{ Difundir nuevo proceso: "Atención al Cliente" } & \multirow{6}{*}{ Jefe de Servicios } & \multirow{6}{*}{66} & Jefe de Servicios & 3 & & & & & & & & & & & & \\
\hline & & & Administrador & 3 & & & & & & & & & & & & \\
\hline & & & Ingeniero de Servicios & 3 & & & & & & & & & & & & \\
\hline & & & $\begin{array}{l}\text { Asistente de Créditos y } \\
\text { Cobranzas }\end{array}$ & 3 & & & & & & & & & & & & \\
\hline & & & Asistente de Ventas & 3 & & & & & & & & & & & & \\
\hline & & & Personal técnico & 42 & & & & & & & & & & & & \\
\hline
\end{tabular}


Tabla 20 Implementación de mejoras de alto impacto y bajo esfuerzo

\begin{tabular}{|c|c|c|c|c|c|c|c|c|c|c|c|c|c|c|c|c|}
\hline \multicolumn{5}{|c|}{ MEJORAS DE ALTO IMPACTO Y BAJO ESFUERZO DE IMPLEMENTACION } & \multicolumn{12}{|c|}{ Semanas } \\
\hline Actividad & Responsable & HH & \multicolumn{2}{|l|}{\begin{tabular}{|l|} 
Detalle de HH \\
\end{tabular}} & 1 & 2 & 3 & 4 & 5 & 6 & 7 & 8 & 9 & 10 & 11 & 12 \\
\hline $\begin{array}{l}\text { Aprobar nuevo proceso "Planificación de atención al } \\
\text { cliente". }\end{array}$ & Administrador & 1 & Administrador & 1 & & & & & & & & & & & & \\
\hline Aprobar solicitud de compra de una lap top & Administrador & 1 & Administrador & 1 & & & & & & & & & & & & \\
\hline \multirow{7}{*}{$\begin{array}{l}\text { Difundir nuevo proceso: "Planificación de atención al } \\
\text { clienteT" }\end{array}$} & \multirow{7}{*}{ Jefe de Servicios } & \multirow{7}{*}{60} & Jefe de Servicios & 3 & & & & & & & & & & & & \\
\hline & & & Administrador & 3 & & & & & & & & & & & & \\
\hline & & & Ingeniero de Servicios & 3 & & & & & & & & & & & & \\
\hline & & & Asistente de Servicios & 3 & & & & & & & & & & & & \\
\hline & & & Auxiliar de almacén & 3 & & & & & & & & & & & & \\
\hline & & & \begin{tabular}{|l|} 
Personal técnico \\
\end{tabular} & 42 & & & & & & & & & & & & \\
\hline & & & Cajero & 3 & & & & & & & & & & & & \\
\hline \multirow{7}{*}{$\begin{array}{l}\text { Elaborar y estandarizar las comunicaciones entre las } \\
\text { áreas de Servicios, Crédito y Cobranzas y Caja por e- } \\
\text { mail. }\end{array}$} & \multirow{7}{*}{ Jefe de Servicios } & \multirow{7}{*}{22} & Jefe de Servicios & 10 & & & & & & & & & & & & \\
\hline & & & $\begin{array}{l}\text { Asistente de créditos y } \\
\text { cobranzas }\end{array}$ & 2 & & & & & & & & & & & & \\
\hline & & & Asistente de Ventas & 2 & & & & & & & & & & & & \\
\hline & & & Asistente de servicios & 2 & & & & & & & & & & & & \\
\hline & & & Ingeniero de Servicios & 2 & & & & & & & & & & & & \\
\hline & & & Auxiliar de almacén & 2 & & & & & & & & & & & & \\
\hline & & & Cajero & 2 & & & & & & & & & & & & \\
\hline \multirow{9}{*}{$\begin{array}{l}\text { Difundir las "comunicaciones estandarizadas" entre } \\
\text { las áreas }\end{array}$} & \multirow{9}{*}{ Jefe de Servicios } & \multirow{9}{*}{8} & Jefe de Servicios & 1 & & & & & & & & & & & & \\
\hline & & & Administrador & 1 & & & & & & & & & & & & \\
\hline & & & Asistente de créditos y & 1 & & & & & & & & & & & & \\
\hline & & & 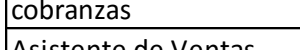 & & & & & & & & & & & & & \\
\hline & & & Asistente de Ventas & 1 & & & & & & & & & & & & \\
\hline & & & Asistente de servicios & 1 & & & & & & & & & & & & \\
\hline & & & Ingeniero de Servicios & 1 & & & & & & & & & & & & \\
\hline & & & Auxiliar de almacén & 1 & & & & & & & & & & & & \\
\hline & & & Cajero & 1 & & & & & & & & & & & & \\
\hline
\end{tabular}


Tabla 21 Implementación de mejoras de medio impacto y bajo esfuerzo.

\begin{tabular}{|c|c|c|c|c|c|c|c|c|c|c|c|c|c|c|c|c|}
\hline \multicolumn{5}{|c|}{ MEJORAS DE MEDIO IMPACTO Y BAJO ESFUERZO DE IMPLEMENTACION } & \multicolumn{12}{|c|}{ Semanas } \\
\hline Actividad & Responsable & HH & \multicolumn{2}{|l|}{ Detalle de HH } & 1 & 2 & 3 & 4 & 5 & 6 & 7 & 8 & 9 & 10 & 11 & 12 \\
\hline $\begin{array}{l}\text { Elaborar la política de alquiler de unidades para } \\
\text { servicios de Sucursales }\end{array}$ & Administrador & 20 & Asistente de Ventas & 16 & & & & & & & & & & & & \\
\hline \multirow{3}{*}{$\begin{array}{l}\text { Difundir la politica de alquiler de unidades para } \\
\text { servicios }\end{array}$} & \multirow{3}{*}{$\begin{array}{l}\text { Asistente de } \\
\text { Ventas }\end{array}$} & \multirow{3}{*}{10} & Administrador & 2 & & & & & & & & & & & & \\
\hline & & & Jefe de Servicios & 2 & & & & & & & & & & & & \\
\hline & & & Asistente de Ventas & 2 & & & & & & & & & & & & \\
\hline $\begin{array}{l}\text { Elaborar/estandarizar/emitir los "presupuestos } \\
\text { estandarizados de evaluación de servicios" }\end{array}$ & Jefe de Servicios & 8 & Jefe de Servicios & 8 & & & & & & & & & & & & \\
\hline $\begin{array}{l}\text { Aprobar los "presupuestos estandarizados de } \\
\text { evaluación de servicios". }\end{array}$ & Administrador & 1 & Administrador & 1 & & & & & & & & & & & & \\
\hline \multirow{2}{*}{$\begin{array}{l}\text { Difundir los "presupuestos estandarizados de } \\
\text { evaluación de servicios" }\end{array}$} & \multirow[b]{2}{*}{ Jefe de Servicios } & \multirow[b]{2}{*}{6} & Jefe de Servicios & 2 & & & & & & & & & & & & \\
\hline & & & \begin{tabular}{|l|} 
Ingeniero de Servicios \\
\end{tabular} & 2 & & & & & & & & & & & & \\
\hline $\begin{array}{l}\text { Aprobación de la politica de créditos para clientes } \\
\text { menores }\end{array}$ & \begin{tabular}{|l|} 
Gerente de \\
Servicios \\
Financieros al \\
cliente
\end{tabular} & 4 & $\begin{array}{l}\text { Gerente de Servicios } \\
\text { Financieros al cliente }\end{array}$ & 4 & & & & & & & & & & & & \\
\hline \multirow{5}{*}{$\begin{array}{l}\text { Difusión de la politica de créditos para clientes } \\
\text { menores }\end{array}$} & \multirow{5}{*}{$\begin{array}{l}\text { Asistente de } \\
\text { Créditos y } \\
\text { cobranzass }\end{array}$} & \multirow{5}{*}{10} & $\begin{array}{l}\text { Asistente de Créditos y } \\
\text { Cobranza }\end{array}$ & 2 & & & & & & & & & & & & \\
\hline & & & Administrador & 2 & & & & & & & & & & & & \\
\hline & & & Jefe de Servicios & 2 & & & & & & & & & & & & \\
\hline & & & Ingeniero de Servicios & 2 & & & & & & & & & & & & \\
\hline & & & \begin{tabular}{|l|} 
Asistente de Servicios \\
\end{tabular} & 2 & & & & & & & & & & & & \\
\hline
\end{tabular}

Fuente: Elaboración propia. 
A fin de conseguir una implementación rápida de las mejoras propuestas, algunas actividades del plan de implementación se han sobrepuesto cuidando que los responsables y personal que participa no tengan que asistir al mismo tiempo a dos actividades a la vez.

Para velar por el cumplimiento del calendario de actividades y del desarrollo de las mejoras propuestas, se propuso establecer una organización encargada de su ejecución. Por esta razón se designó un líder del proyecto con la suficiente capacidad, autoridad y experiencia para gestionar la implantación de las mejoras propuestas recayendo esta designación en el Jefe de Servicios de la Sucursal Lambayeque.

En la figura 11 se muestra el equipo de trabajo que implementará las mejoras propuestas liderado por el jefe de servicios.

Figura 11 Organigrama de equipo para implementación de mejoras.

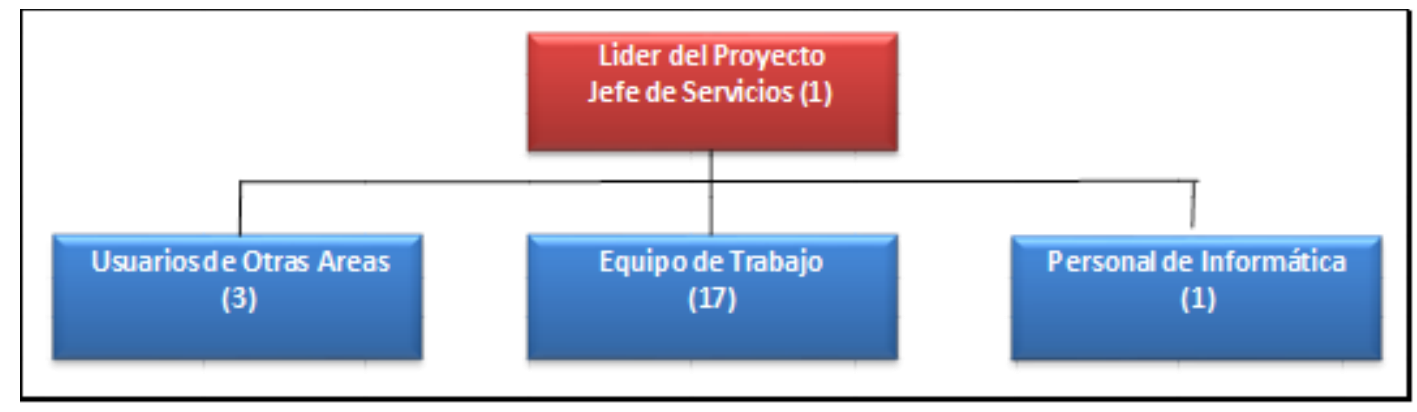

Fuente: Elaboración propia.

- El líder del proyecto: designa, coordina, gestiona con todos los miembros del equipo y encargados de otras área, las funciones, actividades y responsabilidades que cada 
miembro debe ejecutar, así mismo coordina con el área de informática Lima la ejecución de las mejoras propuestas en los sistemas informáticos de la sucursal.

- Equipo de trabajo: conformada por el personal administrativo de servicios que tienen como responsabilidad ser gestores del cambio asumiendo las responsabilidades asignadas por cada actividad dedicando el tiempo planeado para la ejecución y el personal técnico quienes alcanzan la data necesaria para elaborar los indicadores de gestión de los procesos a mejorar.

- Usuarios de otras áreas: son los encargados de las áreas de créditos y cobranza y del área de caja los mismos que contribuyen con la gestión de cambio del proceso y que pueden ser convocados por el líder cuando sea necesario.

- Personal de Informática: presentan una dedicación definida y comprometida a lo largo del tiempo para desarrollar las mejoras propuestas y coordinan con el líder del proyecto las mejoras a aplicar.

\subsection{Indicadores de seguimiento}

Para comprobar el progreso de las propuestas de mejora a los procesos se recomendaron tres indicadores de gestión los mismos que poseen un reto de mejora en el tiempo. Los indicadores enunciados se hicieron pensando tanto en el cliente interno como en el externo y deben contribuir a dirigir el comportamiento de los responsables de los procesos.

Estos indicadores fueron:

- PS-1: Porcentaje de quejas del cliente respecto a las solicitudes de servicio atendidas por no llegar el personal técnico a la hora programada.

- PS-2: Porcentaje de quejas del personal técnico respecto a las solicitudes de servicio atendidas por falta de disponibilidad de herramientas en el almacén. 
- PS-3: Porcentaje de quejas del personal técnico respecto a las solicitudes de servicio atendidas por no estar la OT de servicio abierta.

En el anexo 3 se encuentran las fichas técnicas de los indicadores propuestos.

\subsection{Costo y beneficio de la implementación de mejoras}

\subsubsection{Costo}

En ciertos casos no es costeable implementar todo un proceso ya que el costo de la implementación puede no representar posibilidad de recuperar lo invertido. No obstante, para nuestro caso, se ha desarrollado un costeo en base a las horas - hombre necesarias para la implementación de las mejoras del nuevo proceso agrupándose de acuerdo a la tabla 22 adjunta.

Tabla 22 Costos de implementación de mejoras.

\begin{tabular}{|l|c|}
\hline Mejoras de alto impacto - Alto esfuerzo de implementación & 3,101 \\
\hline Mejoras de alto impacto - Medio esfuerzo de implementación & 4,359 \\
\hline Mejoras de alto impacto - Bajo esfuerzo de implementación & 6,439 \\
\hline Mejoras de medio impacto - Bajo esfuerzo de implementación & 3,319 \\
\hline COSTO TOTAL DE IMPLEMENTACION DE MEJORAS (*) & $\mathbf{S / . 1 7 , 2 1 8}$ \\
\hline
\end{tabular}

$\left({ }^{*}\right)$ No se estan considerando el costo del software para mejorar los sistemas

Fuente: Elaboración propia.

La tabla 22 contiene el costo total de la implementación. El cálculo de este costeo ha sido desarrollado en el anexo 5. 


\subsubsection{Beneficio}

El beneficio de las mejoras a desarrollar puede medirse tanto cualitativa como cuantitativamente.

A continuación se enunciarán todos los beneficios cualitativos de las mejoras propuestas las mismas que fueron mencionadas en la matriz de mejoras propuestas:

Estandarización de los procesos de atención al cliente y planificación de la OT lo que permitirá conocer detalladamente las actividades del proceso sirviendo adicionalmente como herramienta de capacitación para el personal actual y el personal nuevo que ingrese a la empresa.

Inicio del proceso en un solo punto lo que permitirá ordenar y controlar mejor el desarrollo de los procesos.

Dar mayor responsabilidad al asistente de servicios y agilizar los procesos de apertura de OT’s debido a la visualización del módulo de créditos.

Se asegura la disponibilidad de unidades debido a la aplicación de la política de alquileres de unidades.

Se asegura la disponibilidad de herramientas del almacén de servicios en caso se aplique la instalación de los módulos de disponibilidad de herramientas.

Se mejora la planificación de los servicios, se mejora las comunicaciones entre áreas y se eleva la satisfacción del cliente.

Para establecer una mejor comparación entre el costo (impacto negativo) y el beneficio (impacto positivo), se procede a elaborar diferentes escenarios para establecer el anális is cualitativo. Dichos escenarios son: la estandarización del proceso, elaboración de políticas de crédito, adquisición de una lap top y políticas de alquiler de unidades y mejoras en sistemas informáticos. Estos escenarios son presentados en las tabla 23, en ella se determina que los beneficios para le empresa por la implementación de las mejoras 
propuestas permitirá que los procesos de atención al cliente y planificación de la OT puedan ordenarse, organizarse y optimizarse a la vez que se mejora la comunicación con otras áreas lo que traerá como consecuencia elevar la satisfacción del cliente.

Tabla 23: Escenarios de comparación costo-beneficio cualitativo.

Escenario: Estandarización del proceso a traves de la documentación

\begin{tabular}{|l|l|}
\hline \multicolumn{1}{|c|}{ BENEFICIO } & \multicolumn{1}{c|}{ COSTO } \\
\hline Proceso documentado & Proceso indocumentado \\
\hline Optimización de los procesos & Pérdida de tiempo, desorden. \\
\hline Mecanismos de coordinación & Descoordinación a todo nivel \\
\hline $\begin{array}{l}\text { Control/seguimiento/evaluación de } \\
\text { procesos de acuerdo a los indicadores }\end{array}$ & $\begin{array}{l}\text { Descontrol por ausencia de } \\
\text { indicadores }\end{array}$ \\
\hline Eliminación de duplicidad de tareas & Repetición de tareas \\
\hline Segregación de funciones & Falta de delegación de funciones \\
\hline Roles definidos & Roles no establecidos \\
\hline
\end{tabular}

Escenario: Elaboración de politicas de crédito y de alquiler de unidades

\begin{tabular}{|l|l|}
\hline \multicolumn{1}{|c|}{ BENEFICIO } & \multicolumn{1}{c|}{ COSTO } \\
\hline $\begin{array}{l}\text { Se asegura la disponibilidad de } \\
\text { unidades para servicios }\end{array}$ & $\begin{array}{l}\text { Dejar de atender solicitudes de } \\
\text { servicio }\end{array}$ \\
\hline Ampliación de la cartera de clientes & Pérdida de oportunidades de venta. \\
\hline Mejor toma de decisiones & Toma de decisiones incorrectas \\
\hline
\end{tabular}

Escenario: Mejora en sistemas informáticos

\begin{tabular}{|l|l|}
\hline \multicolumn{1}{|c|}{ BENEFICIO } & \multicolumn{1}{c|}{ COSTO } \\
\hline Se agilizan los procesos & Pérdidas de tiempo \\
\hline $\begin{array}{l}\text { Información disponible para varios } \\
\text { usuarios. }\end{array}$ & Comunicaciones innecesarias. \\
\hline
\end{tabular}

Fuente: Elaboración propia.

Respecto al beneficio económico y a fin de cuantificar cuánto dinero está perdiendo la empresa por las deficiencias del proceso utilizaremos la tabla 8 y el cuadro del anexo 6 . En esta tabla 8 se puede apreciar que en el mes de julio tenemos 125 horas perdidas debido a las ineficiencias del proceso de atención al cliente y planificación de la OT, así mismo 
en el anexo 6 se puede apreciar que el costo horario del personal técnico para el mes de julio fue de S/ 70.00 por hora, entonces considerando que el periodo de implementación de las mejoras se puede realizar en tres meses y realizando la conversión de soles a dólares ( $\mathrm{TC}=\mathrm{S} / 2,8 /$ dólar) las pérdidas por las ineficiencias del proceso se estiman en US \$ 9,375.00. Este resultado se muestra en la tabla 24 .

Tabla 24 Beneficio cuantitativo en USD.

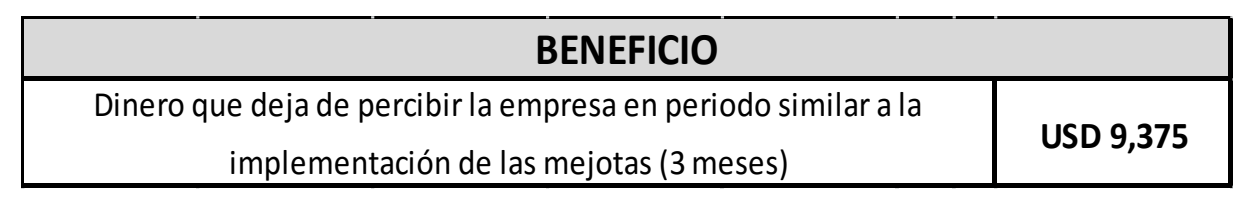

Fuente: Elaboración propia

El análisis anterior puede proyectarse al periodo de un año, para ello se calculará la cantidad de dinero que dejaría de percibir la empresa en el transcurso de un año y que el costo de implementación es una inversión a largo plazo.

Para éste cálculo se ha desarrollado en la tabla 25 dos escenarios. El primer escenario en el cual no se aplican las mejoras se estima pérdidas por US \$37,500, en el segundo escenario considerando el costo de implementación de las mejoras al proceso como una inversión a largo plazo y sin considerar el valor del dinero en el tiempo obtenemos un ahorro de US $\$ 13,315$.

Tabla 25: Análisis costo-beneficio - Periodo 1 año en USD. 


\begin{tabular}{|l|c|c|c|c|c|}
\hline \multirow{2}{*}{ ESCENARIO DETALLE } & \multicolumn{3}{c|}{ AÑ 1 } & \multirow{2}{*}{ TOTAL \$ } \\
\cline { 2 - 5 } & TRIM. 1 & TRIM. 2 & TRIM. 3 & TRIM. 4 & \\
\hline Escenario 1 : Sin mejoras & & & & & \\
\hline $\begin{array}{l}\text { Cantidad que deja de percibir la empresa } \\
\text { por ineficiencias en los procesos }\end{array}$ & $-9,375$ & $-9,375$ & $-9,375$ & $-9,375$ & $\mathbf{- 3 7 , 5 0 0}$ \\
\hline
\end{tabular}

\begin{tabular}{|l|c|c|c|c|c|}
\hline Escenario 2: Implementando la propuesta al proceso & \multicolumn{1}{l|}{} \\
\hline Inversión para implementación & $-6,149$ & & & $-6,149$ \\
\hline $\begin{array}{l}\text { Cantidad de percibir la empresa por } \\
\text { ineficiencias en los procesos }\end{array}$ & $-9,375$ & 0 & 0 & 0 & $-9,375$ \\
\hline Oportunidad de Ahorro & 0 & 9,375 & 9,375 & 9,375 & 28,125 \\
\hline
\end{tabular}

Fuente: Elaboración propia.

A fin de ajustar el resultado de acuerdo al valor del dinero en el tiempo y de acuerdo a la tasa promedio que otorgan los bancos en moneda extranjera por depósitos a plazo fijo de un año, se toma de referencia una taza de 3\% para cuantificar el ahorro al día de hoy. Las tazas de otros instrumentos financieros al ser variables no fueron tomadas en cuenta ya que la rentabilidad no está garantizada.

Si en un caso hipotético consideramos se logre implementar las mejoras propuestas y una tasa efectiva anual de $3 \%$, se concluye que la inversión realizada para la implementación de las mejoras en el proceso en estudio, permite ahorrar USD 17,865 los cuales pueden ser destinados a: capacitación del personal técnico, invertir en herramientas, implementar más mobiliario para el taller, mejorar las áreas de trabajo e incluso contribuir con el costo de las mejoras informáticas pendientes. La tabla 26 muestra el análisis de la inversión inicial para la implementación de las mejoras, así como la oportunidad de ahorro por las ineficiencias del proceso.

Tabla 26: Análisis costo-beneficio - Periodo 1 año (USD) * 


\begin{tabular}{|l|c|c|c|c|}
\hline Escenario 2: Implementando la propuesta de mejora al proceso & & \\
\hline ESCENARIO/DETALLE & TRIM. 1 & TRIM. 2 & TRIM. 3 & TRIM. 4 \\
\hline Inversión para implementación & $-6,149$ & & & \\
\hline $\begin{array}{l}\text { Cantidad que deja de percibir la empresa } \\
\text { por ineficiencias en los procesos }\end{array}$ & $-9,375$ & & & \\
\hline Oportunidad de Ahorro & 0 & 9,375 & 9,375 & 9,375 \\
\hline Flujo & $-15,524$ & 9,375 & 9,375 & 9,375 \\
\hline Valor económico HOY en USD & US \$ 17,865 & &
\end{tabular}

Fuente: Elaboración propia.

*considerando el valor del dinero en el tiempo

Como se puede apreciar, el costo que asume el área de servicios por las ineficie ncias del proceso al facturar las OTs a clientes por atención al cliente y planificación de la OT es considerable toda vez que representa el $5 \%$ aproximadamente del costo total de ventas si lo comparamos con los resultados del 2010. 


\section{CAPITULO 4 CONCLUSIONES, RECOMENDACIONES Y LIMITACIONES DEL ESTUDIO}

El objetivo del presente capítulo es elaborar el cierre del estudio a través de la elaboración de conclusiones, recomendaciones y limitaciones derivadas del desarrollo de las diferentes etapas del presente estudio.

\subsection{Conclusiones}

El poco conocimiento de la interrelación que existe en todas las etapas del proceso por parte de la administración, la jefatura del área y del personal técnico no permite una gestión adecuada del proceso de atención al cliente.

La falta de comunicación oportuna del área de servicios con créditos y cobranzas dificulta la apertura de las órdenes de trabajo. Por otra parte, el retraso en la atención del área de caja así como la falta de independencia del área de servicios para alquilar camionetas y aprobar créditos menores a US \$1,000.00 retrasaba la atención oportuna de los clientes.

El sistema informático para aperturar OTs DWF adicional a ser lento y ocasionar retrasos en el inicio del proceso, no soporta adecuadamente el flujo del proceso por cuanto no genera indicadores de gestión del área y no realiza reportes con información relevante para la toma de decisiones.

Gestión deficiente de herramientas en el área de almacén por falta de un sistema de control ágil de ingreso/salida de materiales así como deficiente stock de herramientas importantes. La falta de una lap top ocasionaba una deficiente atención de los servicios. 
La aplicación de la herramienta RAPID para identificar si las decisiones operativas y administrativas se toman por las personas adecuadas a lo largo del proceso permitió determinar que en la mayoría de los casos las funciones no estaban correctamente definidas, por consiguiente, las descoordinaciones y falta de segregación de funciones al interior de las áreas retardaban actividades a lo largo del proceso

La clasificación de las mejoras sugeridas en tres grupos permitió establecer un calendario de implantación y su respectiva priorización. Esta priorización se realizó conjuntamente con la administración de la sucursal por lo que su impacto y correcta difusión a los niveles operativos tendrá mayor recepción y aceptación.

Implementar las mejoras sugeridas en el período de un año permitirá ahorrar a la empresa aproximadamente USD 17,865 dólares. Por consiguiente la viabilidad del proyecto es aceptable y las deficiencias encontradas en el proceso disminuirán o erradicarán según sea el caso.

\subsection{Recomendaciones}

Se debe considerar el fortalecimiento del equipo de trabajo indicado en el presente estudio durante la etapa de implantación de las mejoras del proceso. El liderazgo del jefe de equipo y la colaboración de las personas involucradas serán determinantes para esta etapa del proceso.

Se recomienda hacer el seguimiento respectivo a las mejoras informáticas sugeridas toda vez que contribuirá significativamente en la agilización del proceso.

Aplicar la herramienta RAPID a todas las áreas de la sucursal a fin de determinar si las decisiones operativas y estratégicas están siendo tomadas por el personal adecuado. 


\subsection{Limitaciones}

La información de los sueldos del personal involucrado en el proceso proporcionado por el área de RRHH solo fue referencial. Esto no permitió realizar un costeo exacto de la implementación de las mejoras.

La falta de motivación del personal involucrado en el proceso y/o la falta de liderazgo del jefe de equipo pueden afectar la implantación de las mejoras del proceso.

El sistema DWF (Domino Work Flow) utilizado para abrir las OTs presenta limitaciones debido a su falta de integración con los sistemas de créditos y cobranzas y caja.

No se obtuvieron los datos de los resultados de la implementación de las mejoras debido al traslado del jefe de servicios a otra sucursal. 


\section{REFERENCIAS BIBLIOGRÁFICAS}

Abascal, F. (2002) Consumidor, Clientela y Distribución. Madrid: ESIC EDITORIAL

ASOCIACIÓN DE LA INDUSTRIA NAVARRA (AIN) (1991) La Calidad en el área del diseño. Madrid: Díaz de Santos

Berry, L. (2002) Un buen Servicio ya no basta. Bogotá: Editorial Norma

Campanella, J. (1992) Costo de la calidad: una filosofía de gestión. Madrid: Ediciones Díaz de Santos S. A.

Campanella, J. (1992) Principios de los Costes de Calidad. 2da. Edición. Madrid: Ediciones Díaz de Santos S. A.

Camisón, C. (2007) Gestión de la calidad conceptos, enfoques, modelos y sistemas. Madrid: Pearson Educación. (658.4013 CAMI)

Collier, D. (2009) Administración de operaciones: bienes, servicios y cadenas de valor. México, D. F. Cengage Learning. (670.5 COLL)

Domínguez, J. (1995) Dirección de operaciones: aspectos estratégicos en la producción y los servicios. Madrid: McGraw-Hill. 
Evans, J. R. (2005) Administración y control de la calidad. México, D.F.: Thomson. (658.4013 EVAN 2005)

Gryna, F. (2007) Método Juran: análisis y planeación de la calidad. México, D. F: McGraw- Hill Interamericana. (658.562 GRYN)

Heizer, J. (2004) Principios de administración de operaciones. Naucalpan de Juárez: Pearson Educación. (670.5 HEIZ)

Kotler, P. (2003) Fundamentos de marketing. Naucalpan de Juárez: Pearson Educación. (658.8 KOTL/F 2003)

Krajewski, L. (2000) Administración de operaciones: estrategia y análisis. México, D.F: Pearson Educación. (670.5 KRAJ/A)

Lambin, J. (1995) Marketing estratégico. Madrid: McGraw-Hill. (658.802 LAMB)

Noori, H. (1997) Administración de operaciones y producción: calidad total y respuesta sensible rápida. Bogotá: McGraw-Hill. (670.5 NOOR)

Lozano, J. (2001) Asistencia Técnica de Post Venta: Volumen 1. 2da. Edición. España: Fundación Confametal.

Juran, J.M. Frank, Jr. y BINGHAM, R.S., Jr. (2005) Manual de control de la calidad. 2a.ed. Barcelona: Reverté. 2 vols. 
Marchant, L. (2006) Actualizaciones para el Management y el Desarrollo Viña del Mar: Organizacional Universidad

Paz, R. (2005) La Comunicación y la Calidad del Servicio en la Atención al Cliente. España: Ideas propias Editorial.

Publicaciones Vértice (2008) Calidad en el Servicio y Atención al Cliente de Malaga: Editorial Vértice. 


\section{ANEXOS}

ANEXO 1. ESTRUCTURA DE ENCUESTA DE SATISFACCIÓN DEL CLIENTE

\section{CATERPILLAR ${ }^{\circ}$}

\section{Programa de Encuestas Transaccionales}

Scripts de Cuestionario - Encuesta de servicio de campo

\section{Screener/Introducción:}

S1. Hola, mi nombre es [NOMBRE]. Llamo en nomkre de [NOMBRE DEL DISTRIBUIDOR]. ¿Puedo hablar con [NOMBRE DE CONTACTO] por favor?

Si la persona que esta hablando es el contacto, continue. Si el contacto no esta disponible, agende un llamado.

S2. Llamo para realizar un seguimiento sobre que tan satisfecho se encuentra usted con una reciente visita de Servicio en Terreno realizada por [INSERTAR NOMBRE DEL DISTRIBUIDOR] el [INSERTAR FECHA DEL SERVICIO]. Es acerca del servicio para su [INSERTAR MODELO]. ¿Se encuentra usted familiarizado con este servicio en particular?

En caso de si, Continue. Si la respuesta es NO vaya a “¿Existe otra persona con la que pueda hablar..."

S3. Su negocio es muy importante por lo que deseamos aseguramos de que esta visita haya cumplido con sus expectativas. Tengo unas pocas preguntas que sólo le tomarán 5 minutos de su fempo. ¿Es este buen momento para haklar?

En caso de si, comienza la encuesta. En caso de NO, agende otro llamado.

S4. ¿Existe otra persona con la que pueda hablar que pueda estar famliarizada con este servicio?

En caso de si, capture el nombre y numero telefonico del nuevo contacto, agradezca y termine o empiece nuevamente, si lo transfieren En caso de NO, agradezca y termine

S5. Para fines de calidad, esta llamada podria estar siendo grabada.

\section{Encuesta:}

Para apoyar las mejoras del proceso, su respuesta será compartida con su distrikuidor y con Catenillar. Al participar, usted expresa su consentimiento para el uso de su información.

Ahora, me gustaria hacerle unas pocas preguntas sobre su reciente experiencia con el Servicio en Terreno. Por favor, calfique cada pregunta de 1 a 10, donde 10 significa "Muy satisfecho" o "Muy probable" y 1 es "Muy insatisfecho" o "Muy improbable."

Satisfacción general:

1. En general, ¿qué tan satisfecho se encontra usted con su experiencia de Servicio en Terreno el (FECHA DEL SERVICIO) con (NOMBRE DEL DISTRIBUIDOR)?

\section{Recompra:}

2. En base a esta experiencia, ¿qué tan probable es que se dirija usted a (NOMBRE DEL DISTRIBUIDOR) para solicitar un futuro trakajo de Servicio en Terreno?

2.5 Explorar si el 7 o menos: ¿Cómo podria (NOMBRE DEL DISTRIBUIDOR) mejorar para que fuese más probable que usted lo vuelva a contactar nuevamente para un Servicio en Terreno?

\section{Recomienda:}

3. ¿Qué tan probable seria que usted recomendase a (NOMBRE DEL DISTRIBUIDOR) a otra persona para Servicio en Terreno? 3.5 Explorar si la Recomendación (Q3) es 3 o mas puntos menor que el puntaje de Recompra (Q2): He notado que es mucho más probable que usted utilice un servicio de (NOMBRE DEL. DISTRIBUIDOR) nuevamente en lugar de remitir a un amigo o colega. ¿Existe alguna razón en particular para elo?

Facilidad para hacer negocios:

4. ¿Qué tan satisfecho se encontró usted con la faclidad de contactar al distribuidor para programar este servicio? 4.5 Explorar si el 7 o menos: ¿Cómo podria (NOMBRE DEL DISTRIBUIDOR) mejorar la facilidad de programar un Servicio en Terreno con ellos? 


\section{PATERPILAR Programa de Encuestas Transaccionales \\ Scripts de Cuestionario - Encuesta de servicio de campo}

Disponibilidad y Fiabilidad:

5. ¿Qué tan satisfecho se encontró usted con la dísponibilidad de un técnico dentro del tiempo esperado?

5.5 Explorar si el 7 o menos: En base a su experiencia en Servicio en Terreno del día (FECHA DEL SERVICIO), ¿qué podria haker hecho (NOMBRE DEL DISTRIBUIDOR) para mejorar su satisfacción respecto a su disponikilidad?

Respuesta:

6. ¿Qué tan satisfecho se encontró usted de que el técnico de sevvicio llegara en el tiempo prometido?

6.5 Explorar si el 7 o menos: En base a su experiencia en Servicio en Terreno del día (FECHA DEL SERVICIO), ¿qué podria haber hecho (NOMBRE DEL DISTRIBUIDOR) para mejorar su satisfacción respecto a su capacidad de respuesta?

Comunicación:

7. ¿Qué tan satisfecho se encontró usted con la calidad de la comuricación de (NOMBRE DEL DISTRIBUIDOR) durante este servicio?

7.5 Explorar si el 7 o menos: En base a esta transacción, ¿cómo deberia (NOMBRE DEL DISTRIBUIDOR) mejorar la caldad de su comunicación?

Preparación:

8. ¿Qué tan satisfecho se encontró usted con el hecho de que el técrico haya verido equipado con los repuestos y herramientas adecuadas para completar su Servicio en Terreno el dia (FECHA DEL SERVICIO)?

8.5 Explorar si el 7 o menos: ¿Qué podria haker hecho (NOMBRE DEL DISTRIBUIDOR) para mejorar su satisfacción respecto a su preparación?

Duración:

9. ¿Qué tan sabiffecho se encontró usted con el hecho de que este servicio se completara en el tiempo prometido? 9.5 Explorar si el 7 o menos: ¿Qué podria haber hecho (NOMBRE DEL DISTRIBUIDOR) para mejorar su satisfacción respecto a la puntualidad de este Servicio en Terreno?

\section{Calidad:}

10. ¿Qué tan satisfecho se encontró usted con el hecho de que este servicio se completará correctamente? 10.5 Explorar si el 7 o menos: ¿Qué podria haber hecho (NOMBRE DEL DISTRIBUIDOR) para mejorar su sabisfacción respecto a la calidad de su sevicio?

Puntualidad de la factura:

11. ¿Qué tan satisfecho se encontró usted con la puntualdad de la factura por su Servicio en Terreno del (FECHA DEL SERVICIO)?

11.5 Explorar si el 7 o menos: ¿Qué podria haber hecho (NOMBRE DEL DISTRIBUIDOR) para mejorar su satisfacción respecto a la puntualidad de su factura?

\section{Precisión de la factura:}

12 ¿Cuán satisfecho está con la exactitud de la factura final? 12.5 Explorar si el 7 o menos: ¿Qué podria haber hecho (NOMBRE DEL DISTRIBUIDOR) para mejorar su satisfacción respecto a la exactidud de su factura por este Servicio en Terreno?

Comentarios de Clientes:

13. ¿Qué opinión adicional le gustaria compartir con (NOMBRE DEL DISTRIBUIDOR) acerca de su Servicio en Tereno?

\section{Conclusión:}

(NOMBRE DEL DISTRIBUIDOR) le agradece por su negocio y por su fempo el día de hoy. Su opinión es importante y los ayudará a prestar un mejor sevicio en el futuro. ¡Gracias! 
ENCUESTAS DE SATISFACCIÓN DEL CLIENTE

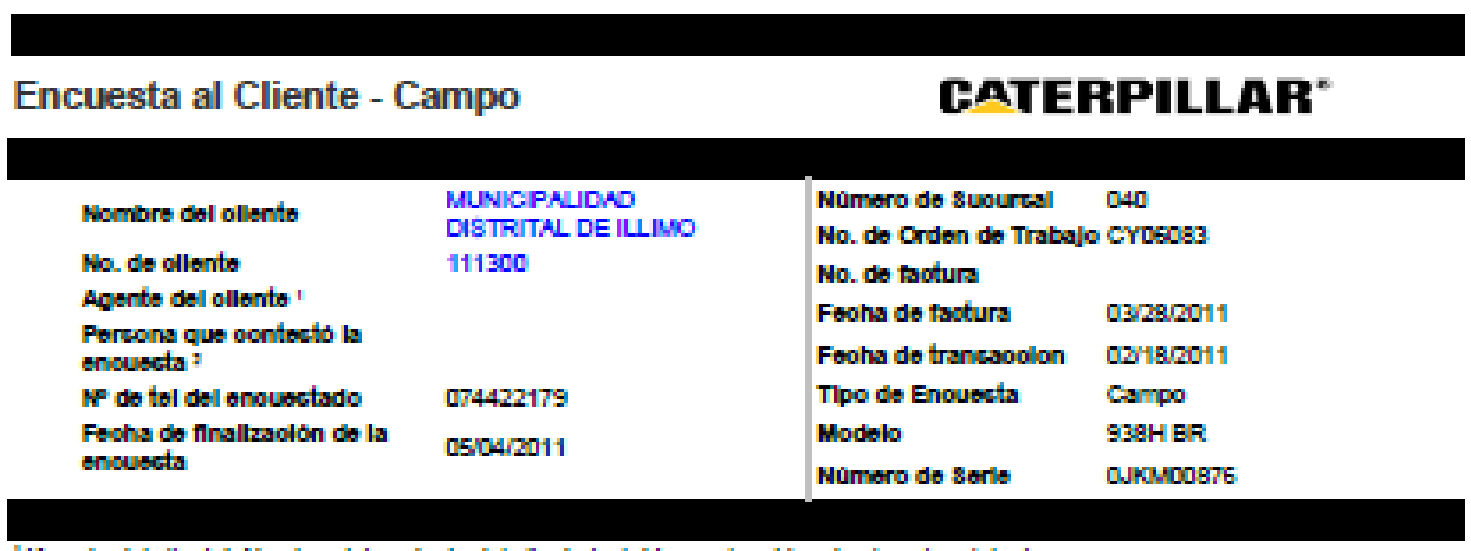

"Agente del cliente'-Nombre del contacto del clente inciuldo en el archivo de ejemplo onginal.

" 'Persona que cortesto la encuesta'- Inalidido que completo is encuesta.

Datos de encuesta

$\triangle$ Correo Eectronico $\Theta$ imprimir Procuntac do ta onouccta Callineacion Ectado do lestad: docoonooldo

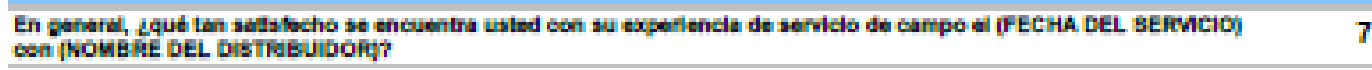

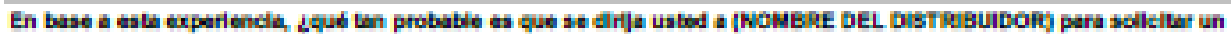
nituro tabajo de aervielo de camper?

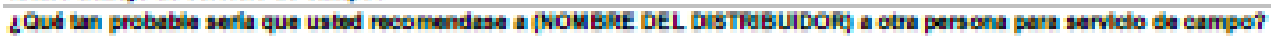

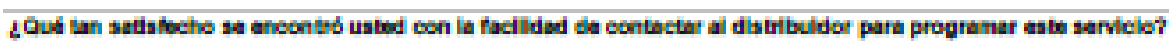

$-$

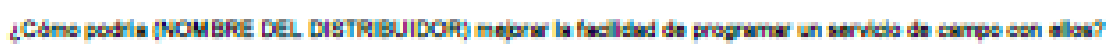

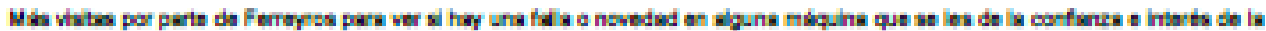
ampresa por brinder un bush sarvida.

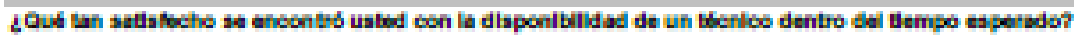

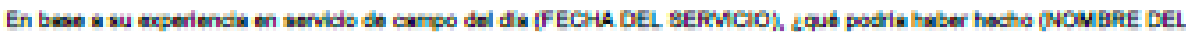

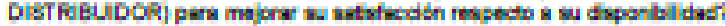

Simplamente seartar lau bampau de standion.

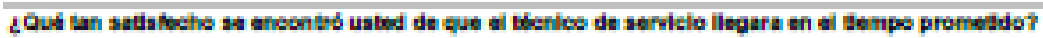

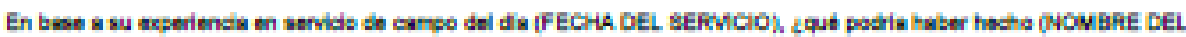

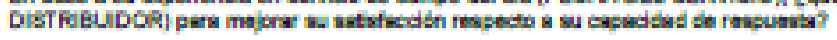

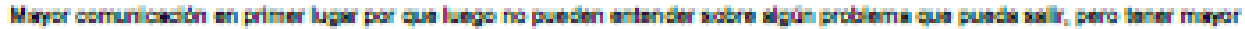

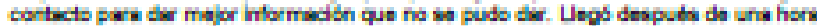

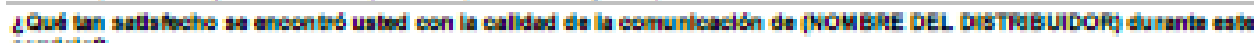
sarvicle?

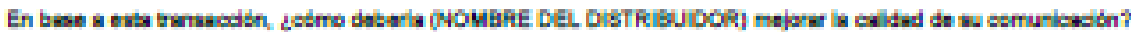

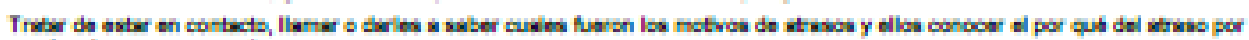
que las demiaran on sciendishas.

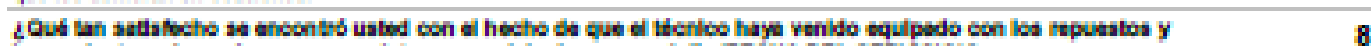
hertamiantas odeevades para compietar su servielo de campo el dle (FECHA DEL SEVicheioj?

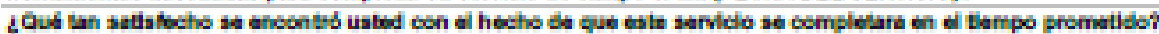

6

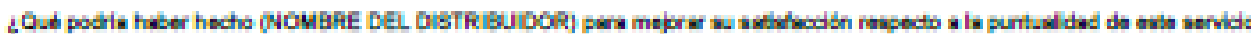
da carrpa?

Aglear mb las pedidos y poner mayst intartes a alas esmo clertin.

¿Qub tan sattafoeho se aneonteb uated con al heeho de que este sarviclo se cempletart blen?

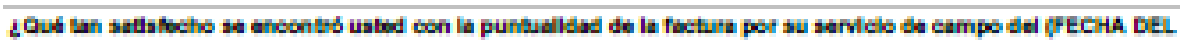

serviciol?

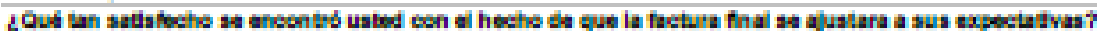

8

7

Comentarios Adcionales

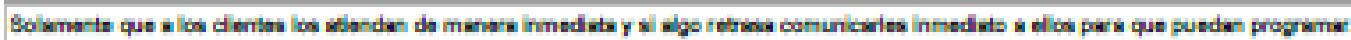




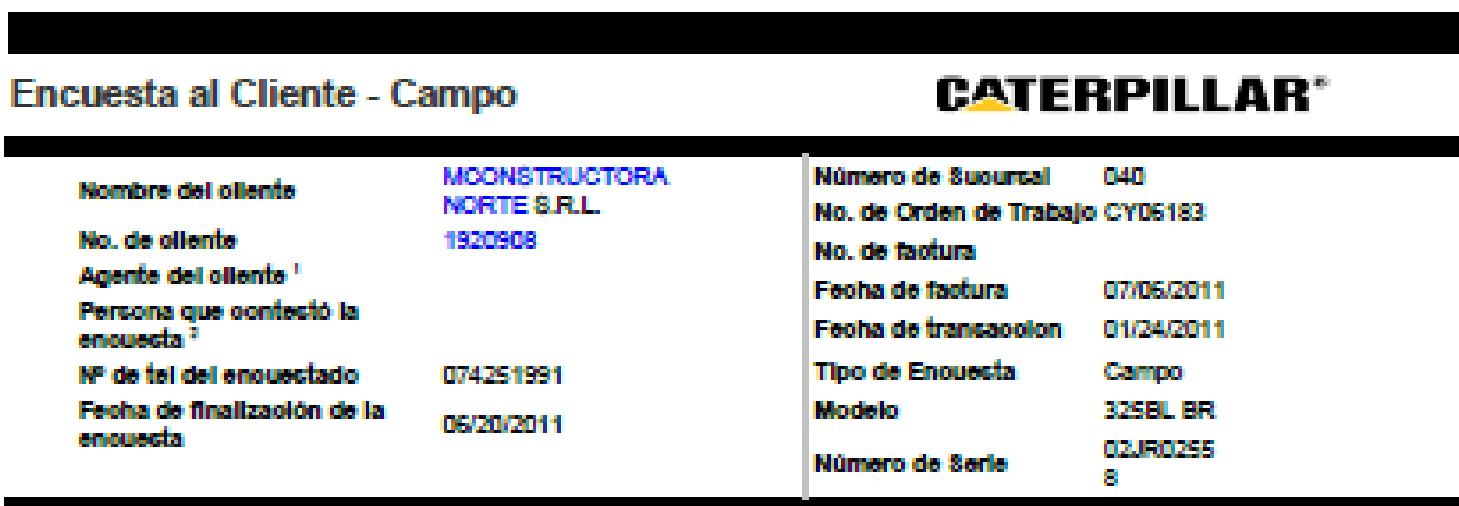

"'Agente del clente'-Nombre del contacto del clente inciuldo en el archivo de ejemplo onginal.

2 "Persona que cortesto la encuesta'- Individjo que compleso is encuesta.

Datos de encuesta

$\triangle$ Correo Eectronico $B$ imprimir

\begin{tabular}{|c|c|}
\hline Preountac do la enouecta & Callinescion \\
\hline Ectado do lostad: & \\
\hline 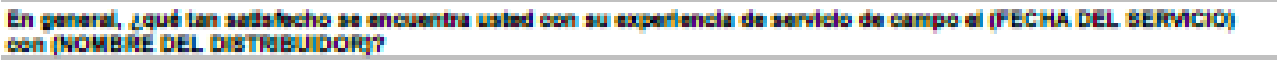 & 8 \\
\hline 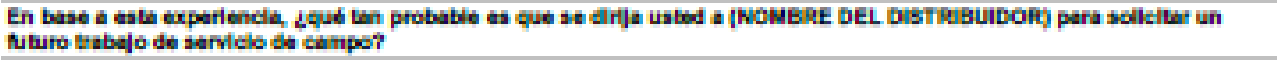 & - \\
\hline 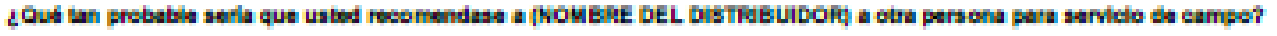 & 8 \\
\hline
\end{tabular}

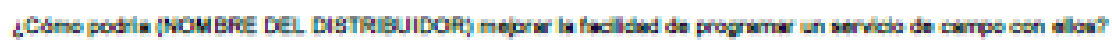

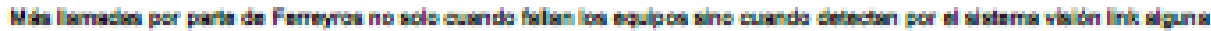
sensmale de les squpse.

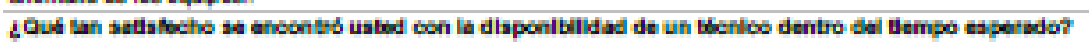

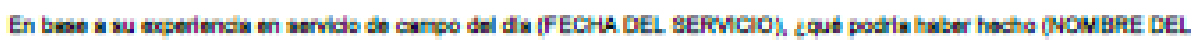

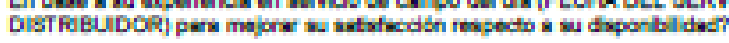

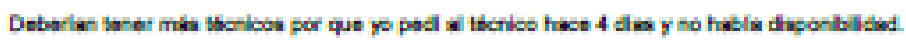

¿Qub tan sattafbeho se aneenteb uated de que al theriles de serviclo llegara en al tempo promeddo?

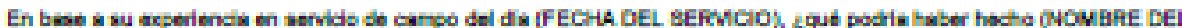

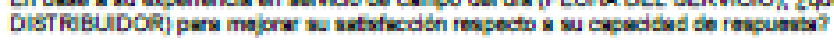

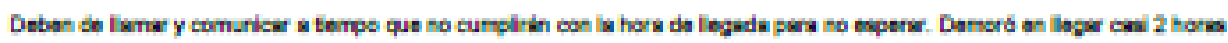

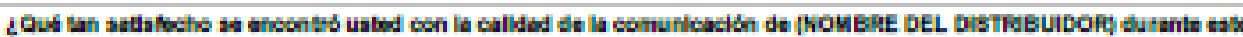
iarvielo?

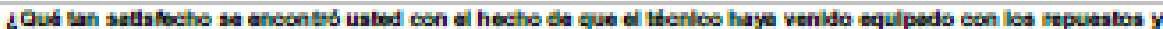

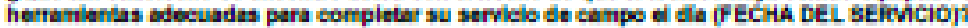

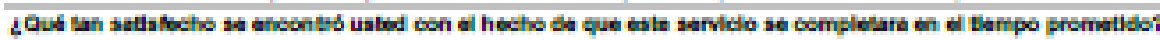

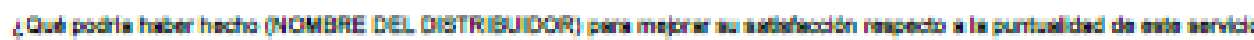
da campa?

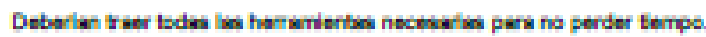

¿Qub tan sattafbeho se aneonteb uated con al heeho be que esis sarviclo se cempletart bien? 7

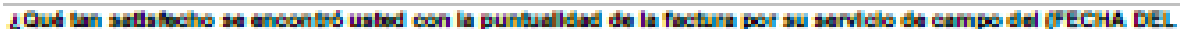
Besmcion?

¿Qub tan satisfocho se eneonteb uated con al heeho de que ia factura final se aluatara a sus expectatvas? 
Encuesta al Cliente - Campo

eaterpillaR:

Nombre dol ollento

No. de ollente

Aqente del ollento '

Percona que ocntecto is

encuscta?

Ne de tol del enousctado

Fecha do finallzaolon do la

enouscta

\section{JYC MENDOZA BAL}

14001219

979725675

$07 / 13 / 2011$
Nûmero de Suourcal 040

No. de Orden de Trabajo Cro6245

No. de taoture

Fooha de factura $\quad 07 / 13 / 2011$

Fooha de trancaoolion 1005/2011

Tlpo de Enouscta Campo

Modelo

Númoro de sorle OHENDS438

'Agente del clente'-Nombre del contacto del clente incluido en el archivo de efemplo onginal.

' 'Persona que contesto is encuesta'- Individjo que completo is encuesta.

Datos de encuesta

$\triangle$ Correo Electronico $\Theta$ imprimir

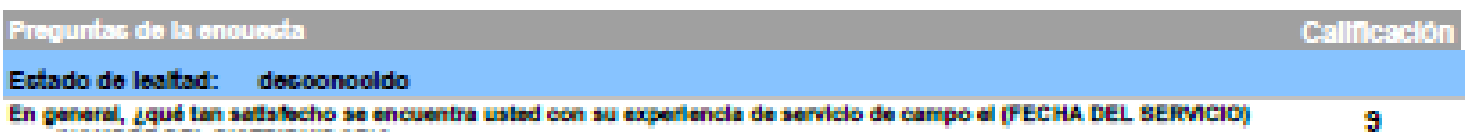

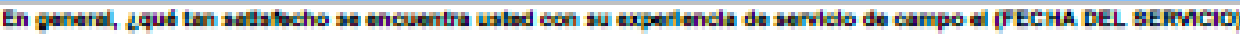
cen (NoMBa DEL DisTTABUibong?

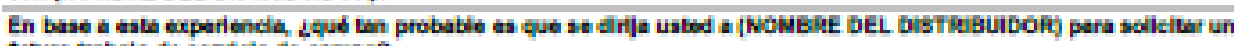
nuturo trabajo de sarviele de campo?

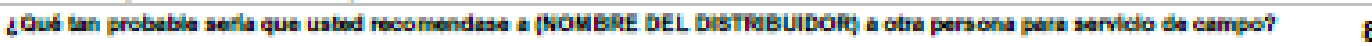

$-$

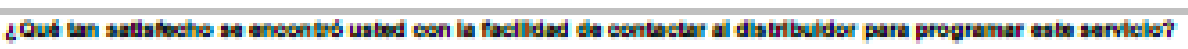

8

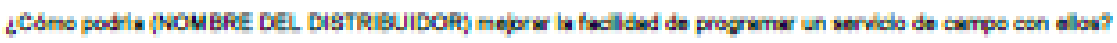

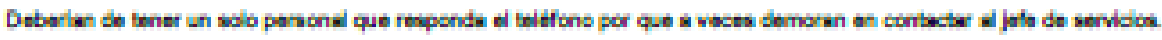

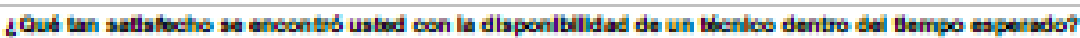

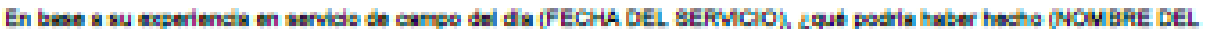

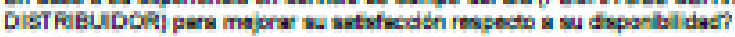

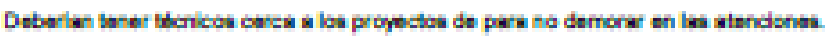

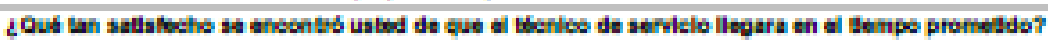

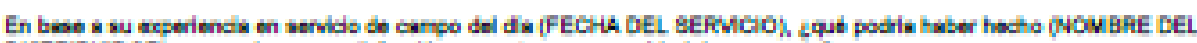

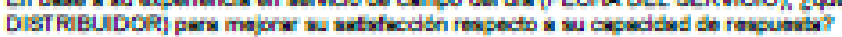

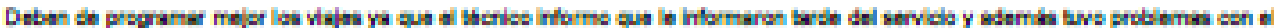

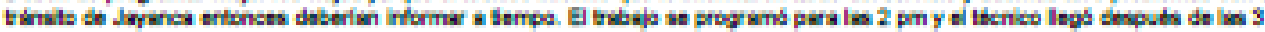

pm.

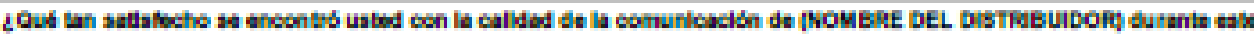
sarvilelo?

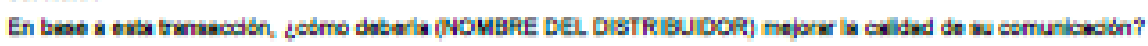

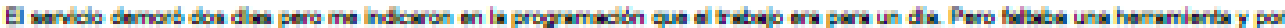

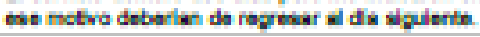

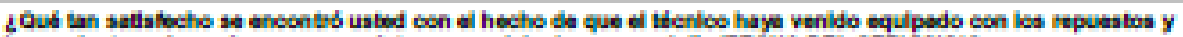

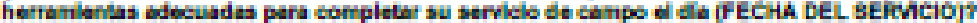

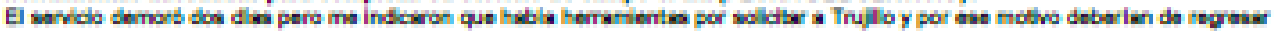

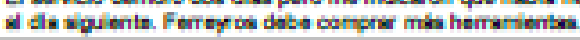

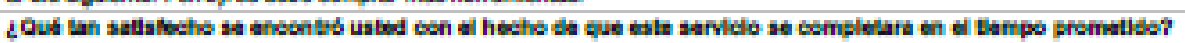

6

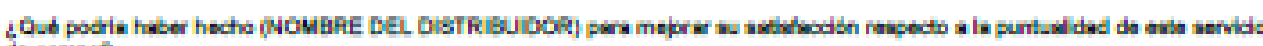
da carrpa?

Deban saver mak herrarientas.

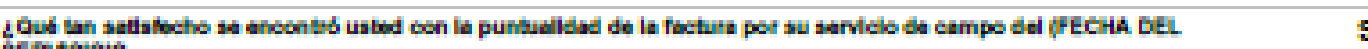

se rivicion?

¿Qub tan satialocho se aneontsb uated con al hecho de que la factura final se ajuatara a sus expectatvas?

9

Comentarios Adcionales

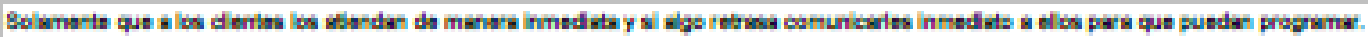




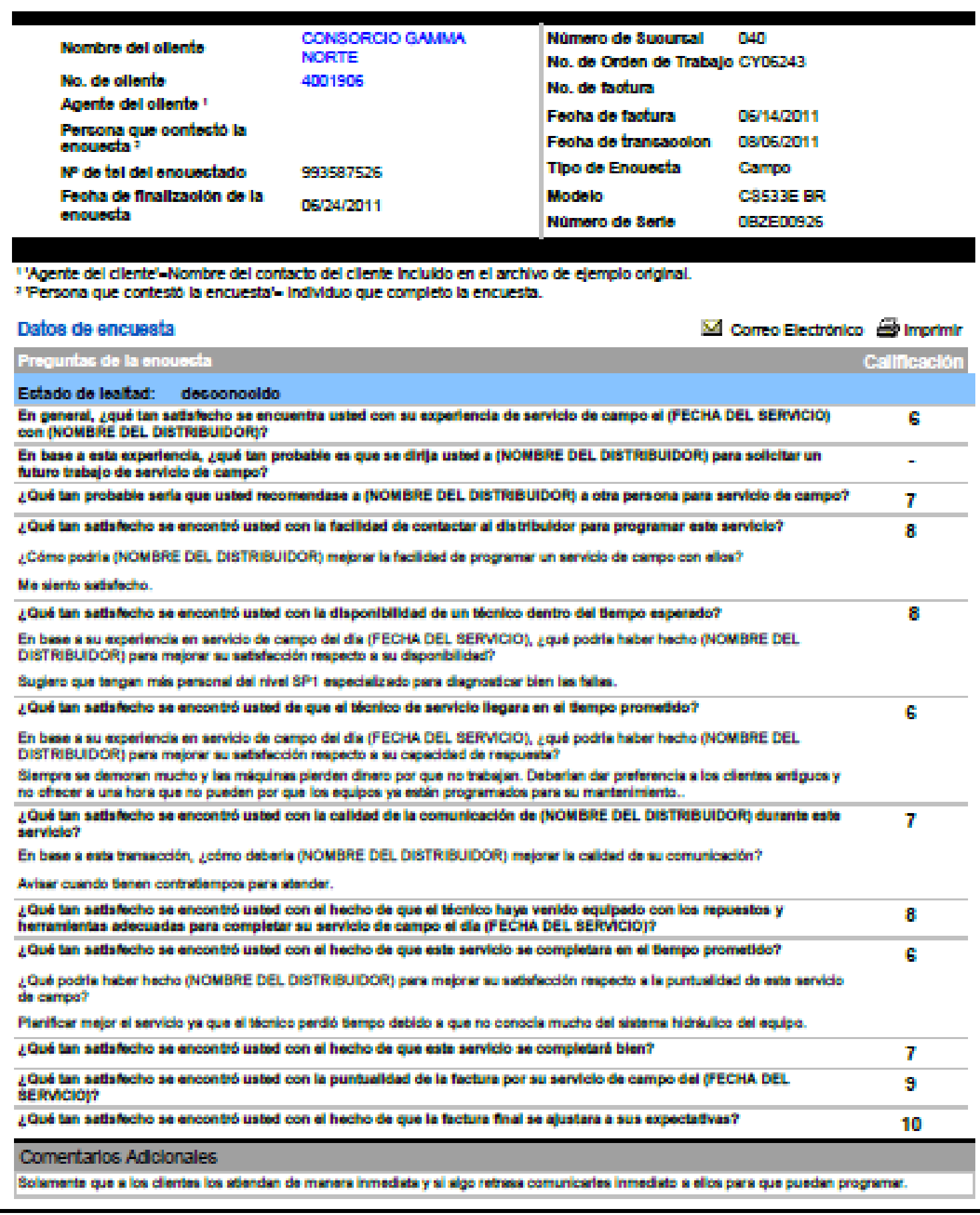




\section{ANEXO 2. ENCUESTA SOBRE ERRORES EN EL PROCESO DE ATENCIÓN AL CLIENTE Y PLANIFICACIÓN DE LA ORDEN DE TRABAJO}

\begin{tabular}{|c|c|c|}
\hline \multicolumn{3}{|c|}{ ENCUESTA DE SERVICIOS } \\
\hline \multicolumn{3}{|c|}{$\begin{array}{l}\text { Dirigido a: } \\
\text { Jefe, asistente, ingeniero de servicios, auxiliar de almacén y personal técnico del área de servicios. } \\
\text { La presente encuesta tiene como fin identificar los errores más frecuentes y sitios potenciales de mejora en el } \\
\text { proceso de atención del cliente y planificación de órdenes de trabajo de una empresa de comercialización de } \\
\text { bienes de capital y servicios. }\end{array}$} \\
\hline \multicolumn{3}{|c|}{ Nombre del Personal encuestado: } \\
\hline \multicolumn{3}{|c|}{ Cargo que desempeña en la empresa: } \\
\hline \multirow{2}{*}{\multicolumn{3}{|c|}{$\begin{array}{l}\text { A su criterio, cuantes veces al mes se producen éstos errores: } \\
\text { Marcar N.A. en caso NO aplique la descripción del item a su labor. }\end{array}$}} \\
\hline & & \\
\hline \multicolumn{2}{|r|}{ RECURSOS (Me Ilama el cliente y............) } & MES \\
\hline 1 & NO HAY HERRAMIENTAS DE DIAGNOSTICO (maletas de evaluación, tetragauge, pistola de temp., etc.) & \\
\hline & NO HAY SUMINISTROS (lijas, disolventes, paños, trapo, film strech) & \\
\hline & NO HAY LAP TOP & \\
\hline \multicolumn{3}{|c|}{\begin{tabular}{l|l|}
4 & NO HAY MOVILIDAD \\
\end{tabular}} \\
\hline \multicolumn{2}{|r|}{ PROCESOS DE TRABAJO (El cliente me Ilama y) } & MES \\
\hline \multicolumn{3}{|c|}{\begin{tabular}{l|l}
1 & ME INFORMARON DEL TRABAJO A ULTIMA HORA
\end{tabular}} \\
\hline \multicolumn{3}{|c|}{2 LA OT NO ESTA APERTURADA } \\
\hline \multicolumn{3}{|c|}{\begin{tabular}{l|l}
3 & EN CAJA NO HAY DINERO PARA LOS GASTOS DEL TECNICO \\
\end{tabular}} \\
\hline \multicolumn{3}{|c|}{4 FUERA DEL HORARIO DE TRABAJO X NUEVO TRABAJO } \\
\hline \multicolumn{3}{|c|}{\begin{tabular}{l|l|}
5 & NO RESPONDEN CONSULTA DE ESTADO DE CUENTAS \\
\end{tabular}} \\
\hline \multicolumn{3}{|c|}{\begin{tabular}{l|l}
6 & LAS MAQUINAS LLEGAN FUERA DE HORA
\end{tabular}} \\
\hline \multicolumn{3}{|c|}{7 ME VEO OBLIGADO A PROGRAMAR EN OTRO TRABAJO AL TECNICO Y NO LO DEJO TERMINO EL ANTERIOR } \\
\hline \multicolumn{3}{|c|}{\begin{tabular}{l|l}
8 & LOS SISTEMAS SON LENTOS: SIS, AGCO, INTERNET, CORREO, ETC. \\
\end{tabular}} \\
\hline \multicolumn{3}{|c|}{\begin{tabular}{l|l}
9 & NO HAN LLEGADO LOS REPUESTOS QUE NECESITO. \\
\end{tabular}} \\
\hline \multicolumn{2}{|r|}{ ALMACEN DE HERRAMIENTAS (el técnico me informa que...) } & MES \\
\hline \multicolumn{3}{|c|}{\begin{tabular}{l|l}
1 & NO HAN LLEGADO LOS REPUESTOS
\end{tabular}} \\
\hline \multicolumn{3}{|c|}{2 DEMORAS EN ENTREGA DE REPUESTOS } \\
\hline \multicolumn{3}{|c|}{\begin{tabular}{l|l}
3 & ATENCIÓN LENTA EN EL ALMACEN DE HERRAMIENTAS \\
\end{tabular}} \\
\hline \multicolumn{2}{|r|}{ PERSONAL HUMANO } & MES \\
\hline \multicolumn{3}{|c|}{\begin{tabular}{l|l}
1 & FALTA COMPROMISO EN EL PERSONAL
\end{tabular}} \\
\hline 2 & FALTA COMUNICACION ENTRE COMPAÑEROS & \\
\hline & FALTA COORDINACION ENTRE VENTAS Y SERVICIO & \\
\hline 4 & NO ME DAN INFORMACION TÉCNICA & \\
\hline 5 & COMUNICACIÓN TÉCNICA ES LENTA & \\
\hline & ME SOBRECARGAN DE TRABAJO & \\
\hline & MUCHOS JEFES & \\
\hline & FALTA ORDEN Y LIMPIEZA & \\
\hline & NO RESOLVI EL PROBLEMA RAPIDAMENTE POR FALTA DE CAPACITACION & \\
\hline & LOS INFORMES TECNICOS CON OBSERVACIONES: corregir/modificar/consultar & \\
\hline$O S E$ & ERVACIONES / COMENTARIOS ADICIONALES: & \\
\hline
\end{tabular}




\section{ANEXO 3. INDICADORES DE SEGUIMIENTO}

\begin{tabular}{|c|c|c|c|}
\hline \multicolumn{4}{|c|}{ Ficha técnica del indicador } \\
\hline Código: & \multicolumn{3}{|c|}{ PS-1 } \\
\hline Indicador: & \multicolumn{3}{|c|}{ Porcentaje de quejas del cliente } \\
\hline Fundamento: & \multicolumn{3}{|c|}{$\begin{array}{l}\text { Medir el porcentaje de quejas por retrasos en } \\
\text { la atención de solicitudes de servicio }\end{array}$} \\
\hline Perspectiva: & \multicolumn{3}{|c|}{ Proceso Externo } \\
\hline Objetivo: & \multicolumn{3}{|c|}{ Satisfacción del cliente } \\
\hline Unidad de medida: & \multicolumn{3}{|c|}{ Porcentaje } \\
\hline Fuente de Datos: & \multicolumn{3}{|c|}{ Cliente - encuesta } \\
\hline Forma de cálculo & \multicolumn{3}{|c|}{$\mathrm{N}^{\circ}$ quejas del cliente $/ \mathrm{N}^{\circ}$ de OTs atendidas } \\
\hline Frecuencia de actualización & \multicolumn{3}{|c|}{ Mensual } \\
\hline Frecuencia de Medición: & \multicolumn{3}{|l|}{ Diaria } \\
\hline Rango: & $>50 \%$ & $>50 \%-30 \%<$ & $<30 \%$ \\
\hline Metas Propuestas: & 4 meses: $50 \%$ & 8 meses: $40 \%$ & 1 año: $30 \%$ \\
\hline Responsable de Fijar la Meta: & \multicolumn{3}{|c|}{ Administrador } \\
\hline Responsable de Lograr la Meta: & \multicolumn{3}{|c|}{ Jefe de Servicios } \\
\hline Responsable del Seguimiento: & \multicolumn{3}{|c|}{ Asistente de Servicios } \\
\hline
\end{tabular}

\begin{tabular}{|c|c|c|c|}
\hline \multicolumn{4}{|c|}{ Ficha técnica del indicador } \\
\hline Código: & \multicolumn{3}{|l|}{ PS-2 } \\
\hline Indicador: & \multicolumn{3}{|c|}{ Porcentaje de quejas por falta de herramientas } \\
\hline Fundamento: & \multicolumn{3}{|c|}{$\begin{array}{l}\text { Medir el porcentaje de quejas por falta de } \\
\text { herramientas de diagnóstico }\end{array}$} \\
\hline Perspectiva: & \multicolumn{3}{|c|}{ Proceso Interno } \\
\hline Objetivo: & \multicolumn{3}{|c|}{ Disminir costos por pérdidas de tiempo } \\
\hline Unidad de medida: & \multicolumn{3}{|c|}{ Porcentaje } \\
\hline Fuente de Datos: & \multicolumn{3}{|c|}{ Personal técnico } \\
\hline Forma de cálculo & \multicolumn{3}{|c|}{$\frac{\mathrm{N}^{\circ} \text { de quejas por falta de herramientas }}{\mathrm{N}^{\circ} \text { de Ots atendidas }}$} \\
\hline Frecuencia de actualización & \multicolumn{3}{|l|}{ Mensual } \\
\hline Frecuencia de Medición: & \multicolumn{3}{|l|}{ Diaria } \\
\hline Rango: & $>15 \%$ & $>15 \%-5 \%<$ & $<5 \%$ \\
\hline Metas Propuestas: & 4 meses: $15 \%$ & 8 meses: $10 \%$ & 1 año: $5 \%$ \\
\hline Responsable de Fijar la Meta: & \multicolumn{3}{|l|}{ Administrador } \\
\hline Responsable de Lograr la Meta: & \multicolumn{3}{|c|}{ Jefe de Servicios } \\
\hline Responsable del Seguimiento: & \multicolumn{3}{|c|}{ Asistente de Servicios } \\
\hline
\end{tabular}




\begin{tabular}{|c|c|c|c|}
\hline \multicolumn{4}{|c|}{ Ficha técnica del indicador } \\
\hline Código: & \multicolumn{3}{|c|}{ PS-3 } \\
\hline Indicador: & \multicolumn{3}{|c|}{ Porcentaje de quejas por falta de OT } \\
\hline Fundamento: & \multicolumn{3}{|c|}{ Medir el porcentaje de quejas por falta de OT } \\
\hline Perspectiva: & \multicolumn{3}{|c|}{ Proceso Interno } \\
\hline Objetivo: & \multicolumn{3}{|c|}{ Disminir costos por pérdidas de tiempo } \\
\hline Unidad de medida: & \multicolumn{3}{|c|}{ Porcentaje } \\
\hline Fuente de Datos: & \multicolumn{3}{|c|}{ Personal técnico } \\
\hline \multirow{2}{*}{ Forma de cálculo } & \multicolumn{3}{|c|}{$\mathrm{N}^{\circ}$ de quejas por falta de OT } \\
\hline & \multicolumn{3}{|c|}{$\mathrm{N}^{\circ}$ de Ots atendidas } \\
\hline Frecuencia de actualización & \multicolumn{3}{|l|}{ Mensual } \\
\hline Frecuencia de Medición: & \multicolumn{3}{|l|}{ Diaria } \\
\hline Rango: & $>20 \%$ & $>20 \%-10 \%<$ & $<10 \%$ \\
\hline Metas Propuestas: & 4 meses: $20 \%$ & 8 meses: $15 \%$ & 1 año: $10 \%$ \\
\hline Responsable de Fijar la Meta: & \multicolumn{3}{|c|}{ Administrador } \\
\hline Responsable de Lograr la Meta: & \multicolumn{3}{|c|}{ Jefe de Servicios } \\
\hline Responsable del Seguimiento: & \multicolumn{3}{|c|}{ Asistente de Servicios } \\
\hline
\end{tabular}

\begin{tabular}{|c|c|c|c|}
\hline \multicolumn{4}{|c|}{ Ficha técnica del indicador } \\
\hline Código: & \multicolumn{3}{|c|}{ PS-4 } \\
\hline Indicador: & \multicolumn{3}{|c|}{ Porcentaje solicitudes de servicio atendidas } \\
\hline Fundamento: & \multicolumn{3}{|c|}{ Medir el porcentaje de solicitudes atendidas } \\
\hline Perspectiva: & \multicolumn{3}{|c|}{ Proceso Interno } \\
\hline Objetivo: & \multicolumn{3}{|c|}{ Evaluar porcentajes de solicitudes atendidas. } \\
\hline Unidad de medida: & \multicolumn{3}{|c|}{ Porcentaje } \\
\hline Fuente de Datos: & \multicolumn{3}{|l|}{ Sistema DWF } \\
\hline Forma de cálculo & \multicolumn{3}{|c|}{$\frac{\mathrm{N}^{\circ} \text { de solicitudes de clientes }}{\mathrm{N}^{\circ} \text { de Ots abiertas }}$} \\
\hline Frecuencia de actualización & \multicolumn{3}{|l|}{ Mensual } \\
\hline Frecuencia de Medición: & \multicolumn{3}{|l|}{ Diaria } \\
\hline Rango: & $>70 \%$ & $>70 \%-80 \%<$ & $<80 \%$ \\
\hline Metas Propuestas: & 4 meses: $70 \%$ & 6 meses: $75 \%$ & 1 año: $80 \%$ \\
\hline Responsable de Fijar la Meta: & \multicolumn{3}{|l|}{ Administrador } \\
\hline Responsable de Lograr la Meta: & \multicolumn{3}{|c|}{ Jefe de Servicios } \\
\hline Responsable del Seguimiento: & \multicolumn{3}{|c|}{ Asistente de Servicios } \\
\hline
\end{tabular}




\begin{tabular}{|l|l|}
\hline \multicolumn{2}{|c|}{ Formato del Indicador PS-3 } \\
\hline \multicolumn{2}{|c|}{ FALTA DE OT } \\
Fecha de envío de \\
presupuesto: $:$ \\
OT \\
Motivo de falta de OT \\
\hline \\
\\
\hline \\
\hline CC. \\
\hline \\
\hline Ingeniero de Servicios \\
\hline Jefe de Servicios \\
\hline Créditos y cobranzas \\
\hline
\end{tabular}




\section{ANEXO 5. COSTO TOTAL DE IMPLEMENTACIÓN DE MEJORAS}

\begin{tabular}{|c|c|c|c|c|}
\hline MEJORAS DE ALTO IMPACTO - ALTO ESFUERZO DE IMPLEMENTACIÓN & $\begin{array}{c}\text { Sueldo diario } \\
(\mathrm{S} / .)\end{array}$ & $\begin{array}{c}\text { Sueldo horario } \\
(\mathrm{S} / .)\end{array}$ & $\begin{array}{c}\mathrm{HH} \\
\text { invertidas }\end{array}$ & $\begin{array}{c}\text { Costo de } \\
\text { inversión (S/.) }\end{array}$ \\
\hline Administrador & 650 & 81 & 24 & 1950 \\
\hline Jefe de Servicios & 410 & 51 & 4 & 205 \\
\hline Personal de Informática & 200 & 25 & 8 & 200 \\
\hline Asistente de créditos y cobranza & 115 & 14 & 4 & 58 \\
\hline \begin{tabular}{|l|} 
Ingeniero de servicios \\
\end{tabular} & 140 & 18 & 16 & 280 \\
\hline Auxiliar de almacén (Lima) & 34 & 4 & 48 & 204 \\
\hline \multirow[t]{2}{*}{ Auxiliar de almacén (Suc. Lambayeque) } & 34 & 4 & 48 & 204 \\
\hline & & & SUB TOTAL & 3,101 \\
\hline MEJORAS DE ALTO IMPACTO - MEDIO ESFUERZO DE IMPLEMENTACIÓ| & $\begin{array}{c}\text { Sueldo diario } \\
(\mathrm{S} / .)\end{array}$ & $\begin{array}{c}\text { Sueldo horario } \\
(\mathrm{S} / .)\end{array}$ & $\begin{array}{c}\text { HH } \\
\text { invertidas }\end{array}$ & $\begin{array}{c}\text { Costo de } \\
\text { inversión (S/.) }\end{array}$ \\
\hline Administrador & 650 & 81 & 5 & 406 \\
\hline Jefe de Servicios & 410 & 51 & 3 & 154 \\
\hline Asistente de créditos y cobranza & 115 & 14 & 11 & 158 \\
\hline Personal de Informática & 200 & 25 & 8 & 200 \\
\hline Ingeniero de servicios & 140 & 18 & 3 & 53 \\
\hline Asistente de servicios & 115 & 14 & 11 & 158 \\
\hline Auxiliar de almacén & 34 & 4 & 3 & 13 \\
\hline Personal técnico: 14 técnicos & 560 & 70 & 42 & 2940 \\
\hline Asistente de Ventas & 120 & 15 & 3 & 45 \\
\hline \multirow{2}{*}{ Representante de Ventas } & 620 & 78 & 3 & 233 \\
\hline & & & SUB TOTAL & 4,359 \\
\hline MEJORAS DE ALTO IMPACTO - BAJO ESFUERZO DE IMPLEMENTACIÓN & $\begin{array}{c}\text { Sueldo diario } \\
(\mathrm{S} / .)\end{array}$ & $\begin{array}{c}\text { Sueldo horario } \\
(\mathrm{S} / .)\end{array}$ & $\begin{array}{c}\mathrm{HH} \\
\text { invertidas }\end{array}$ & $\begin{array}{c}\text { Costo de } \\
\text { inversión (S/.) }\end{array}$ \\
\hline Administrador & 650 & 81 & 5 & 406 \\
\hline Adquisión de una lap top (precio corporativo) & & & & 2000 \\
\hline Jefe de Servicios & 410 & 51 & 14 & 714 \\
\hline Ingeniero de Servicios & 140 & 18 & 6 & 108 \\
\hline Asistente de créditos y cobranza & 115 & 14 & 3 & 43 \\
\hline Asistente de Servicios & 115 & 14 & 6 & 86 \\
\hline Asistente de Ventas & 120 & 15 & 3 & 45 \\
\hline Cajero & 95 & 12 & 6 & 71 \\
\hline Auxiliar de almacén (Sucursal Lambayeque) & 34 & 4 & 6 & 26 \\
\hline \multirow[t]{2}{*}{ Personal técnico: 14 técnicos } & 560 & 70 & 42 & 2940 \\
\hline & & & SUB TOTAL & $6,439.38$ \\
\hline $\begin{array}{l}\text { MEJORAS DE MEDIO IMPACTO - BAJO ESFUERZO DE } \\
\text { IMPLEMENTACIÓN }\end{array}$ & $\begin{array}{l}\text { Sueldo diario } \\
(\mathrm{S} / .)\end{array}$ & \begin{tabular}{|c|}
$\begin{array}{c}\text { Sueldo horario ( } \\
\text { S/.) }\end{array}$ \\
\end{tabular} & $\begin{array}{c}\mathrm{HH} \\
\text { invertidas } \\
\end{array}$ & $\begin{array}{c}\text { Costo de } \\
\text { inversión (S/.) }\end{array}$ \\
\hline Administrador & 650 & 81 & 17 & 1381 \\
\hline \begin{tabular}{|l|} 
Jefe de Servicios \\
\end{tabular} & 410 & 51 & 14 & 718 \\
\hline Asistente de créditos y cobranza & 115 & 14 & 18 & 259 \\
\hline Ingeniero de servicios & 140 & 18 & 6 & 105 \\
\hline Asistente de servicios & 115 & 14 & 6 & 86 \\
\hline Asistente de Ventas & 120 & 15 & 18 & 270 \\
\hline \multirow[t]{2}{*}{ Gerente de Servicios Financieros al cliente } & 1000 & 125 & 4 & 500 \\
\hline & & & SUB TOTAL & 3,319 \\
\hline \multicolumn{3}{|l|}{ COSTO TOTAL DE IMPLEMENTACION (*) } & US \$ 6149.15 & S/. 17,218 \\
\hline
\end{tabular}

$\left({ }^{*}\right)$ No están considerados los costos de software para mejorar los sistemas.

T.C $=2.80$ 
ANEXO 6. COSTO HORARIO DEL PERSONAL TÉCNICO A NIVEL NACIONAL

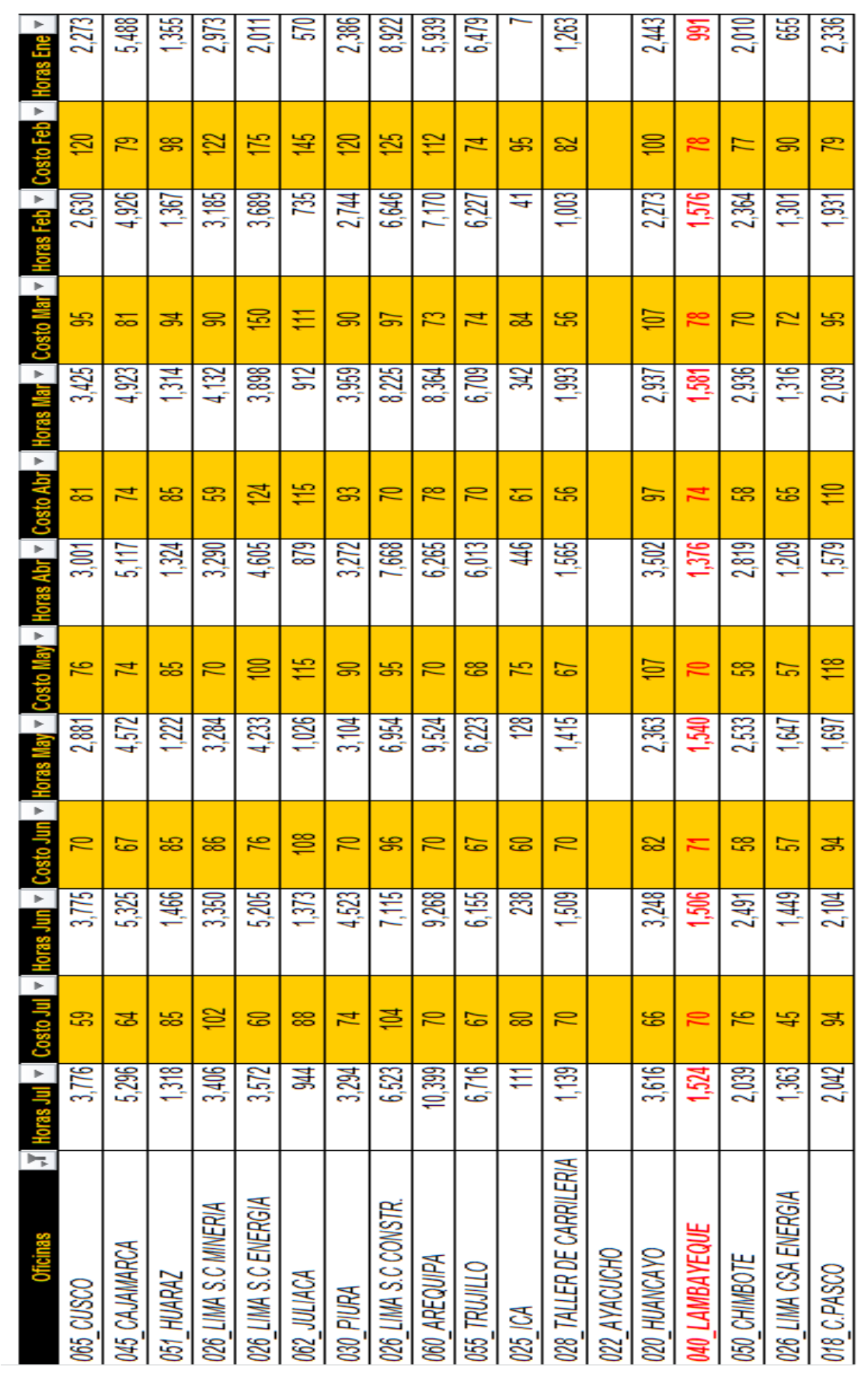




\section{GLOSARIO}

- Proceso: Conjunto de recursos y actividades interrelacionados que transforman elementos de entrada en elementos de salida. Los recursos pueden incluir personal, finanzas, instalaciones, equipos, técnicas y métodos.

- Proceso clave: Son aquellos procesos que inciden de manera significativa en los objetivos estratégicos y son críticos para el éxito del negocio.

- Subprocesos: son partes bien definidas en un proceso. Su identificación puede resultar útil para aislar los problemas que pueden presentarse y posibilitar diferentes tratamientos dentro de un mismo proceso.

- Sistema: Estructura organizativa, procedimientos, procesos y recursos necesarios para implantar una gestión determinada, como por ejemplo la gestión de la calidad, la gestión del medio ambiente o la gestión de la prevención de riesgos laborales. Normalmente están basados en una norma de reconocimiento internacional que tiene como finalidad servir de herramienta de gestión en el aseguramiento de los procesos.

- Procedimiento: forma específica de llevar a cabo una actividad. En muchos casos los procedimientos se expresan en documentos que contienen el objeto y el campo de aplicación de una actividad; que debe hacerse y quien debe hacerlo; cuando, donde y como se debe llevar a cabo; que materiales, equipos y documentos deben utilizarse; y como debe controlarse y registrarse.

- Actividad: es la suma de tareas, normalmente se agrupan en un procedimie nto para facilitar su gestión. La secuencia ordenada de actividades da como resultado un subproceso o un proceso. Normalmente se desarrolla en un departamento o función. 
- Proyecto: suele ser una serie de actividades encaminadas a la consecución de un objetivo, con un principio y final claramente definidos. La diferencia fundamental con los procesos y procedimientos estriba en la no repetitividad de los proyectos.

- Indicador: es un dato o conjunto de datos que ayudan a medir objetivamente la evolución de un proceso o de una actividad. 